Portland State University

PDXScholar

$1-1-2010$

\title{
Molecular Changes Associated with Anoxia Tolerance in Austrofundulus limnaeus embryos
}

Camie Lynn Meller

Portland State University

Follow this and additional works at: https://pdxscholar.library.pdx.edu/open_access_etds Let us know how access to this document benefits you.

\section{Recommended Citation}

Meller, Camie Lynn, "Molecular Changes Associated with Anoxia Tolerance in Austrofundulus limnaeus embryos" (2010). Dissertations and Theses. Paper 85.

https://doi.org/10.15760/etd.85

This Dissertation is brought to you for free and open access. It has been accepted for inclusion in Dissertations and Theses by an authorized administrator of PDXScholar. Please contact us if we can make this document more accessible: pdxscholar@pdx.edu. 


\title{
Molecular Changes Associated with Anoxia Tolerance in Austrofundulus limnaeus embryos
}

by

Camie L. Meller

A dissertation submitted in partial fulfillment of the requirements for the degree of

\author{
Doctor of Philosophy \\ in \\ Biology
}

Dissertation Committee:

Jason Podrabsky, Chair

Bradley Buckley

Deborah Duffield

Suzanne Estes

Carl Wamser

Portland State University

(C) 2010 


\section{ABSTRACT}

Embryos from the annual killifish Austrofundulus limnaeus have a unique and unequalled ability among vertebrates to withstand extended periods of anoxia (maximum lethal time to $50 \%$ mortality of 65 days at $25^{\circ} \mathrm{C}$ ). In addition, tolerance of anoxia is gained and subsequently lost during the normal development of this species. Thus, anoxia tolerant and anoxia sensitive individuals can be compared within the same species, making $A$. limnaeus an excellent model for studying the molecular changes associated with survival of oxygen deprivation in vertebrates. The aim of this project is to analyze the molecular changes associated with anoxia tolerance in the embryos of $A$. limnaeus. Understanding how the cells of these embryos become tolerant to anoxia will aid in identifying novel therapeutic targets to reduce cell death following periods of ischemia in heart, brain or other tissues.

Three major analyses were used to investigate the molecular changes associated with anoxia tolerance in this species. The first was a cell cycle and cell cycle arrest analysis using flow cytometry along with an immnuoblot analysis of both positive and negative regulators of cell cycle progression. The second was a cell death analysis utilizing caspase-3/7 activity as well as TUNEL staining. The third was an immunoblot analysis of three different posttranslational modifers (ubiquitin, SUMO-1 and SUMO-2/3). 
The overall findings from this study indicate that the embryos of $A$.

limnaeus do indeed experience some degree of cellular stress (i.e. increase in ubiquitinated proteins, increase in p53 expression, evidence of DNA damage from TUNEL staining and increases in caspase activity) in response to anoxic treatment, even in their most protective state of diapause II. However, despite these observations, the whole organisms are still able to recover from anoxia and do not succumb to death. The overall low levels of TUNEL-positive cells and caspase activity relative to the positive controls indicates that the damage accrued in response to anoxic treatment is minimal. It appears that embryos are able to either "sacrifice" a certain portion of cells or they are able to repair the damage required for resumed development following anoxia. 


\section{ACKNOWLEDGEMENTS}

I would like to acknowledge the following individuals for their help in completing this study. First and foremost, I would like to thank my advisor, Jason Podrabsky, for accepting me as his graduate student, for his mentoring as well as editing throughout this process and for his enduring support. I could not have asked for a better advisor. I would also like to thank my dissertation committee members, Bradley Buckley, Deborah Duffield, Suzanne Estes, Carl Wamser for all of their detailed and thoughtful edits and insights. I want to thank Dr. Roger Simon for his support and for allowing me to collaborate with members of his research team at the Robert S. Dow Neurobiology Laboratories on the Ubiquitin and Sumoylation analyses. I would like to thank Pamela Canaday at the Oregon Stem Cell Center at Oregon Health Sciences University for her support on the cell cycle flow cytometery analyses. I also offer my appreciation to several undergraduate students at Portland State University who assisted me along the way, Jose Aguilar, Michael Knapp, Deidre Phillips, Claire Riggs and Avishan Saberian. I would also like to thank my fellow graduate students, Victoria Alla, Ian Garrett and Benjamin Pri-Tal, for their support in the completion of this project as well. Lastly, I would like to offer my sincere appreciation to my fellow scientist and husband, Robert Meller, for his never-ending support, patience and love throughout my entire graduate career. I could not have finished this project without all of the support of these generous people. Thanks again to all of you! 


\section{Table of Contents}

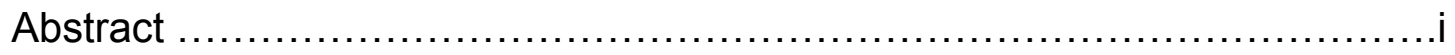

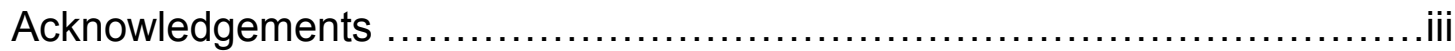

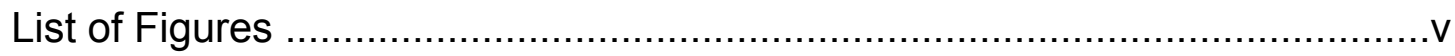

Chapter 1 Anoxia Tolerance ................................................................

Chapter 2 Cell Cycle and Cell Cycle Arrest ...............................................

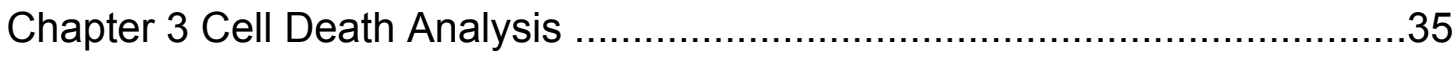

Chapter 4 Ubiquitination and SUMOylation Analysis ..................................61

Chapter 5 Summary and Future Directions .............................................104

Chapter 6 Establishing an Embryonic Cell Line from Austrofundulus

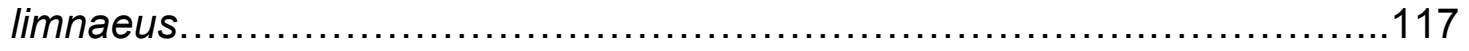

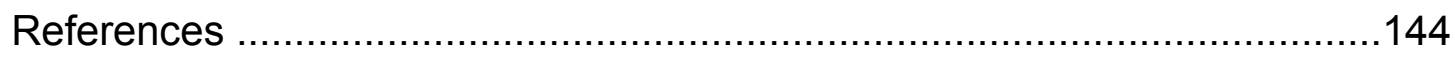




\section{List of Figures}

Figure 2.1 Sampling regimen for embryos exposed to anoxia and subsequent recovery from anoxia for western blot analysis...............................17

Figure 2.2 Anoxia preconditioning survival ...................................19

Figure 2.3 Flow cytometry analysis of cell cycle in early embryos ............21

Figure 2.4 Percent of cells isolated from $\mathrm{G}_{1}$ and $\mathrm{G}_{2}$ in early embryos .........22

Figure 2.5 Flow cytometry analysis of cell cycle in diapause II and post-

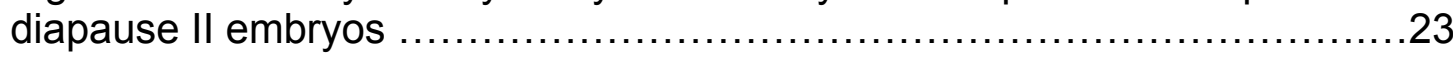

Figure 2.6 Percent of cells isolated from $\mathrm{G}_{1}$ and $\mathrm{G}_{2}$ in diapause II and postdiapause II embryos

Figure 2.7 Representative immunoblot image and quantification of p53 expression in diapause II, $4 \mathrm{dpd}$ and $12 \mathrm{dpd}$ embryos

Figure 2.8 Representative immunoblot image and quantification of p53 expression in control and preconditioned $12 \mathrm{dpd}$ embryos

Figure 2.9 Representative immunoblot image and quantification of cyclin D1 expression in diapause II, $4 \mathrm{dpd}$ and $12 \mathrm{dpd}$ embryos

Figure 2.10 Representative immunoblot image and quantification of cylcin D1 expression in control and preconditioned $12 \mathrm{dpd}$ embryos

Figure 3.1 TUNEL staining in $16 \mathrm{dpf}$, diapause II, $4 \mathrm{dpd}$ and $12 \mathrm{dpd}$ embryos

Figure 3.2 Representative images from TUNEL staining analysis .53

Figure 3.3 Caspase-3/7 activity in $16 \mathrm{dpf}$, diapause II, $4 \mathrm{dpd}$ and $12 \mathrm{dpd}$ embryos

Figure 4.1 Sampling regimen for embryos exposed to anoxia and subsequent recovery from anoxia for western blot analysis

Figure 4.2 Representative immunoblot image of ubiquitin conjugation in diapause II, $4 \mathrm{dpd}$, and $12 \mathrm{dpd}$ embryos 
Figure 4.3 Representative immunoblot image of ubiquitin conjugation in control and preconditioned $12 \mathrm{dpd}$ embryos

Figure 4.4 Quantification of total ubiquitin conjugation in diapause II, $4 \mathrm{dpd}$ and 12 dpd embryos

Figure 4.5 Quantification of total ubiquitin conjugation in control and preconditioned 12 dpd embryos

Figure 4.6 Quantification of ubiquitin conjugation at $23 \mathrm{kDa}$ band in diapause II, $4 \mathrm{dpd}$ and $12 \mathrm{dpd}$ embryos 80

Figure 4.7 Quantification of ubiquitin conjugation at $23 \mathrm{kDa}$ band in control and preconditioned $12 \mathrm{dpd}$ embryos

Figure 4.8 Representative immunoblot image of SUMO-1 conjugation in diapause II, $4 \mathrm{dpd}$, and $12 \mathrm{dpd}$ embryos

Figure 4.9 Representative immunoblot image of SUMO-1 conjugation in control and preconditioned 12 dpd embryos

Figure 4.10 Quantification of total SUMO-1 conjugation in diapause II, $4 \mathrm{dpd}$ and 12 dpd embryos

Figure 4.11 Quantification of total SUMO-1 conjugation in control and preconditioned $12 \mathrm{dpd}$ embryos

Figure 4.12 Quantification of SUMO-1 conjugation at $30 \mathrm{kDa}$ band in diapause II, $4 \mathrm{dpd}$ and $12 \mathrm{dpd}$ embryos

Figure 4.13 Quantification of SUMO-1 conjugation at $30 \mathrm{kDa}$ band in control and preconditioned 12 dpd embryos

Figure 4.14 Quantification of SUMO-1 conjugation at $75 \mathrm{kDa}$ band in diapause II, $4 \mathrm{dpd}$ and $12 \mathrm{dpd}$ embryos

Figure 4.15 Quantification of SUMO-1 conjugation at $75 \mathrm{kDa}$ band in control and preconditioned $12 \mathrm{dpd}$ embryos

Figure 4.16 Representative immunoblot image of SUMO-2/3 conjugation in diapause II, $4 \mathrm{dpd}$, and $12 \mathrm{dpd}$ embryos

Figure 4.17 Representative immunoblot image of SUMO-2/3 conjugation in control and preconditioned $12 \mathrm{dpd}$ embryos 
Figure 4.18 Quantification of total SUMO-2/3 conjugation in diapause II, 4 dpd and 12 dpd embryos

Figure 4.19 Quantification of total SUMO-2/3 conjugation in control and preconditioned $12 \mathrm{dpd}$ embryos

Figure 4.20 Quantification of SUMO-2/3 conjugation at $75 \mathrm{kDa}$ band in diapause II, $4 \mathrm{dpd}$ and $12 \mathrm{dpd}$ embryos

Figure 4.21 Quantification of SUMO-2/3 conjugation at $75 \mathrm{kDa}$ band in control and preconditioned $12 \mathrm{dpd}$ embryos

Figure 6.1a Image of two populations of blastomeres; flat, multinucleate enveloping layer cells on surface and round, deep blastomeres beginning to disperse

Figure 6.1b Close-up image of deep blastomeres further dispersed in an expanding hollow blastula stage embryo

Figure 6.2 Series of solutions used in the embryo bleaching protocol carried out in a sterile six-well tissue culture plate

Figure 6.3 List of the plating techniques tested for optimization of cell culture with embryonic cells isolated from $A$. limnaeus 130

Figure 6.4 A. limnaeus deep blastomeres isolated from embryos 4 days post fertilization and grown in an in vitro culture

Figure 6.4a Intact embryo 131

Figure 6.4b Dissociated cells 131

Figure 6.4c Amoeboid cells 131

Figure 6.5 Embyronic cells isolated from A. limnaeus embryos in diapause II at 29 days post-fertilization

Figure 6.5a Day 0 in culture 132

Figure $6.5 \mathrm{~b}$ Day 2 in culture 132

Figure 6.5c Day 3 in culture 132 
Figure 6.6 Complete growth medium for $A$. limnaeus cell culture

Figure 6.7 Examples of $A$. limnaeus cells maintained in culture. Cells were isolated from $12 \mathrm{dpd}$ embryos and maintained in culture for 25 days

Figure 6.7a Fibroblast-like cells

Figure $6.7 \mathrm{~b}$ Contractile cardiac tissue which actively contracted for 19 days in culture

Figure 6.7c Example of a neuronal cell in culture 135

Figure 6.8 Examples of embryoid bodies formed in culture from embryonic $A$. limnaeus cells

Figure 6.8a Embryoid bodies formed from $4 \mathrm{dpf}$ embryonic cells 136

Figure 6.8b Embryoid bodies formed from $36 \mathrm{dpf}$ embryonic cells 136

Figure 6.8c A close-up view of embryoid bodies formed from $36 \mathrm{dpf}$ embryonic cells

Figure 6.9 Examples of $A$. limnaeus cells maintained in culture

Figure 6.9 a Neuronal-like cells after 25 days in culture that were initially isolated from embryos at $36 \mathrm{dpf}$

Figure $6.9 \mathrm{~b}$ Fibroblast-like cells after 25 days in culture that were initially isolated from $36 \mathrm{dpf}$ embryos

Figure 6.9c Growth ring formed after 31 days in culture. Cells were initially isolated from embryos at $5 \mathrm{dpf}$ 137

Figure 6.10 Alkaline phosphatase staining in whole A. limnaeus embryos .140

Figure 6.10a Deep blastomeres in a 5 dpf embryo (dispersed phase) ......140

Figure 6.10b Aggregation of deep blastomeres in a $12 \mathrm{dpf}$ embryo 140

Figure 6.11 Alkaline phosphatase staining of somites in whole A. limnaeus embryos 141

Figure 6.11a Somites stained in a 19 dpf embryo 141 
Figure $6.11 \mathrm{~b}$ Close-up of somite staining in $19 \mathrm{dpf}$ embryo ...................141 


\section{CHAPTER 1:}

\section{Anoxia Tolerance}

\section{Oxygen is vital to life}

Oxygen serves a pivotal role in organismal physiology. Consequently, most eukaryotes are sensitive to periods of oxygen deprivation or conditions of reduced oxygen concentrations. For animals, metabolically active tissues like the heart and brain are particularly sensitive to reduced oxygen.

Cardiovascular diseases in humans such as heart attack and stroke often lead to severe tissue and organ damage, have high morbidity rates and are the leading cause of disability in the United States (Lloyd-Jones et al., 2010). Stroke is the most frequent cause of disability and as such produces a huge economic burden. The major damages caused by heart attack and stroke are often due to the blockage of blood flow (ischemia) to tissues in the heart and brain. Although much has been learned about the molecular mechanisms that mediate cell death following a period of ischemia, to date there are no therapeutic strategies to block these mechanisms. As a result, a great deal of research effort has been dedicated to understanding endogenous mechanisms of protection. 


\section{Anoxia Tolerance in other species}

Many organisms have evolved altered cellular biochemistry and physiology that allows for prolonged survival of anoxia. These endogenous mechanisms of protection are present in both vertebrate and invertebrate species. This phenomenon is most dramatically demonstrated by the brine shrimp, Artemia franciscana. The embryos of this species have been reported to survive up to four years of continuous anoxia (Clegg, 1997). A small number of vertebrate species also exhibit extraordinary anoxia tolerance. Most vertebrates' brains are unable to withstand more than a few minutes of anoxia, however some freshwater turtles (Trachemys scripta and Chrysemys picta), frogs (Rana pipiens and Rana temporaria), and fish (Crucian carp, goldfish, annual killifish) can survive anoxia for hours and some for months (Lutz and Nilsson, 2004; Podrabsky et al., 2007).

Among fish species, the Crucian carp (Carassius carassius L.) and the goldfish (Carassius auratus L.) exemplify noteworthy anoxia tolerance. Both can survive without oxygen for days at room temperature and the Crucian carp can survive months of anoxia at temperatures close to $0^{\circ} \mathrm{C}$ (Blazka, 1958; Holopainen and Hyvarinen, 1985; Piironen and Holopainen, 1986). The embryos of some species of fish have also demonstrated anoxia tolerance. Zebrafish embryos can survive 24 hours in the absence of oxygen in a state of suspended animation where all observable movement, cell division, developmental progression and motility ceased (Padilla and Roth, 2001). Wild 
zebrafish embryos may not be routinely exposed to anoxic conditions and as such are not necessarily adapted for hypoxic or anoxic conditions. On the other hand, annual killifish are routinely exposed to such conditions and therefore provide a useful model species to study the molecular and physiological underpinnings of anoxia tolerance.

\section{Overview of Annual Killifish}

The annual killifish, Austrofundulus limnaeus is a cyprinodont fish that is endemic to ephemeral ponds in regions of northern South America where it is most commonly found in the Maracaibo basin of Venezuela (Lilyestrom and Taborn, 1982; Taborn and Thomerson, 1978), a region that has been described as having extreme fluctuations in temperature and drought conditions (Podrabsky et al., 1998). The adult and juvenile forms die out on a seasonal basis when their ponds desiccate during dry seasons (Nico and Thomerson, 1989). This severe and unpredictable climate has given rise to several unique developmental adaptations, including the ability to enter a profound state of metabolic dormancy termed diapause, which allows populations of $A$. limnaeus to persist under conditions that are lethal to almost all other species of fish (Myers, 1952; Wourms, 1972a, c). During this period of developmental arrest, the embryos are extremely resistant to a variety of harsh environmental conditions including a wide range of salt concentrations (Machado and Podrabsky, 2007), complete lack of oxygen (Fergusson-Kolmes 
and Podrabsky, 2007; Podrabsky et al., 2007), extreme levels of oxidative stress (Knapp and Podrabsky, unpublished) UV-C radiation (Wagner, Vege and Podrabsky, unpublished), and complete dehydration of their habitat (Podrabsky et al., 2001). Rainy periods cause the ponds to refill and the embryos resume development, hatch and continue the life cycle (Podrabsky and Hand, 1999).

Embryos from the species Austrofundulus limnaeus have a unique and unequalled ability among vertebrates to withstand extended periods of anoxia (maximum lethal time to $50 \%$ mortality of 65 days at $25^{\circ} \mathrm{C}$ (Podrabsky and Somero, 2007). In addition, tolerance of anoxia is gained and subsequently lost during the normal development of this species (Podrabsky et al., 2007). Thus, anoxia tolerant and anoxia sensitive individuals can be compared within the same species, making $A$. limnaeus an excellent model for studying the molecular changes associated with survival of oxygen deprivation in vertebrates. The aim of this project is to analyze the molecular changes associated with anoxia tolerance in the embryos of $A$. limnaeus. Understanding how the cells of these embryos become tolerant to anoxia will aid in identifying novel therapeutic targets to reduce cell death following periods of ischemia in heart, brain or other tissues. 


\section{Organization of remaining chapters}

The three chapters that follow are organized into three distinct but related portions of this study that addresses the overarching goal of better understanding the proximal causes of anoxia tolerance exhibited by the cells of $A$. limnaeus embryos. These chapters have been written as three independent publishable units. The first of these chapters (Chapter 2) entitled, Cell cycle and cell cycle arrest, describes two sets of experiments. The first experiment uses the technique of flow cytometry to estimate the proportion of cells in the various stages of the cell cycle at multiple time points across embryonic development. The second is a series of immunoblot assays investigating the roles of an established positive and negative regulator on cell cycle progression (Cyclin D1 and p53, respectively) at three distinct embryonic developmental time points.

The next chapter (Chapter 3) entitled, Cell death analysis, describes two sets of experiments designed to measure established markers of cell death or enzymatic activity that typically lead to cell death. These assays were used to help determine whether the embryonic cells of $A$. limnaeus were avoiding the cell death that accompanies most organismal responses to anoxia. The first experiment utilizes a fluorescent TUNEL assay (Terminal deoxynucleotide transferase dUTP Nick End Labeling) designed to measure DNA damage often indicative of cell death. The second experiment uses a 
luminescence-based assay to measure caspase-3/7 activity in four distinct embryonic stages.

The next chapter (Chapter 4) entitled, Ubiquitination and SUMOylation analysis, describes two sets of immunoblot assays designed to measure protein modification by two well-known post-translational modifiers, ubiquitin and SUMO. Both have been shown to be involved in ischemic protection and were therefore investigated in this study.

The next chapter to follow (Chapter 5) entitled, Summary and future directions, describes my overall interpretation of results from the three major portions of the study, future directions for research, and the significance of this study to the overall topic of anoxia tolerance in vertebrate cells.

The final chapter (Chapter 6) entitled, Establishing an embryonic cell line from Austrofundulus limnaeus, is not related to the overall anoxia tolerance study. It is also not a hypothesis-driven experiment but rather a description of my efforts to establish an embryonic stem cell line from $A$. limnaeus embryos. This chapter is provided to document the primary cultures that were unsuccessfully as well as successfully established and the preliminary data collected in order to better inform any future effort to culture embryonic stem cells in this species. 


\section{CHAPTER 2:}

\section{Cell cycle and cell cycle arrest}

\section{Background/Introduction}

Cells undergo a cycle of growth and division, which involves regulated and biochemically defined steps. Intracellular as well as extracellular signals are used to determine whether a cell will enter and progress through a mitotic cycle or enter an alternative non-proliferative state such as quiescence or differentiation (Pardee, 1989). The process is highly conserved and while some features such as the actual time required for the individual processes vary greatly between and amongst species, the basic molecular machinery remains virtually identical for all eukaryotes, from yeast to humans (Alberts et al., 2008).

The eukaryotic cell cycle is divided into four major phases: $G_{1}, S, G_{2}$ and $\mathrm{M}$. Within those four phases, the two major periods of transition are $S$ phase denoting Synthesis and M-phase denoting Mitosis. DNA replication occurs during S-phase, followed by chromosome segregation and nuclear division in the M-phase (Alberts et al., 2008). Often cellular replication also includes time for the cell's store of proteins and organelles to double in mass in order to supply two new daughter cells with all of the necessary molecular machinery. Parenthetically, it can be noted that this is not true during early embryonic development as cell size is continuously reduced. The two G- 
phases $\left(G_{1}\right.$ and $\left.G_{2}\right)$, or gap phases (sometimes also referred to as "growth" phases) are in place to provide time for growth of these components.

Together, the $G_{1}, S$ and $G_{2}$ phases comprise a period of the cell cycle termed Interphase. Cell cycle duration in zebrafish embryonic cells has been measured to range from 14.2 to 33.5 minutes depending on the developmental stage, with the earliest stages taking the least amount of time to complete a cycle (Kane and Kimmel, 1993).

The gap phases of the cell cycle provide more than a pause for the cell to manufacture the components necessary for division. They also provide checkpoints for determining whether conditions internally and externally are suitable for continuing the energetically costly and environmentally vulnerable process of cellular replication. $G_{1}$ is particularly important in determining whether the external environment is favorable. If conditions are not suitable, cells can enter a specialized non-proliferating resting state known as $\mathrm{G}_{0}$ or quiescence, where they can remain for days, weeks, years or even permanently until death of the cell or death of the organism occurs (Pardee, 1989). Late in $\mathrm{G}_{1}$, there is a restriction point, where the commitment to enter or withdraw from a mitotic cycle occurs (Pardee, 1989). The $G_{1}$ checkpoint serves as an important point for determining if cells will arrest progression through the cell cycle.

Passage through the restriction point and into S-phase requires the phosphorylation of the retinoblastoma tumor suppressor protein $(R b)$ which is 
controlled by the actions of the Cyclin-dependent kinases (CDKs) (Vermeulen et al., 2003). CDKs are central initiators of the cell cycle. CDKs have positive regulatory subunits, the cyclins, and negative regulatory subunits, CDKinhibitory proteins (CKIs) (Vermeulen et al., 2003). The D-type cyclins (D1, $\mathrm{D} 2$, and D3) are part of a group of $\mathrm{G}_{1}$ phase-specific cyclins whose activation is required for entry into S-phase (Koff et al., 1992; Lew et al., 1991; Xiong et al., 1991). Cyclin-D dependent kinase activity is detected in mid- $\mathrm{G}_{1}$ phase as cells approach the $G_{1} / S$ boundary (Vermeulen et al., 2003). Retinoblastoma protein is a negative regulator of the transcription factors that regulate $G_{1}$ to $S$ phase transition. If conditions are favorable for cell proliferation, the CDKs will inactivate $\mathrm{Rb}$ by phosphorylation, releasing the transcription factors it once bound and allowing them to initiate transcription of the genes necessary for progression to S-phase (Vermeulen et al., 2003).

The tumor suppressor protein, p53 is involved in multiple cellular stress response pathways and is central to cell survival. Hypoxia has been shown to stimulate an increase in levels of p53 protein (Graeber et al., 1996). p53 plays a pivotal role in the regulation of both apoptosis and cell cycle arrest and will therefore be a vital component of this study. In undamaged cells p53 is typically found in very low concentration and is highly unstable (Levine, 1997). It is bound to a protein called Mdm2, which acts as an ubiquitin ligase targeting p53 for proteasomal degradation. When a cell experiences DNA damage, various protein kinases are recruited to the sites of DNA damage 
initiating a signaling pathway that can halt progression through the cell cycle. The first kinases on site are either ATM or ATR, which in turn recruit and activate check point kinase 1 (Chk1) and Chk2. Chk1 and Chk2 act to phosphorylate the transcription factor p53. When p53 is phosphorylated it causes Mdm2 to be released. Unbound p53 is no longer targeted for proteasomal degradation and its concentration increases. In higher concentration, p53 stimulates gene transcription of the CKI protein, p21. The p21 protein in turn, binds and inactivates the $\mathrm{G}_{1} / \mathrm{S}-\mathrm{Cdk}$ and $\mathrm{S}-\mathrm{Cdk}$ complexes, arresting the cell in $\mathrm{G}_{1}$.

The aim of this chapter was to determine the phase of cell cycle arrest for $A$. limnaeus embryos during entry into metabolic dormancy associated with diapause and anoxia-induced quiescence. The rationale for this approach arose from previous studies that showed cells from zebrafish embryos arrested in $\mathrm{S}$ and $\mathrm{G}_{2} / \mathrm{M}$ phase following anoxia treatment (Padilla and Roth, 2001). Zebrafish, however, do not exhibit long-term tolerance of anoxia, thus the significance of this type of cell cycle arrest is unclear. Alternatively, $A$. limnaeus embryos are tolerant of long-term anoxia (Podrabsky et al., 2007). Determining the point in the cell cycle at which cells arrest during dormancy is a first step towards understanding the molecular mechanisms that control the cell cycle during dormancy and will aid in determining what intracellular conditions are necessary for supporting metabolic dormancy associated with diapause and anoxia-induced quiescence. 


\section{Hypotheses}

As naturally anoxia tolerant organisms, A. limnaeus embryos may possess a mechanism for arresting progress in the cell cycle prior to replication of their DNA. I therefore hypothesized that the anoxia-tolerant cells

from $A$. limnaeus embryos would arrest in the $G_{1}$ phase of the cell cycle, and that the molecular events associated with this arrest would result in an anoxia tolerant phenotype. Flow cytometry was used to determine the phase of cell cycle arrest for normoxic and anoxia-treated $A$. limnaeus embryos throughout embryonic development. Western blot analysis was also used to investigate the possible role of cyclin D1 and p53 in regulating cell cycle arrest associated with diapause and anoxia-induced quiescence. I hypothesized that for the anoxia tolerant embryos, cyclin D1, a positive cell cycle regulator, would decrease in response to anoxia and p53, a negative cell cycle regulator, would in increase in response to anoxic treatment. 


\section{Materials and Methods}

\section{Exposure to Anoxia}

The protocol used for the anoxia treatment for this study was previously described by Podrabsky et al. (Podrabsky et al., 2007). Briefly, embryos were washed and transferred to a glass vial with nitrogen-purged embryo medium (45-60 min of robust bubbling). To ensure anoxic conditions, sodium sulfite was added to a final concentration of $1 \mathrm{mg} / \mathrm{ml}$ to scavenge residual oxygen. This amount of sodium sulfite has been previously illustrated to have no toxic effect on the embryos (Podrabsky et al., 2007). The vials were sealed, placed in a plastic bell jar gassed with $\mathrm{N}_{2}$ for 5 minutes, and then stored under vacuum at room temperature $\left(\sim 24-26^{\circ} \mathrm{C}\right)$.

\section{Cell Cycle Analysis by Flow Cytometry}

Cells were harvested from whole embryos at the following developmental stages: $3,7,10,14,17,20,24$ days post-fertilization (dpf); Diapause II, and 4, 12, 24 and 36 days post diapause (dpd). Two independent sample sets of the pre-diapause II developmental time points were prepared and three independent sample sets of diapause II and postdiapause II developmental time points were prepared from matched sets of embryos developing under normoxic conditions as well as embryos that had been exposed to 24 hours of anoxia. 
To prepare embryonic cells for the cell cycle analysis, 200 to 300 embryos (normoxic controls and those exposed to anoxia for 24 hours) were dissociated into single-cell suspensions using a small $24 \mathrm{~mm}, 500 \mu \mathrm{m}$-mesh basket (Netwell ${ }^{\mathrm{TM}}$, Corning Product \#3480) in a $50 \mathrm{~mm}$ Petri dish and a glass

pestle. Cell suspensions were then rinsed several times in serum-free L-15 (Cellgro® Leibovitz's L-15 Medium with L-glutamine \#10-045-CV) media to remove yolk proteins. The cells were pelleted by centrifugation $(300 \times g, 5$ min) and resuspended in $200 \mu$ l of phosphate buffered saline (PBS). Cells were permeabilized and fixed with the addition of $1 \mathrm{ml}$ methanol (100\%) and then incubated with propidium iodide $(\mathrm{PI})(1 \mathrm{mg} / \mathrm{ml})$ for $10 \mathrm{~min}$ at room temperature. Cells were then washed with PBS and stored at $4^{\circ} \mathrm{C}$ until the day of the assay (cells were processed within $24 \mathrm{hr}$ of preparation).

Cells were analyzed by flow cytometry (Cytopeia Influx Analyzer, Cytopeia Incorporated @2004) at the Oregon Stem Cell Center, Flow Cytometry Core at Oregon Health Sciences University.

\section{Immunoblot Analysis of Cyclin $D_{1}$ and p53 Proteins:}

To complement the flow cytometry cell cycle analysis, western blot analysis of levels of cyclin D1 (a marker for $G_{1}$ of the cell cycle) and p53 (an important $\mathrm{G}_{1}$ checkpoint regulator) was performed.

Cells were harvested from whole embryos at the following developmental stages: diapause II, 4 days post-diapause II (dpd), and 12 
dpd. For the Diapause II and 4 dpd developmental time-points, embryos were sampled after a harmful anoxic exposure [DII -21 days, 4 dpd -32 days, 12 dpd -72 hours; $50 \%$ of the $L_{50}$ value; (Podrabsky et al., 2007)] and after 24 hr of subsequent normoxic recovery from the anoxic exposure. Embryos at 12 dpd were treated with an additional "preconditioning" regime that has been previously shown to induce increased survival of anoxia in this stage of embryo (Riggs and Podrabsky, unpublished). The sampling regime for all three stages used for the immunoblots is presented in Figure 2.1. Three independent sample sets were prepared for each of the three developmental time points (diapause II, $4 \mathrm{dpd}$ and $12 \mathrm{dpd}$ ). A matched normoxic control sample was prepared for each set of anoxic samples.

To prepare samples for immunoblot analysis, 50 to 100 embryos were transferred to a small $24 \mathrm{~mm}, 500 \mu \mathrm{m}$-mesh basket (Netwell ${ }^{\mathrm{TM}}$, Corning Product \#3480) in a $50 \mathrm{~mm}$ Petri dish containing $2 \mathrm{ml}$ of PBS and protease inhibitor (Roche Complete Mini, \#11836153001). Embryos were dissociated into cell suspensions by using a flat-bottom glass pestle to mash the embryos through the screen. Cell suspensions were then transferred to a $1.7 \mathrm{ml}$ microcentrifuge tube and pelleted ( $300 \times \mathrm{g}, 5 \mathrm{~min})$. The cells were then rinsed two times in PBS with protease inhibitor to remove yolk proteins. After the final rinse all the supernatant was removed and the cell pellet was snap-frozen in liquid nitrogen. Samples were stored at $-80^{\circ} \mathrm{C}$ until the day of analysis. 
Embryo lysates were prepared for immunoblot by lysing the cells in a buffer (0.1M NaCl, 0.02M Tris-HCl, pH 7.6, 1mM EDTA, pH 8.0, 1\% NP-40) containing protease inhibitors $(0.99 \mu \mathrm{g} / \mathrm{ml}$ aprotinin, $0.3 \mu \mathrm{g} / \mathrm{ml}$ leupeptin, 1.5 $\mu \mathrm{g} / \mathrm{ml}$ pepstatin and $15 \mu \mathrm{g} / \mathrm{ml}$ PMSF and a phosphatase inhibitor cocktail (15 $\mu \mathrm{g} / \mathrm{ml}$, Sigma P2850) used as prescribed by the manufacturer. Lysates were sonicated at $15 \%$ amplitude for 10 to 15 seconds or until homogenized (Branson Digital Sonifier, S-450D). Total protein was determined using a Bradford Protein Assay according to the manufacturer's instructions (Bio-Rad $\# 500-0205)$. A standard curve containing $12.5,6.25,3.125,1.75$ and $0 \mu \mathrm{g}$ of BSA was used to calculate the total protein concentration in each of the samples. All samples were read on a Molecular Devices Spectramax plate reader. Lanes were loaded with equal amounts of protein $(25 \mu \mathrm{g})$. Samples were boiled for $5 \mathrm{~min}$ at $100^{\circ} \mathrm{C}$ prior to loading.

Lysates were loaded on a 10\% SDS-polyacrylamide gel and subjected to electrophoresis $(115 \mathrm{mV}$ for $\sim 2 \mathrm{hr}$ ). Proteins were transferred onto PVDF membranes (30V, overnight). The following day the membranes were blocked with $5 \%$ nonfat dried milk in Tris-buffered saline with $0.1 \%$ Tween (TBST solution) for $30 \mathrm{~min}$ on an agitator at room temperature. After blocking, the membranes were incubated on a rotator with primary antibody in $5 \%$ nonfat dried milk/TBST solution in a sealed plastic bag for $2 \mathrm{hr}$ at room temperature (cyclin D1 primary antibody diluted 1:1000, Manufacturer: Neomarkers \#Rb010-PO, rabbit polyclonal; p53 primary antibody diluted 1:500, Manufacturer: 
Santa Cruz \#6243, rabbit polyclonal). Membranes were removed from the plastic bag then washed for $5-10$ min four times in TBST on an agitator at room temperature. For secondary antibody incubation, membranes were again sealed in a plastic bag and incubated with HRP-conjugated secondary antibody in 5\% nonfat dried milk/TBST solution (anti-rabbit secondary antibody used for both cyclin D1 and p53 conjugated membranes was diluted 1:2000, Cell Signaling \#7074).

Antigen binding was determined by chemiluminescence (Visualizer ${ }^{\mathrm{TM}}$ Western Blot Detection Kit - mouse, Millipore \#64-201) and detected digitally using a digital image station (Kodak image station 2000RT) and analyzed with 1D 3.6 software. Protein levels (intensity) were determined digitally and expressed as OD units and normalized to a standard normoxic sample so that samples from different developmental stages and those run on different blots could all be compared on a common scale. 
A. Exposure regime for diapause ll embryos

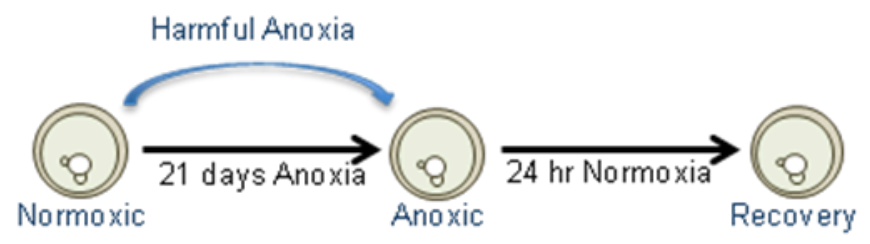

B. Exposure regime for $4 \mathrm{dpd}$ embryos

Harmful Anoxia

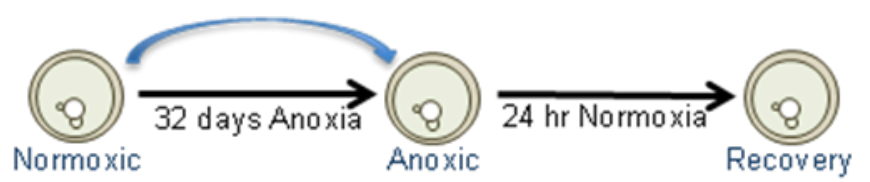

C. Exposure regime for $12 \mathrm{dpd}$ embryos with anoxic preconditioning

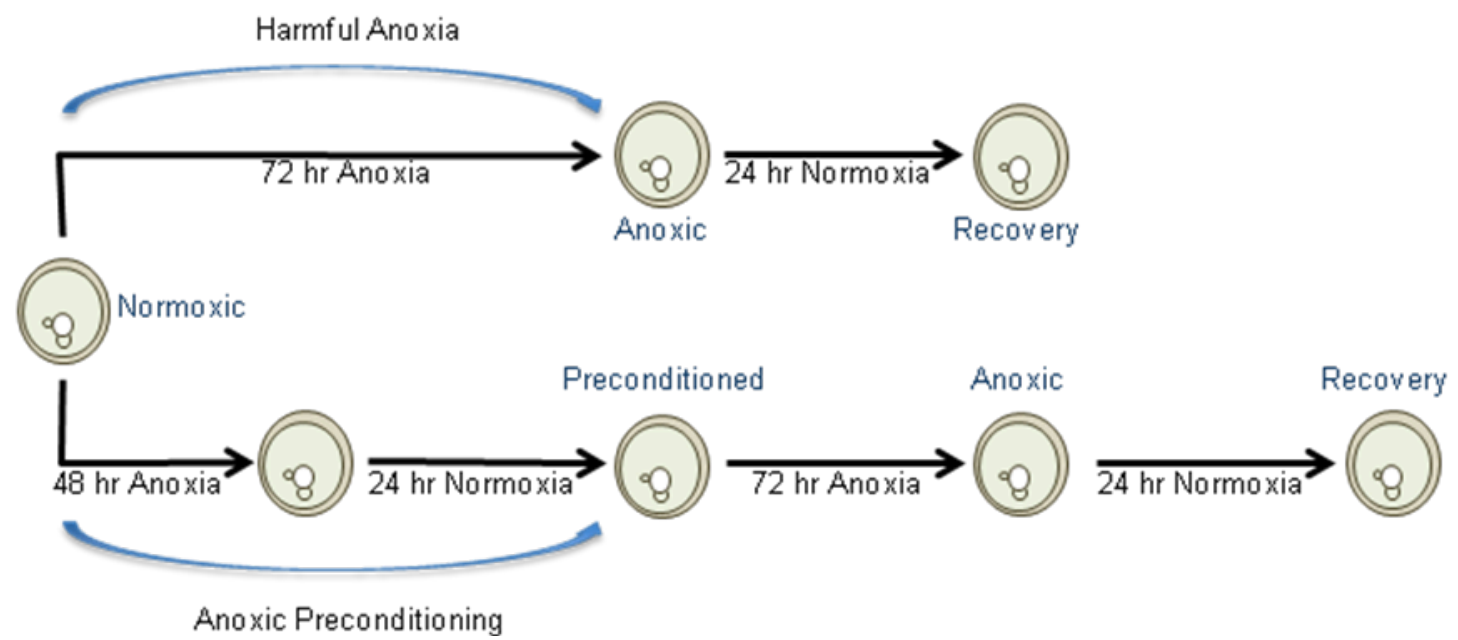

Figure 2.1. Sampling regimen for embryos exposed to anoxia and subsequent recovery from anoxia for western blot analysis. 


\section{Results}

\section{Anoxic Preconditioning}

The anoxic preconditioning experiment (Fig. 2.2) was carried out on embryos that were $12 \mathrm{dpd}$, a period of embryonic development in which the embryos are relatively sensitive to anoxia for this species. While overall survival was not enhanced with both sets of embryos reaching $0 \%$ survival by around 18 days of anoxia, the embryos that received the anoxic preconditioning treatment had a significantly greater $L T_{50}$ value ( $\sim 10.2$ days) than the control embryos (7.4 days) (two-way ANOVA, $F(7,56)=122.57$, $p<0.0001)$. 


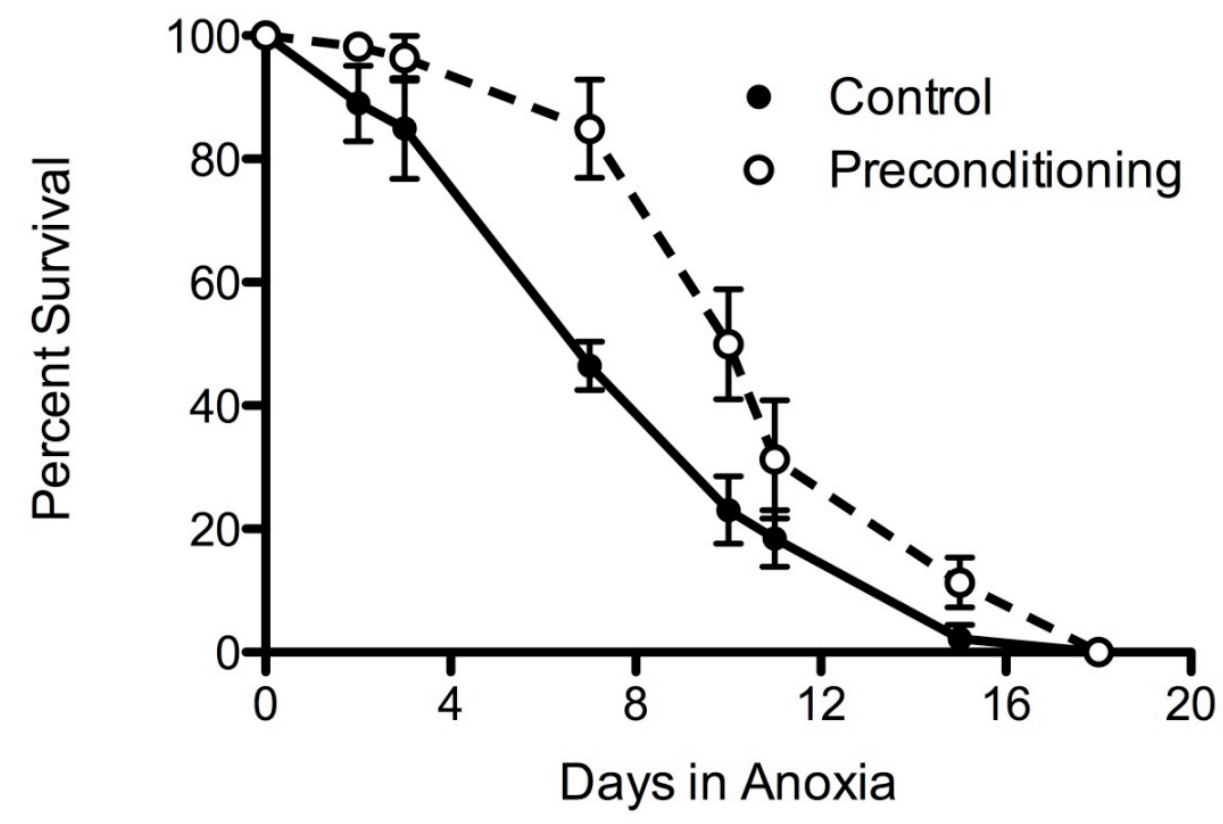

Figure 2.2. Initial survival of $12 \mathrm{dpd}$ embryos of $A$. limnaeus exposed to anoxia is significantly enhanced (two-way ANOVA, $F(7,56)=122.57, p<0.0001$ ) in preconditioned $\left(\mathrm{LT}_{50}=10.2 \pm 0.8\right.$ days) compared to control embryos $\left(\mathrm{LT}_{50}\right.$ $=7.4 \pm 0.7$ days $)$. Symbols represent means \pm S.E.M. $(n=5)$. 


\section{Flow Cytometry}

The vast majority of cells isolated from embryos of $A$. limnaeus were in the $\mathrm{G}_{1}$ phase of the cell cycle regardless of developmental stage or treatment with anoxia (Figures $2.3-2.6$ ). Only during very early development, prior to the formation of the embryonic axis, were there a significant number of cells in $\mathrm{S}$ or $\mathrm{G}_{2}$ phases (Figures 2.3 and 2.4). It appears that cells arrest in whatever stage of the cell cycle that they happen to be in when they are exposed to anoxia in stages that are older than $3 \mathrm{dpf}$. For $3 \mathrm{dpf}$ embryos, a high proportion of the embryos appeared to be in S phase, but these cells disappeared leaving 2 distinct populations of cells in $\mathrm{G}_{1}$ and $\mathrm{G}_{2}$ after exposure to $24 \mathrm{hr}$ of anoxia (Figure 2.3). 


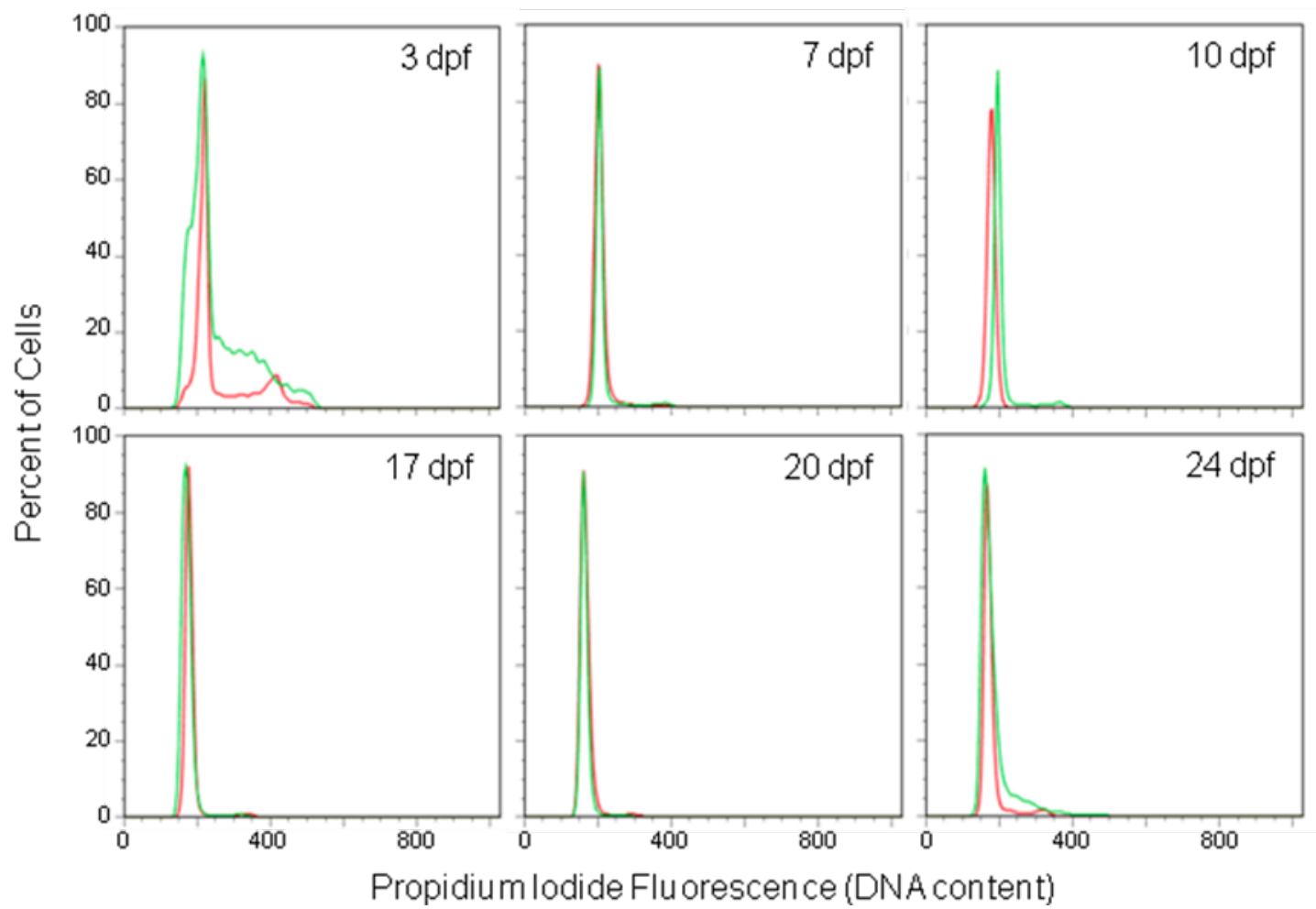

Figure 2.3. Flow cytometry cell cycle analysis of cells isolated from early embryos through diapause II (24 dpf) exposed to normoxia (green) or $24 \mathrm{hr}$ of anoxia (red). Most cells are in $\mathrm{G}_{1}$ during the duration of early development through diapause II. 


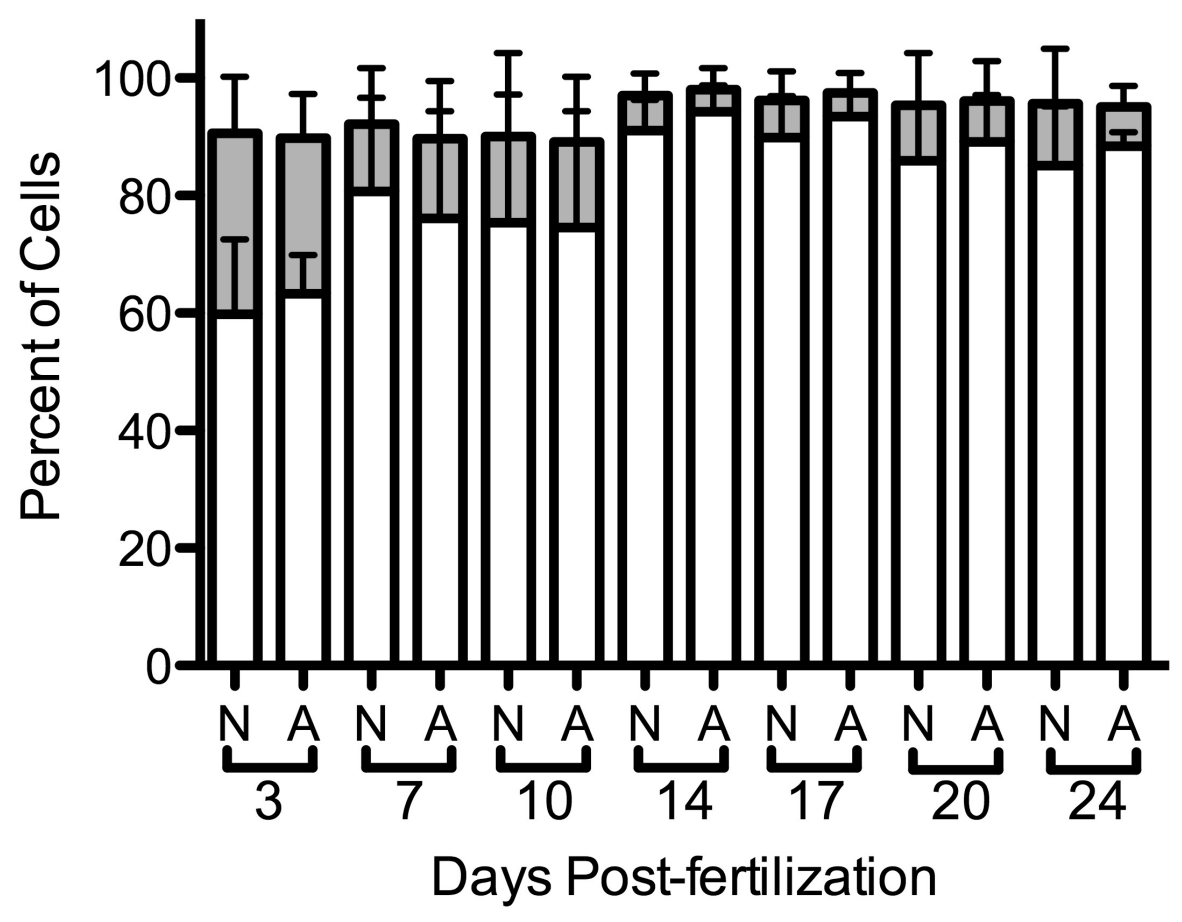

Figure 2.4. Percent of cells isolated from early embryos through diapause II in either $\mathrm{G}_{1}$ (white) or $\mathrm{G}_{2}$ (gray) phases of the cell cycle based on flow cytometry analysis. Bars are means and error bars are the range $(n=2)$. 


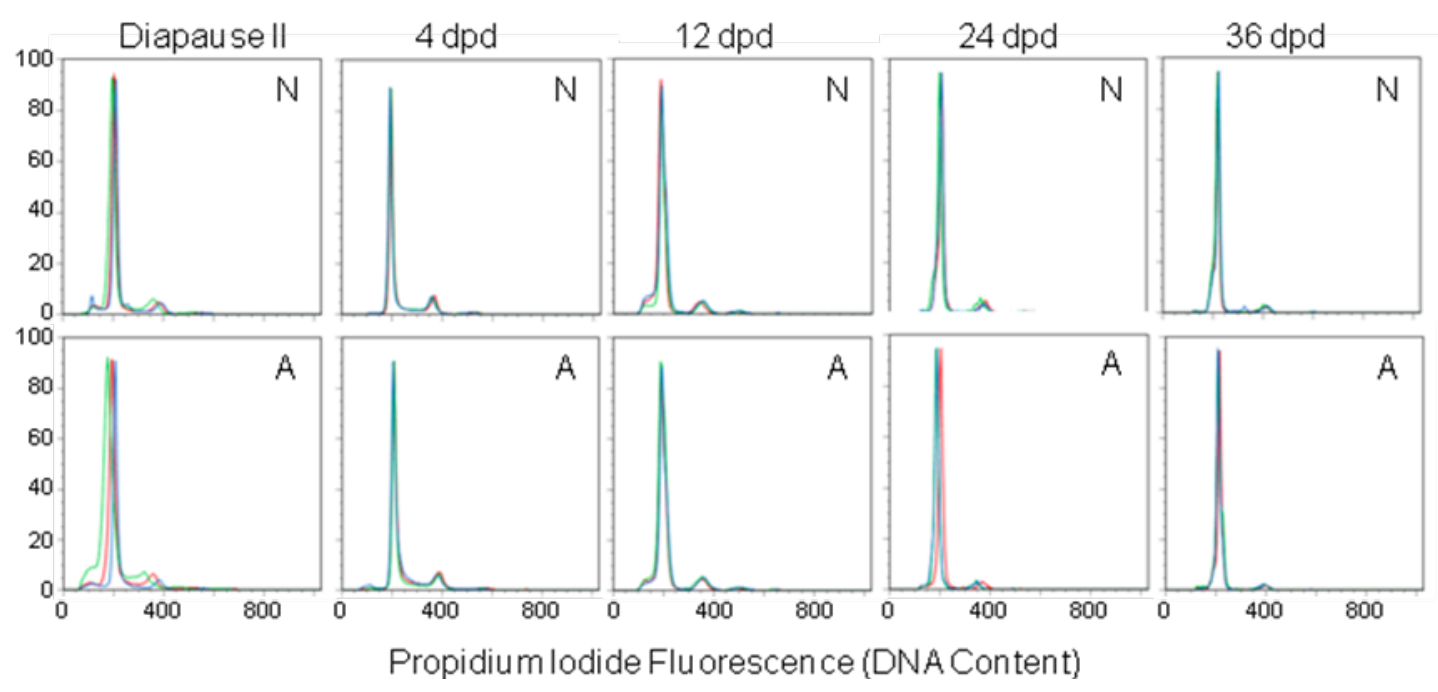

Figure 2.5. Flow cytometry analysis of post-diapause II embryos exposed to normoxia (N) or $24 \mathrm{hr}$ of anoxia (A). The age of the embryos is listed above the panels. Three independent replicates $(n=3)$ are presented for each stage (green, red, blue). 


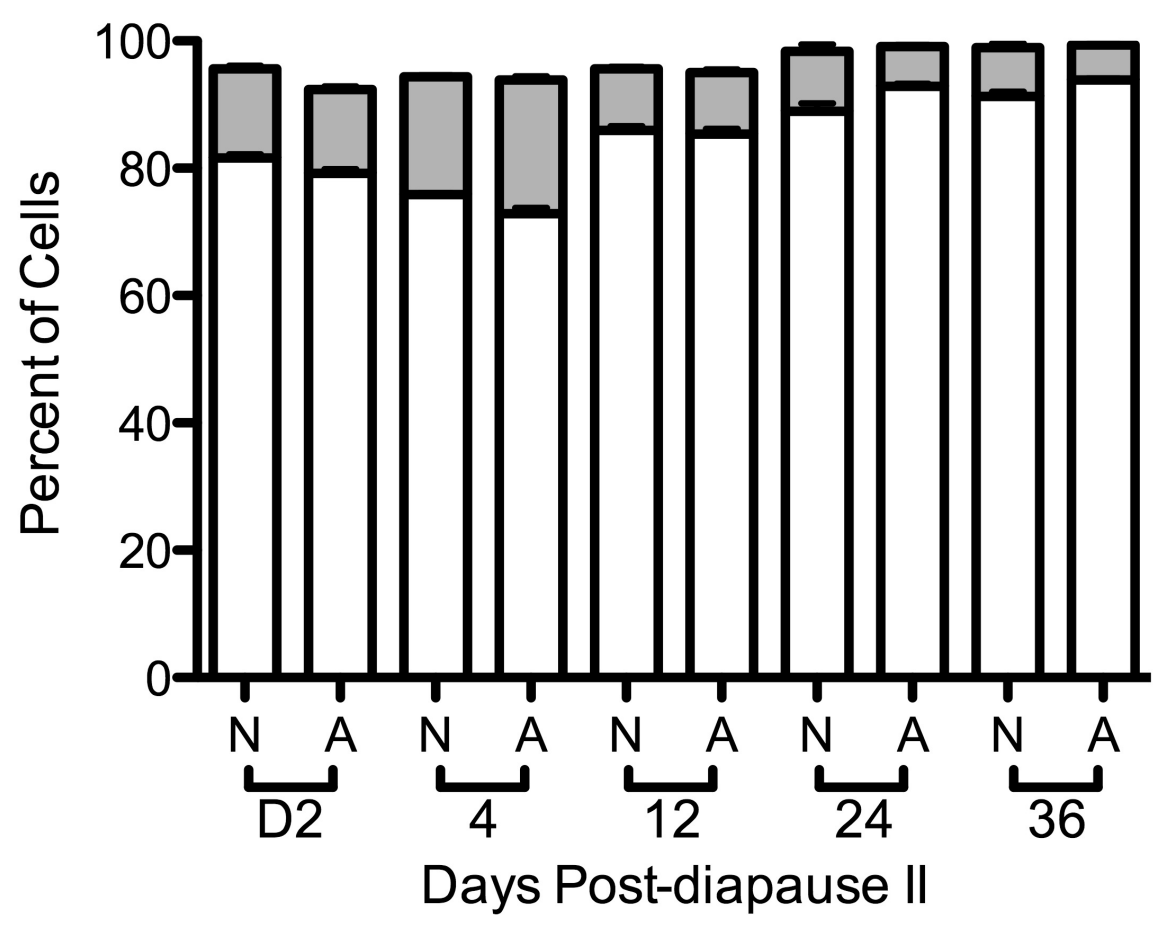

Figure 2.6. The percent of cells in post-diapause II embryos exposed to normoxia ( $N$ ) or 24 hr of anoxia $(A)$ in $G_{1}$ (white) or $G_{2}$ (gray). Bars represent means and error bars are S.E.M. $(n=3)$. Two-way ANOVA indicates no significant affect of anoxia on the proportion of cells in $\mathrm{G}_{1}(p=0.15)$, while there is a significant difference between developmental stages, $F(4,10)=148.7$, $p<0.0001$. 


\section{p53}

The levels of p53 appeared to be very low in normoxic diapause II embryos (Figure 2.7). Upon exposure to anoxia however, levels of p53 protein increased significantly (one-way ANOVA, $F(2,6)=6.69, p=0.0296$, Bonferroni post hoc, $p<0.05)$. After 24 hours of normoxic recovery the levels of p53 decreased by $\sim 50 \%$ but were still significantly higher than the normoxic control (one-way ANOVA, $F(2,6)=6.69, p=0.0296$, Bonferroni post hoc, $p<0.05$ ). The pattern of p53 expression in the 4 and 12 dpd embryos appeared to be reversed from that of the diapause II embryos. p53 appeared to be constitutively expressed in these embryos and decreased by $\sim 50 \%$ upon harmful anoxic treatment although the decrease was not significant in either sample set (4 dpd: one-way ANOVA, $F(2,6)=4.90, p>0.05,12 \mathrm{dpd}$ : one-way ANOVA, $F(2,6)=1.03, p>0.05)$. Similarly, $p 53$ levels recovered to normoxic control levels following 24 hours of normoxic recovery.

The anoxia sensitive, 12 dpd embryos, were further tested in an anoxic preconditioning regimen (see Figure 2.1). For these embryos, there were no significant differences (one-way ANOVA, $F(6,14)=1.75, p>0.05$ ) in response to harmful anoxia or subsequent aerobic recovery in the preconditioned embryos as compared to the non-preconditioned embryos (Figure 2.8). 


\section{Cyclin D1}

For normoxic embryonic cells in diapause II, the levels of cyclin D1 were expressed at low levels (Fig. 2.9). Upon 48 hours of anoxic exposure these levels rose slightly and remained slightly elevated after 24 hours of normoxic recovery. However, none of these changes were statistically significant (one-way ANOVA, $F(2,6)=5.03, p>0.05$, Bonferroni post hoc $p>0.05$ ). For embryonic cells isolated from $4 \mathrm{dpd}$ embryos there was an increase in the level of cyclin D1, however this was only true for one sample and due to this variability the change was not statistically significant (one-way ANOVA, $F(2,6)=0.49, p>0.05$, Bonferroni post hoc $p>0.05)$. After 24 hours of normoxic recovery the levels of cyclin D1 were not significantly different in comparison to the normoxic control sample (one-way ANOVA, $F(2,6)=0.49$, $p>0.05$, Bonferroni post hoc $p>0.05$ ). The $12 \mathrm{dpd}$ samples exhibited the lowest overall levels of cyclin D1 out of the three developmental stages tested. There were no significant changes in cyclin D1 expression in response to anoxic treatment in this developmental stage (one-way ANOVA, $F(2,6)=0.29$, $p>0.05$, Bonferroni post hoc $p>0.05$ ).

The $12 \mathrm{dpd}$, anoxia sensitive embryos were further tested in an anoxic preconditioning regimen (see Figure 2.1). There were no significant changes in cyclin D1 expression (one-way ANOVA, $F(6,14)=1.33, p>0.05$, Bonferroni post hoc $p>0.05$ ) following harmful anoxic exposure in the preconditioned embryos as compared to the non-preconditioned embryos (Figure 2.10). 
p53
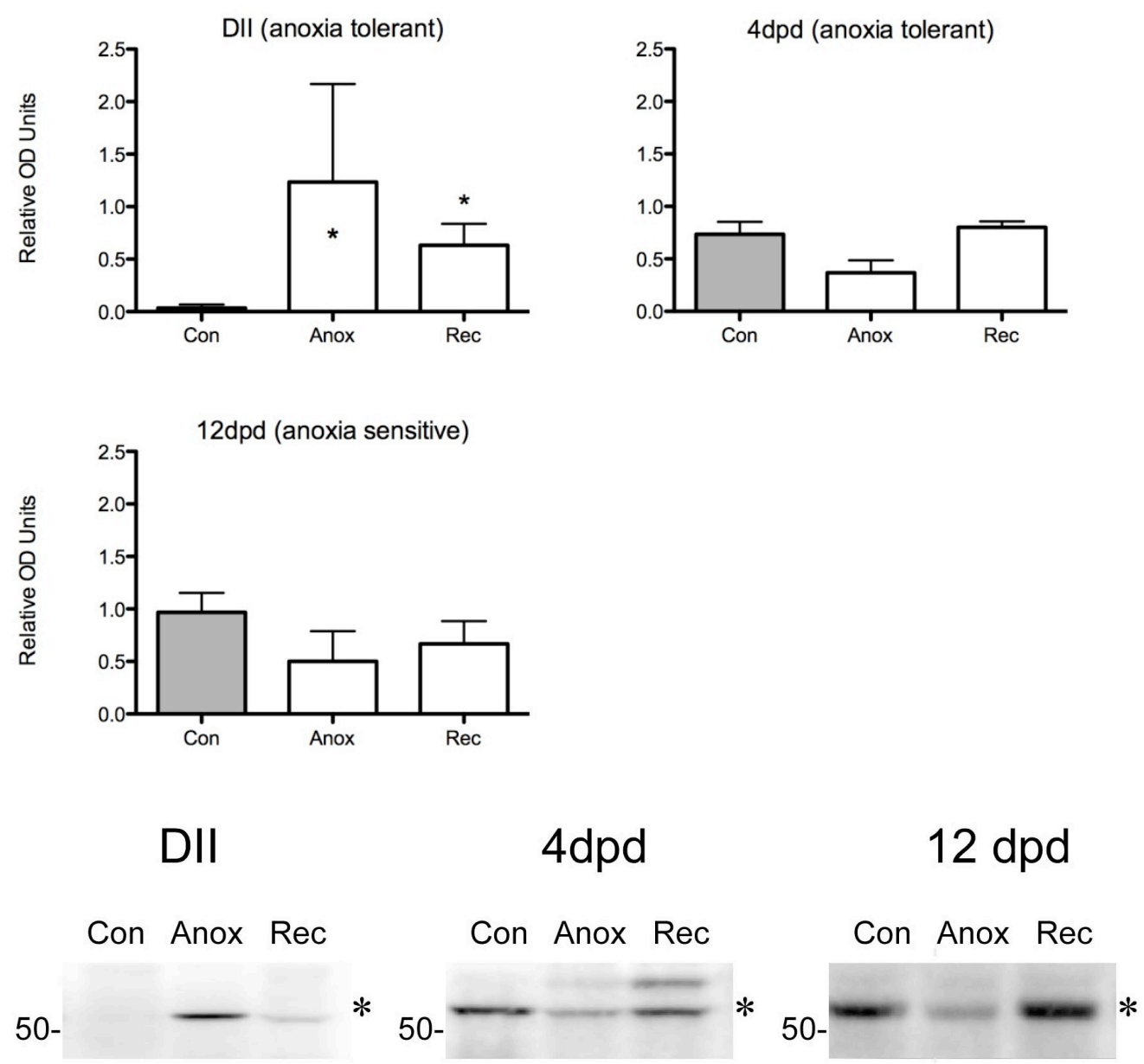

Figure 2.7. Top panel: Immunoblot analysis of p53 expression in diapause II, $4 \mathrm{dpd}$ and $12 \mathrm{dpd}$ embryos; Normoxic control (Con), 48hrs of anoxia (Anox) and 24 hours of normoxic recovery (Rec). Bars represent means and error bars are S.E.M. $(\mathrm{n}=3)$. (DIl: one-way ANOVA, $F(2,6)=6.69, p=0.0296)(4 \mathrm{dpd}$ : one-way ANOVA, $F(2,6)=4.90 p>0.05)$ (12 dpd: one-way ANOVA, $F(2,6)=1.03, p>0.05)$. Asterisks represent values that differ significantly from normoxic control values (Bonferroni post hoc, $p<0.05$ ). Data were log transformed prior to statistical analysis in order to meet assumptions of normal distributions for one-way ANOVA.

Bottom panel: representative western blots from DII, $4 \mathrm{dpd}$ and $12 \mathrm{dpd}$ samples. Asterisk denotes the $53 \mathrm{kDa}$ p53 protein. 

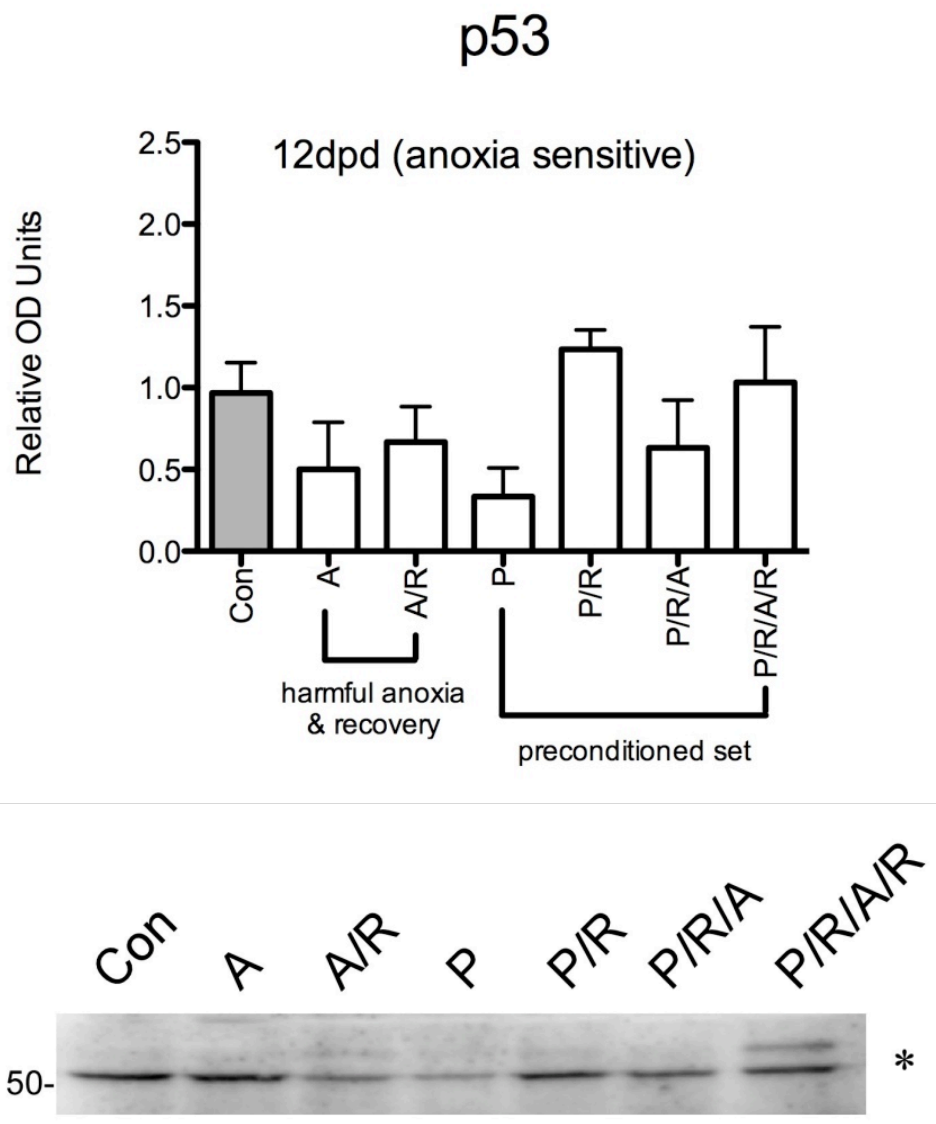

Figure 2.8. Top panel: 12 dpd embryos were preconditioned with a nonharmful treatment of 48 hours of anoxia and then subsequently exposed to harmful anoxia (72 hrs). Con=Normoxic control, $A=$ harmful anoxia (72hrs anoxia), $\mathrm{A} / \mathrm{R}=$ harmful anoxia $(72 \mathrm{hrs})$ followed by 24 hrs recovery, $\mathrm{P}=$ anoxia preconditioning treatment (48hrs), $\mathrm{P} / \mathrm{R}=$ preconditioning (48hrs) followed by $24 \mathrm{hrs}$ recovery, $\mathrm{P} / \mathrm{R} / \mathrm{A}=$ preconditioning (48hrs) followed by $24 \mathrm{hrs}$ recovery followed by harmful anoxia (72hrs), P/R/A/R=preconditioning (48hrs) followed by $24 \mathrm{hrs}$ recovery followed by harmful anoxia (72hrs) followed by $24 \mathrm{hrs}$ recovery. Bars represent means and error bars are S.E.M. (n=3). One-way ANOVA analysis revealed no significant changes from normoxic control values, $F(6,14)=1.75, p>0.05$. Data were log transformed prior to statistical analysis in order to meet assumptions of normal distributions for one-way ANOVA.

Bottom panel: representative western blots from the same $12 \mathrm{dpd}$ samples. Asterisk denotes the 53kDa p53 protein. 


\section{Cyclin D1}
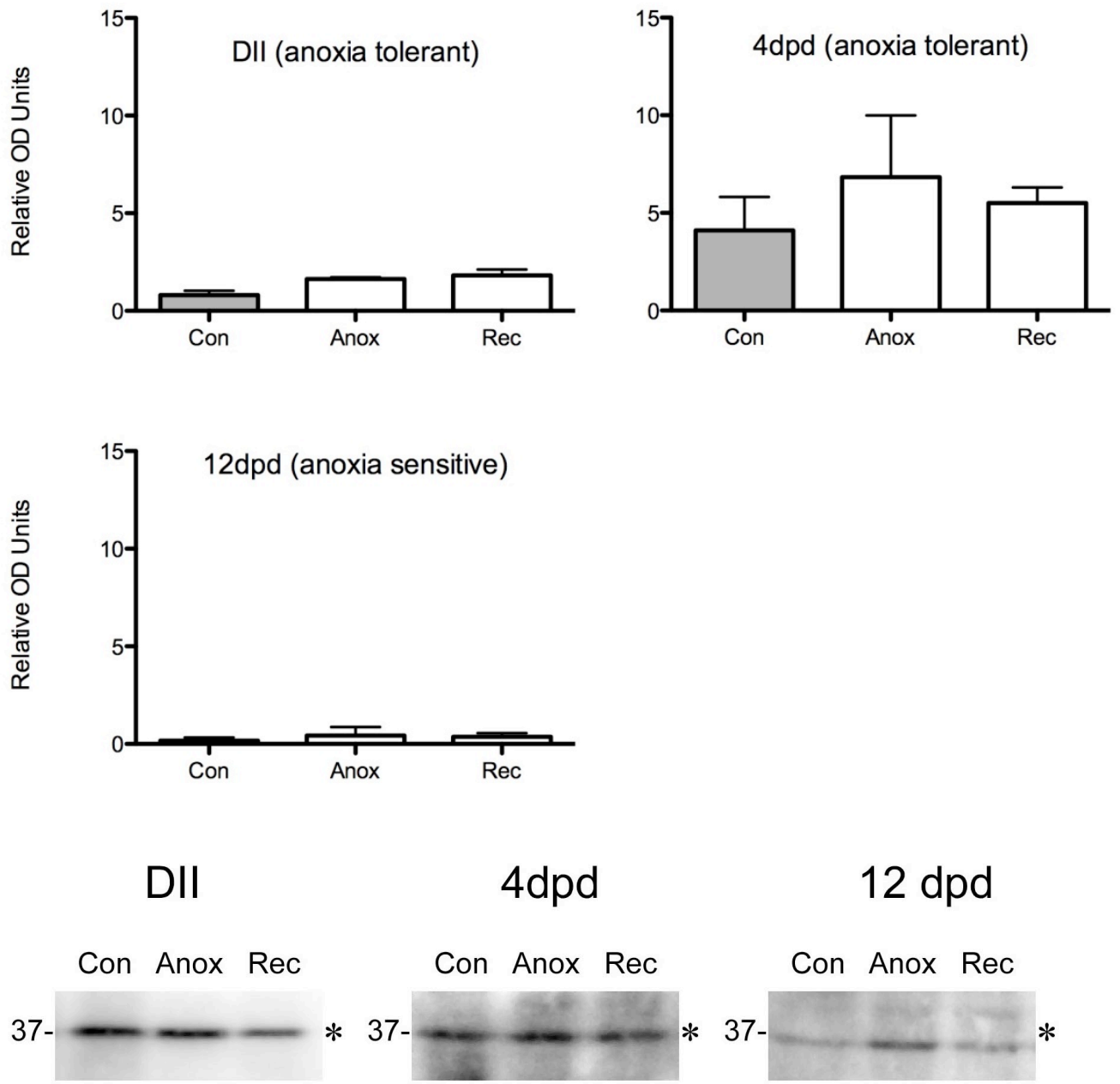

Figure 2.9. Top panel: Immunoblot analysis of cyclin D1 expression in diapause II, $4 \mathrm{dpd}$ and $12 \mathrm{dpd}$ embryos; normoxic control (Con), 48hrs of anoxia (Anox) and 24 hours of normoxic recovery (Rec). Bars represent means and error bars are S.E.M. $(n=3)$. One-way ANOVA analysis revealed no significant changes from normoxic control values (DII: one-way ANOVA, $F(2,6)=5.03, p>0.05)$ (4 dpd: one-way ANOVA, $F(2,6)=0.49 p>0.05)(12 \mathrm{dpd}$ : one-way ANOVA, $F(2,6)=0.29, p>0.05)$. Data were log transformed prior to statistical analysis in order to meet assumptions of normal distributions for one-way ANOVA.

Bottom panel: representative western blots from DII, $4 \mathrm{dpd}$ and $12 \mathrm{dpd}$ samples. Asterisk denotes the cyclin D1 protein. 


\section{Cyclin D1}
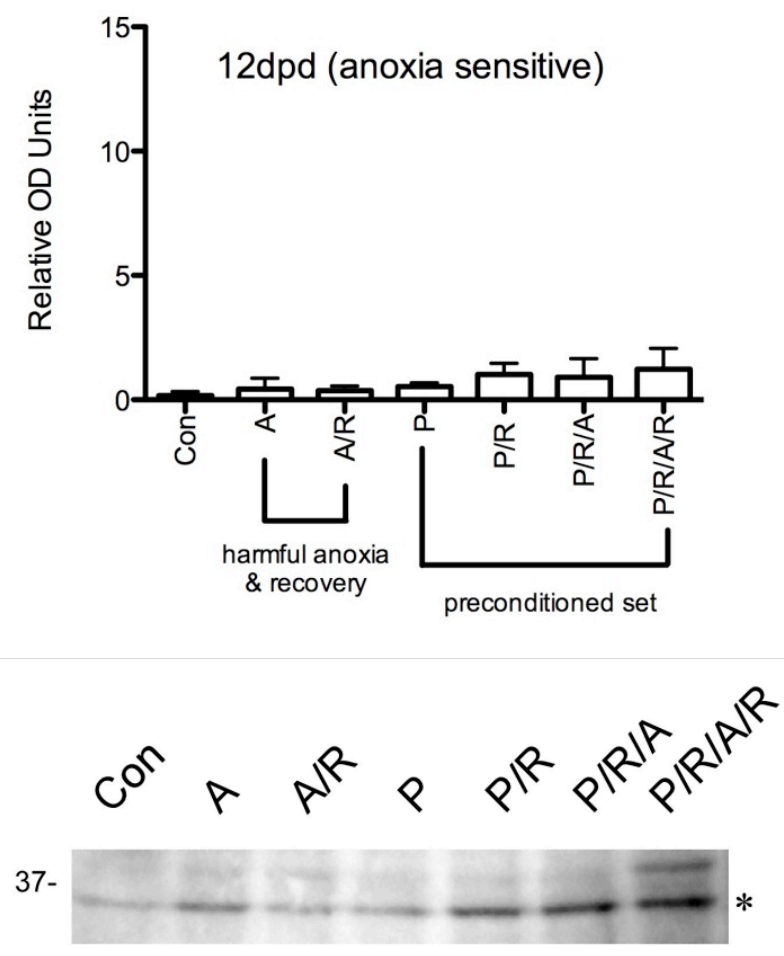

Figure 2.10. Top panel: 12 dpd embryos were preconditioned with a nonharmful treatment of 48 hours of anoxia and then subsequently exposed to harmful anoxia (72 hrs). Con=normoxic control, A=harmful anoxia ( $72 \mathrm{hrs}$ anoxia), $\mathrm{A} / \mathrm{R}=$ harmful anoxia $(72 \mathrm{hrs})$ followed by 24 hrs recovery, $\mathrm{P}=$ anoxia preconditioning treatment (48hrs), $\mathrm{P} / \mathrm{R}=$ preconditioning (48hrs) followed by $24 \mathrm{hrs}$ recovery, $\mathrm{P} / \mathrm{R} / \mathrm{A}=$ preconditioning (48hrs) followed by $24 \mathrm{hrs}$ recovery followed by harmful anoxia (72hrs), P/R/A/R=preconditioning (48hrs) followed by $24 \mathrm{hrs}$ recovery followed by harmful anoxia $(72 \mathrm{hrs})$ followed by $24 \mathrm{hrs}$ recovery. Bars represent means and error bars are S.E.M. $(n=3)$. One-way ANOVA analysis revealed no significant changes from normoxic control values, $F(6,14)=1.33, p>0.05$. Data were log transformed prior to statistical analysis in order to meet assumptions of normal distributions for one-way ANOVA.

Bottom panel: Representative western blots from the same $12 \mathrm{dpd}$ samples. Asterisk denotes the cyclin D1 protein. 


\section{Discussion}

The first aim of this chapter was to determine the stage of the cell cycle at which the embryonic cells of $A$. limnaeus arrest in response to anoxia. It was hypothesized that the anoxia-tolerant cells from A. limnaeus embryos would arrest in the $\mathrm{G}_{1}$ phase of the cell cycle. Early embryos of $A$. limnaeus initially begin with very little anoxia tolerance. As the embryos develop and progress towards diapause II, they gradually acquire a greater degree of anoxia tolerance, reaching the peak of tolerance during diapause II and maintaining that peak tolerance at four days post-diapause II (Podrabsky et al., 2007). Following this period of peak anoxia tolerance they become sensitive to anoxia again (Podrabsky et al., 2007). Flow cytometry indicates that for embryos maintained in a normoxic environment, a majority of the cells are in $\mathrm{G}_{1}$ during the entire course of embryonic development. The only time that cells in $\mathrm{G}_{2}$ increase in proportion is during very early development (3 dpf)

and when the embryos are exiting diapause II at 4 days post-diapause II. For embryos exposed to 24 hours of anoxia this pattern remains the same.

Therefore, it appears that cells from A. limnaeus embryos arrest exactly where they are in the cell cycle at any given point during development. Early embryos at $3 \mathrm{dpf}$ are the one exception as they exhibit a number of cells in $\mathrm{S}$ phase under aerobic conditions, but not under anoxic conditions (Figure 2.2). These cells presumably either die immediately or progress to $G_{2}$ within the first $24 \mathrm{hr}$ of anoxia. Most of the cells at any given time are in $\mathrm{G}_{1}$, and thus they 
enter into dormancy (either diapause or anoxia-induced quiescence) prior to entry into $S$ phase.

Arresting the cell cycle in $\mathrm{G}_{1}$ may be favorable during dormancy for several reasons. First, the integrity of only a single copy of the genome must be maintained which may reduce the chances of damage occurring and/or reduce the cost of maintenance of the genome during dormancy or upon recovery from dormancy. For organisms routinely exposed to unfavorable environmental conditions during development, this strategy could be considered highly adaptive. A much smaller proportion of cells at any given time would be "stuck" with two copies of the genome to maintain during dormancy, a time when energy production is severely limited. A large proportion of cells isolated from zebrafish embryos arrest in the S $(77.7 \%)$ and $\mathrm{G}_{2} / \mathrm{M}(22.3 \%)$ phases upon exposure to anoxia (Padilla and Roth, 2001). It is not clear how or why these cells die after exposure to anoxia, but it is possible that the difference in cell cycle arrest patterns observed in these two species may help to explain the differences in anoxia tolerance observed.

The second aim of this chapter was to determine whether certain cell cycle regulators (specifically cyclin D1 and p53) played a role in cell cycle arrest in response to anoxia treatment. The cyclins are positive regulators of cell cycle progression. The D-type cyclins are a $\mathrm{G}_{1}$-specific group of cyclins necessary for progression to S-phase. Immunoblot analysis of cyclin D1 levels indicated higher levels of cyclin D1 during the $4 \mathrm{dpd}$ stage as compared 
to the diapause II and $12 \mathrm{dpd}$ stages. The overall level of cyclin D1 was much higher than those of diapause II and 12 dpd embryos. This increase in cyclin D1 during the $4 \mathrm{dpd}$ stage coincides with the slight increase in the number of $\mathrm{G}_{2}$ cells observed from the flow cytometry analysis also appearing during this stage. These data suggest that cyclin D1 may be acting as a positive regulator on cell cycle progression as the embryos come out of diapause and resume development.

The transcription factor $p 53$ is a negative regulator of cell cycle progression. It was hypothesized that p53 levels would increase under anoxic conditions, thereby negatively regulating cell cycle progression. The basal levels of p53 during diapause II for embryos maintained in normoxic conditions were almost zero indicating that p53 does not impact cell cycle regulation to a large degree in normoxic diapause II embryos. As hypothesized, p53 expression increased significantly following harmful anoxic treatment. Levels then dropped slightly after 24 hours of subsequent aerobic recovery but still remained significantly elevated relative to the normoxic control. These data suggest that p53 is indeed involved in arresting the cell cycle in response to anoxia in this stage of embryo.

Interestingly this pattern was reversed in the $4 \mathrm{dpd}$ and $12 \mathrm{dpd}$ embryos. Basal levels of p53 for normoxic embryos that have resumed development are higher in concentration than during diapause when development is arrested. Although the changes were not statistically 
significant, there was an interesting trend in both sets of embryos following exposure to anoxia. p53 expression was initially high in the normoxic controls and decreased by $\sim 50 \%$ in both sets of embryos following harmful anoxic treatment and similarly returned to approximately the normoxic values upon 24 hours of aerobic recovery. These data indicate that p53 is not acting as a negative regulator of cell cycle progression in response to harmful anoxia during the post-diapause II developmental stages. The elevated basal (normoxic control) levels of p53 observed in the two post diapause stage sample sets may however be attributed to p53's role in DNA repair (Sarasin and Dessen, 2010; Smith et al., 1995; Wang et al., 1995). This alternate function of p53 may be an important mechanism for repairing damage that accumulated during diapause II. 


\section{CHAPTER 3:}

\section{Cell Death Analysis}

\section{Background/Introduction}

Cell death is a necessary and vital feature of normal development and organismal function. If mitosis occurred without cell death, an 80-year-old human body would contain two tons of bone marrow and lymph nodes and a gut that could span $16 \mathrm{~km}$ (Melino, 2001). Cell death is an inevitable process, and regulated cell death pathways have been highly conserved through evolutionary time. The control of regulated cell death is highly complex and cells are continuously integrating signals from pro-survival and pro-death inputs.

Traditionally, it has been thought that cells dying via regulated cell death pathways are engaged in a process that is reversible until they reach a "point-of-no-return" (Kroemer et al., 2009). Several phenomena have been proposed to represent this critical turning point, including: massive caspase activation (Cohen, 1997), loss of mitochondrial inner membrane potential (Green and Kroemer, 1998), complete permeabilization of the outer mitochondrial membrane (Green and Kroemer, 2004), and exposure of phosphatidylserine residues on the outer leaflet of the plasma membrane (Fadok et al., 1992). A review of the literature on this topic, however, indicates numerous examples where each of these scenarios fails to result in cell death. 
For example, caspases can be activated in cell differentiation pathways as well as many other non-lethal processes (Galluzzi et al., 2008; Garrido and Kroemer, 2004), protonophores can dissipate mitochondrial membrane potential without leading to cell death (de Graaf et al., 2004), and phosphotidylserine exposure can be reversible (Yang et al., 2002). In summary, the biochemical restriction point for cell death has yet to be universally defined.

\section{Defining Cell Death}

Historically, the different categories of cell death have been defined based on cell morphological characteristics, although numerous other classification schemes have been proposed as well. At least twelve different modalities of cell death have been categorized by the 2009 NCCD, including: apoptosis, necrosis, autophagy, cornification, mitotic catastrophe, anoikis, excitotoxicity, wallerian degeneration, paraptosis, pyroptosis, pyronecrosis, and entosis (Kroemer et al., 2009). Cell death can be defined by functional aspects (programmed versus accidental or physiological versus pathological), by enzymatic involvement (dependent or independent of caspases, calpains, cathepsins, or transglutaminases), or by immunological characteristics (immunogenic or non-immunogenic) (Kroemer et al., 2009). As the biochemical processes of cell death have become more defined, the definitions have taken on a more molecular/mechanistic nomenclature. 
Regardless of the mechanism of cell death (regulated or unregulated), defining a cell as dead is not a straightforward task. The Nomenclature Committee on Cell Death (NCCD) (Kroemer et al., 2009) recommends defining a cell as dead when it meets one of the three following molecular or morphological criteria: [1] The cell has lost the integrity of its plasma membrane and is able to incorporate vital dyes (i.e. propidium iodide), [2] The cell has undergone complete fragmentation (including the nucleus) into discrete apoptotic bodies, or [3] the cell has been engulfed by an adjacent cell in vivo (Kroemer et al., 2009).

\section{Programmed Versus Uncontrolled Cell Death}

Although the terms apoptosis and programmed cell death are often used interchangeably, apoptosis is but one form of programmed cell death. Apoptosis is defined by a specific set of morphological features including: cell shrinkage (pyknosis), rounding up of the cell, retraction of pseudopodes, chromatin condensation, nuclear fragmentation (karyorrhexis), classically little to no modification of cytosolic organelles, and in the final stages, "blebbing" of the plasma membrane into apoptotic bodies, and often subsequent engulfment of these apoptotic bodies by resident phagocytes (Kroemer et al., 2009). Programmed cell death as opposed to uncontrolled cell death is implemented by a genetic program and requires some minimal level of ATP (Hand and Menze, 2008). 
Necrosis is largely considered an unregulated cell death modality. Necrotic cell death is characterized morphologically by the absence of apoptotic or autophagic markers (Kroemer et al., 2009). Necrotic cells are identified by: cytoplasmic swelling (oncosis), swelling of cytoplasmic organelles, moderate chromatin condensation, and eventually rupture of the plasma membrane (Kroemer et al., 2009). The contents of necrotic cells released into the extracellular space can activate inflammation responses or damage other neighboring cells, thereby spreading the necrotic area (Hand and Menze, 2008).

Although necrosis has historically been considered an accidental and unregulated form of cell death, recent evidence has shown that necrosis can be induced by some of the death domain receptors (i.e. TNFR1, Fas/CD95 and TRAIL-R) and toll-like receptors (TLR3 and TLR4) especially in the absence of caspase induction (Festjens et al., 2006; Golstein and Kroemer, 2007; Holler et al., 2000). Regulated necrosis appears to be dependent on the activation of the kinase RIP1 (Festjens et al., 2006; Golstein and Kroemer, 2007; Holler et al., 2000). There is no consensus on the biochemical features that cause or define necrosis and for that reason it is still defined negatively in terms of apoptosis (Kroemer et al., 2009).

There are other forms of programmed cell death that do not result in the manifestation of the apoptosis-specific morphologies (Kroemer et al., 2009). For instance, cornification is a particular form of programmed cell death that 
occurs in the epidermis leading to the formation of corneocytes or dead keratinocytes that function as the cornified skin layer (Candi et al., 2005; Lippens et al., 2005). It is morphologically and biochemically distinct from apoptosis (Kroemer et al., 2009; Lippens et al., 2005). Cornification is largely considered a terminal differentiation program similar to the processes that lead to anucleation in mature erythrocytes and in lens epithelium cells (Counis et al., 1998; Testa, 2004). However, unlike the anucleated erythryocytes and lens epithelial cells, cornified cells are able to undergo stress-induced death and display activation of the cell death machinery, mainly the caspases. Thus, cornification can be considered a true programmed cell death pathway (Kroemer et al., 2009).

\section{Apoptosis}

Apoptosis is therefore considered a sub-class of the broader classification of programmed cell death, which includes several different cell "suicide" routes. There are several distinct molecular pathways, such as the "intrinsic" and "extrinsic" signaling pathways that can lead to the morphological changes associated with apoptosis. Despite the morphological similarities between apoptosis associated with these two pathways they are triggered by very different biochemical routes. Activation of both pathways results in similar cellular morphologies, because they both converge at the activation of the effector caspases. Effector caspases, such as caspase-3, are proteases 
which actively degrade cellular components or activate other lytic enzymes (such as the caspase-dependent DNase) that lead to the morphological changes associated with apoptosis (dos Santos et al., 2008). The extrinsic pathway of apoptosis is typically associated with cell removal during development, differentiation and tissue remodeling (Ferri and Kroemer, 2001) and is activated by death receptors on the cell's surface that belong to the tumor necrosis factor receptor (TNFR) superfamily (dos Santos et al., 2008). Activation of the extrinsic pathway typically leads to the activation of caspase8, an initiator caspase that activates the effector caspases such as caspase-3. The intrinsic apoptotic pathway is triggered by disruptions to a cell's internal homeostasis by various stressors such as an increase in reactive oxygen species, hypoxia, anoxia, xenobiotics, viral or bacterial proteins, or accumulation of misfolded proteins (Ferri and Kroemer, 2001). This pathway is regulated by the $\mathrm{Bcl}-2$ family of proteins and is characterized by mitochondrial membrane permeabilization that results in the release of proapoptotic molecules into the cytoplasm, and the subsequent activation of the initiator caspase-9 (dos Santos et al., 2008; Kroemer and Reed, 2000).

\section{The role of caspases in cell death}

Caspases were long thought to be essential modulators in programmed cell death. A growing body of evidence, however, has shown that cell death can still occur even when caspsase activity is inhibited (Green and Kroemer, 
1998). Rather, alterations in mitochondrial membrane function and stability can better predict cell fate (Green and Kroemer, 1998).

While many studies demonstrate the necessity of caspases for certain types of cells to execute programmed cell death (McCall and Steller, 1997; Nicholson and Thornberry, 1997; Rodriguez et al., 1996; Song et al., 1997; Xue and Horvitz, 1995), there are numerous examples in the literature demonstrating programmed cell death that occurs independent of caspase activation (Amarante-Mendes et al., 1998; Brunet et al., 1998; De Maria et al., 1997; Hirsch et al., 1997; Lavoie et al., 1998; Lesage et al., 1997; McCarthy et al., 1997; Ohta et al., 1997; Sarin et al., 1997; Xiang et al., 1996). This caspase-independent cell death does not appear to occur due to a lack of or incomplete blockage of caspase activity, but rather via an alternate mechanism (Green and Kroemer, 1998). This alternate mechanism is believed to be mediated by a loss in mitochondrial membrane integrity that occurs via the opening of the mitochondrial permeability transition pore complex (PTPC) (Kroemer et al., 1995). Opening of the mitochondrial PTPC leads to a disruption of the $\Delta \Psi_{\mathrm{m}}$ and can also cause the release of cytochrome C (Ellerby et al., 1997) and apoptosis inducing factor (AIF) (Susin et al., 1997; Susin et al., 1996).

AIF is a potent contributor to the caspase-independent pathway of cell death (Susin et al., 1999). It is normally found in the intermembrane space of the mitochondria where it appears to act as a terminal electron acceptor/donor 
(oxidoreductase) under non-apoptotic inducing conditions (Lorenzo et al., 1999). Upon induction of apoptosis, however, the role of AlF changes. It translocates to the nucleus and the cytosol where it causes chromatin condensation and large-scale DNA fragmentation (Cande et al., 2002; Lorenzo et al., 1999). Once in the cytosol, AIF causes a change in mitochondrial membrane potential, leading to the release of cytochrome $c$ and more AIF which acts as a positive feedback amplification loop (Cande et al., 2002).

Disruption of mitochondrial membrane function has indeed been shown to cause cell death independent of caspase activation (Brunet et al., 1998; De Maria et al., 1997; Hirsch et al., 1997; Lavoie et al., 1998; Lesage et al., 1997; Xiang et al., 1996). Both mechanisms appear to be crucially involved in cell death and may not behave in a linear model in which one lies upstream or downstream of the other (Green and Kroemer, 1998). Studies have shown that caspases can cause mitochondrial dysfunction in vitro (Marzo et al., 1998; Susin et al., 1997) and mitochondrial events can lead to caspase activation (Ellerby et al., 1997; Kluck et al., 1997; Li et al., 1997; Liu et al., 1996; Susin et al., 1997; Yang et al., 1997; Zou et al., 1997). As such the linear model seems inconsistent with the current evidence and it has been suggested that in many cases the two mechanisms may act together in an amplifying circular feedback loop (Green and Kroemer, 1998). 


\section{Cell Death Analysis via TUNEL Assay}

Terminal deoxynucleotide transferase dUTP Nick End Labeling (TUNEL) is a well-known technique used for detecting DNA breaks or damaged DNA in relation to total cellular DNA. This technique allows cells with high levels of DNA degradation to be identified via flow cytometry or fluorescent microscopy. DNA fragmentation due to nuclease activity cannot be used as an exclusive means to define apoptosis but it is often associated with apoptosis. For this reason, it is typically used in combination with other criteria as a marker of cell death.

DNA fragments resulting from nuclease activity have 3'-hydroxyl ends that are easily labeled by the enzymatic addition of bromolated deoxyuridine triphosphate nucleotides (Br-dUTP) through the action of the enzyme terminal deoxynucleotidyl transferase (TdT). A fluorescent-conjugated (FITC) antibody to Br-dUTP is used to detect the incorporated Br-dUTP. Cells with significant amounts of antibody-labeled break sites will exhibit a high amount of fluorescence (TUNEL-positive) while normal cells will show very little fluorescence. Cells are then stained with propidium iodide (PI), a DNA intercalating agent incorporated by all dead cells. A total cell count can be derived from the number of $\mathrm{PI}$-positive cells. A ratio of TUNEL-positive cells compared to the total cell count will then determine the percent of cells that have undergone cell death. 


\section{Cell Death Analysis via Caspase Activity Assay}

Caspases are a family of cysteine proteases, or cysteine-aspartic proteases associated with cell death processes and inflammation. There are two classes of caspases involved in apoptosis. Initiator caspases, or apical caspases, activate pro-forms of effector caspases by proteolysis. Effector caspases, or executioner caspases, cleave other protein substrates within the cell to begin the cascade of reactions that lead to programmed cell death. The effector caspases are specific players in the apoptotic pathway and can therefore be used as markers of this process.

Both caspase 3 and caspase 7 are members of the effector caspase family. Whereas the TUNEL staining helps to determine how much DNA damage occurred in populations of cells, it is more difficult to elucidate the means of cell death. Therefore, measuring the activity levels of effector caspases will inform more specifically on the process of apoptotic cell death. Both the intrinsic and extrinsic apoptotic pathways converge at the effector caspase stage (dos Santos et al., 2008) so they cannot be used to distinguish between these two well-known pathways. However, they can help to differentiate between caspase-dependent and caspase-independent apoptosis. 


\section{Hypotheses}

The embryos of $A$. limnaeus are able to withstand anoxic conditions that would normally be lethal to most vertebrates. Anoxia is typically a powerful cellular stressor and often leads to apoptosis in vertebrate cells. It is unclear whether the embryos of $A$. limnaeus experience a large degree of cell death from which they are able to subsequently recover or whether they are able to prevent cell death during anoxia. Two assays were employed in order to determine the extent to which cell death was occurring. Both TUNEL staining and caspase activity assays were used as biochemical determinants of apoptosis. I hypothesized that the most anoxia tolerant embryos would exhibit the least TUNEL positive cells in response to harmful anoxic treatment. Additionally, I hypothesized that the most anoxia tolerant embryos would exhibit the least caspase-3/7 activity in response to harmful anoxia. 


\section{Materials and Methods}

\section{TUNEL assay}

Whole embryos of $A$. limnaeus were exposed to a regimen of $48 \mathrm{hr}$ of anoxia followed by aerobic recovery. Embryos were exposed to this experimental protocol (as described in Chapter 1) at the following developmental stages: 16 days post fertilization (dpf), diapause II (DII), 4 days post-diapause II (dpd) and $12 \mathrm{dpd}$. After anoxic treatment the embryos were allowed to recover in normoxic conditions for $0,1,4$, and 24 hours. The postdiapause II samples were allowed an additional normoxic recovery time point of $72 \mathrm{hr}$. Four independent sample sets were prepared for each of the four developmental time points. A matched normoxic control sample was prepared for each set of anoxic samples.

To prepare embryonic cells for the TUNEL analysis, approximately 50 to 100 embryos were transferred to a small $24 \mathrm{~mm}, 500 \mu \mathrm{m}$-mesh basket (Netwell ${ }^{\mathrm{TM}}$, Corning Product \#3480) in a $50 \mathrm{~mm}$ Petri dish containing $2 \mathrm{ml}$ of phosphate buffered saline (PBS). Embryos were dissociated into cell suspensions using a flat-bottom glass pestle. Cell suspensions were then transferred to a $1.7 \mathrm{ml}$ microcentrifuge tube and pelleted $(300 \times \mathrm{g}, 5 \mathrm{~min})$. The cells were then rinsed once in PBS and resuspended in $100 \mu \mathrm{l}$ of PBS. One $\mathrm{ml}$ of $3.7 \%$ paraformaldehyde was then added to fix the cells. Cells were stored in the $3.7 \%$ paraformaldehyde overnight at room temperature. The cells were 
then pelleted $(300 \times g)$ and the paraformaldehyde supernatant was removed. Cells were rinsed once in PBS and suspended in 100 $\mu$ l of PBS. One $\mathrm{ml}$ of $100 \%$ methanol was then added to permeabilize the cells. The cells were stored in methanol at $-20^{\circ} \mathrm{C}$ until the day of the assay.

A TUNEL assay kit from Phoenix Flow Systems, (APO-BRDU, AU1001) was used to quantify TUNEL-positive cells. The kit was used according to the manufacturer's instructions unless noted otherwise. On the day of the assay, the cells were pelleted via centrifugation $(300 \times g)$ and rinsed once in wash buffer (Phoenix Flow Systems). The cell pellet was resuspended in $50 \mu \mathrm{L}$ of DNA labeling solution and the DNA labeling reaction was carried out at $37^{\circ} \mathrm{C}$ for $1 \mathrm{hr}$ with shaking, followed by overnight incubation at room temperature with no shaking. At the end of the DNA labeling incubation, $1 \mathrm{ml}$ of rinse buffer was added (Phoenix Flow Systems). Cells were then pelleted as above and the supernatant was removed. The cells were resuspended in $100 \mu l$ of anti-Br-dUTP antibody solution. Samples were incubated in the dark for $30 \mathrm{~min}$ at room temperature. After the antibody incubation, $0.5 \mathrm{ml}$ of propidium iodide/RNase A solution (Phoenix Flow Systems) was added to each sample. Samples were incubated for $30 \mathrm{~min}$ in the dark at room temperature and analyzed within three hours of staining.

The stained samples were analyzed using fluorescent microscopy on an inverted microscope (Leica, DMIRB) equipped with filter sets to capture both green (TUNEL) and red (nuclear DNA stained with propidium iodide) 
fluorescence. For each microscopic field of view [400X] images were captured at $623 \mathrm{~nm}$ for propidium iodide $(\mathrm{PI})$ fluorescence and at $520 \mathrm{~nm}$ for FITC fluorescence. For each sample, multiple fields of view were used to quantify the number of cells that were TUNEL-positive as well as the total number of PI-positive cells. Positive- and negative-control cells provided in the kit (Phoenix Flow Systems) were used to ensure that the kit reagents and equipment were working properly. A species-specific positive control was generated by treating dissociated $A$. limnaeus embryonic cells at $8 \mathrm{dpf}$ with $1 \mu \mathrm{M}$ staurosporine for $24 \mathrm{hr}$.

\section{Caspase 3/7 Activity}

Caspase-3/7 activity was measured in cells harvested from whole embryos exposed to $48 \mathrm{hr}$ of anoxia and aerobic recovery from anoxia as described above for the TUNEL assays at the following developmental stages: $16 \mathrm{dpf}$, DII, $4 \mathrm{dpd}$, and $12 \mathrm{dpd}$. After anoxic treatment the embryos were allowed to recover in normoxic conditions for $0,1,4$, and $24 \mathrm{hr}$. Four independent sample sets were prepared for each of the four developmental time points. A matched normoxic control sample was prepared for each set of anoxic samples.

To prepare embryonic cells for the caspase analysis, approximately 50 to 100 embryos were transferred to a small $24 \mathrm{~mm}, 500 \mu \mathrm{m}$-mesh basket (Netwell $^{\mathrm{TM}}$, Corning Product \#3480) in a 50mm Petri dish containing $1 \mathrm{ml} \mathrm{L-15}$ 
media. Embryos were dissociated into cell suspensions using a flat-bottom glass pestle. For each of the anoxic recovery samples, the embryos were allowed to recover for the specified amount of time in normoxic conditions before being dissociated into cells. Once the embryonic cells were in suspension, they were transferred to a $1.7 \mathrm{ml}$ microcentrifuge tube and pelleted (300 $\times$ g, 5 min). The cells were then rinsed once in L-15 media and resuspended in $1 \mathrm{ml}$ of $\mathrm{L}-15$ media. Ten $\mu \mathrm{l}$ of each concentrated cell suspension was used to calculate the cell density using a disposable counting chamber (C-Chip \#DHC-N01). Each cell suspension was diluted to 150,000

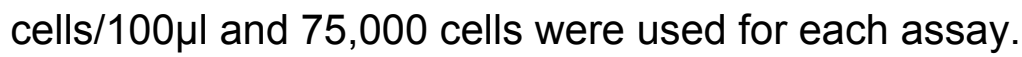

A Caspase-Glo® 3/7 Assay kit (Promega, \#G8091) was used to measure caspase activity in the cell suspensions. The assay contains a luminogenic caspase-3/7 substrate with a tetrapeptide sequence DEVD (aspartic acid-glutamic acid-valine-aspartic acid). When this reagent is mixed with a cell suspension it results in cell lysis and release of caspases that then cleave the kit reagent releasing amino-luciferin. Amino-luciferin is a substrate for luciferase, which generates luminescence during its catalytic cycle. The luminescence produced is proportional to the amount of caspase activity.

Caspase reagent $(50 \mu \mathrm{l})$ was added to $50 \mu \mathrm{l}$ of cell suspension and incubated at room temperature for one hr. A reagent "blank" was prepared each day using $50 \mu \mathrm{l}$ of $\mathrm{L}-15$ media and $50 \mu \mathrm{l}$ of caspase reagent. A positive control was created by harvesting cells from $9 \mathrm{dpf} A$. limnaeus embryos 
exposed to $10 \mu \mathrm{M}$ staurosporine for $24 \mathrm{hr}$. Luminescence was measured using a luminometer (Kikkoman model C-110). Triplicate readings were taken of each sample and averaged.

\section{Data presentation and statistics}

Graphs were prepared and statistical analyses were performed using GraphPad Prism 5.0 software. Statistical significance was set at $p<0.05$ for all comparisons. When appropriate Bonferroni's multiple comparison test was used to compare individual means. Percentage data were transformed using the arcsin of the square root of the proportion transformation prior to statistical analysis. 


\section{Results}

\section{TUNEL assay}

The results for the TUNEL staining assay are presented in Figure 3.1. Representative images for typical TUNEL- and PI-positive cells are presented in Figure 3.2. Exposure to anoxia had no statistically significant effect on the proportion of TUNEL-positive cells observed within any of the developmental stages investigated. While not statistically significant, in some cases exposure to anoxia appeared to decrease the number of TUNEL-positive cells. The only exception to this pattern is in the late developing embryos at $12 \mathrm{dpd}$, which showed an overall increase in TUNEL-positive cells, although due to high variation between samples this effect is not statistically significant (one-way ANOVA, $F(5,24)=0.85, p>0.05)$. While exposure to anoxia appears to have little effect on the number of TUNEL positive cells, there do appear to be some developmental differences in the proportion of TUNEL-positive cells (Figure 3.1). Normoxic control diapause II embryos did have a significantly higher proportion of TUNEL-positive cells compared to normoxic embryos from both post-diapause II stages (one-way ANOVA, $F(3,12)=8.55, p<0.05$, Tukey's Multiple Comparison Test post hoc $p<0.05$ ), but not when compared to control embryos at $16 \mathrm{dpf}$ (one-way ANOVA, $F(3,12)=8.55, p<0.05$, Tukey's Multiple Comparison Test post hoc $p>0.05)$. 


\section{TUNEL staining}
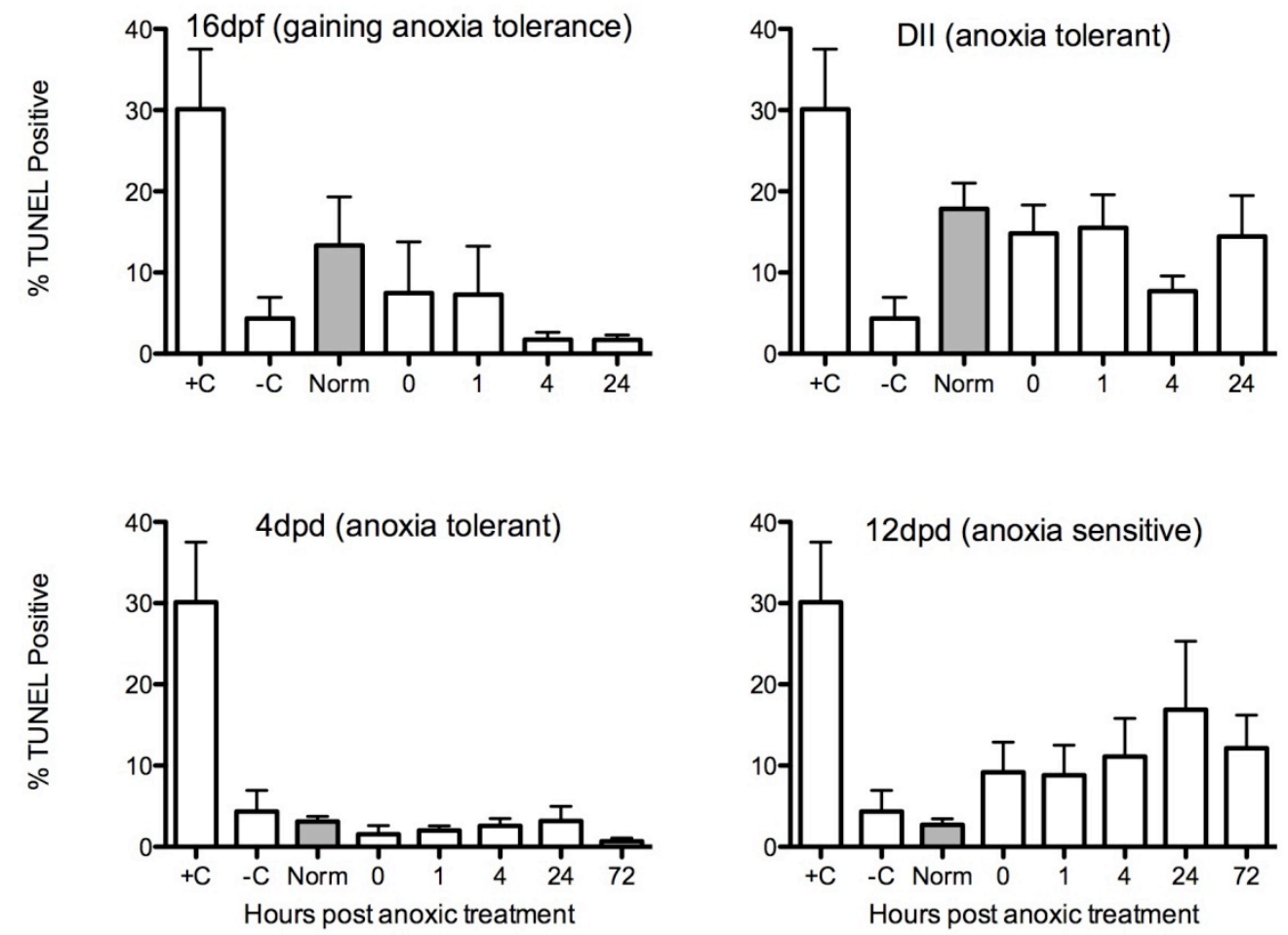

Figure 3.1. The percent of cells that stained TUNEL-positive after exposure to anoxia for 4 different developmental stages. The $x$-axis represents time of aerobic recovery from anoxic treatment. A positive control (+C, $8 \mathrm{dpf} A$. limnaeus cells treated with $1 \mu \mathrm{M}$ Staurosporine for 24 hours) and negative control (-C, Phoenix Flow Systems Kit negative) were provided for each. Bars represent the mean \pm S.E.M. $(n=3-5)$. One-way ANOVA analysis revealed no significant changes from Normoxic control values, $p>0.05$. 


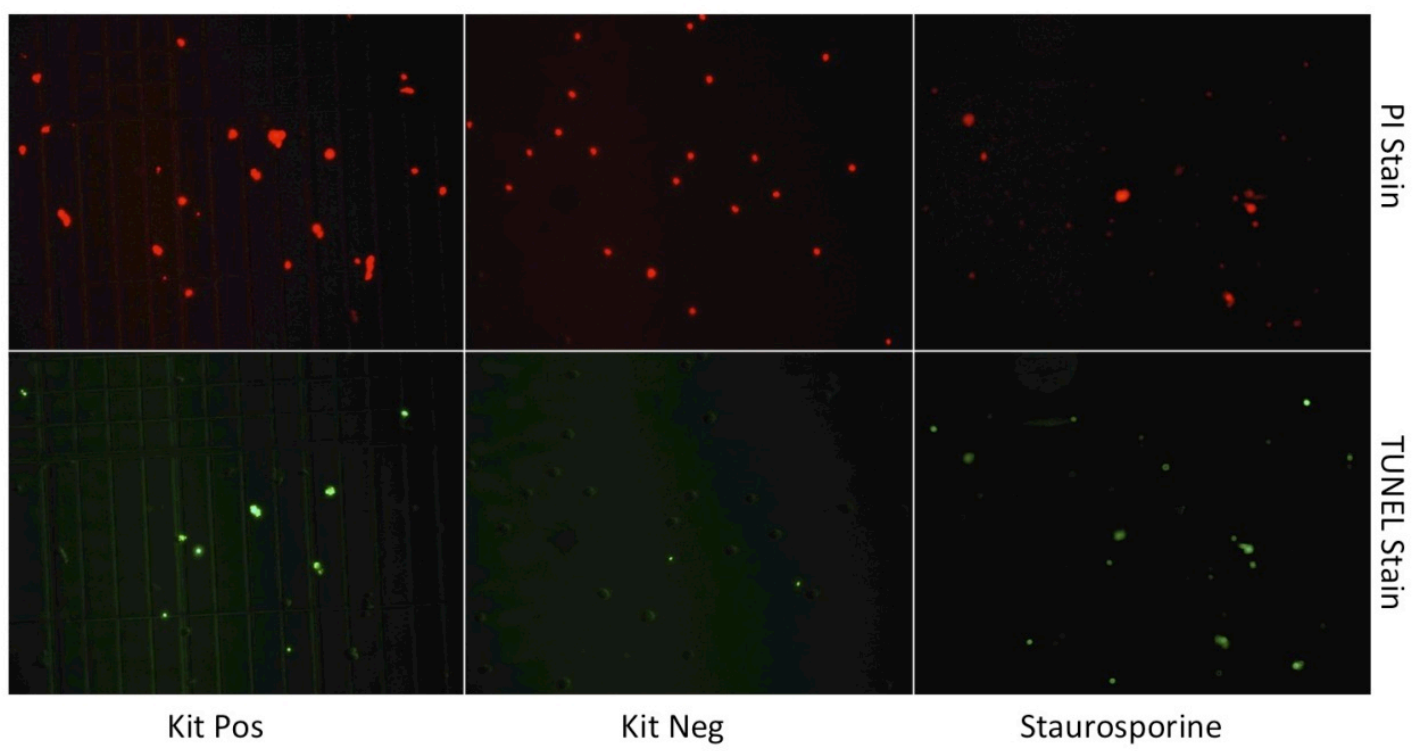

$16 \mathrm{dpf}$ TUNEL assay

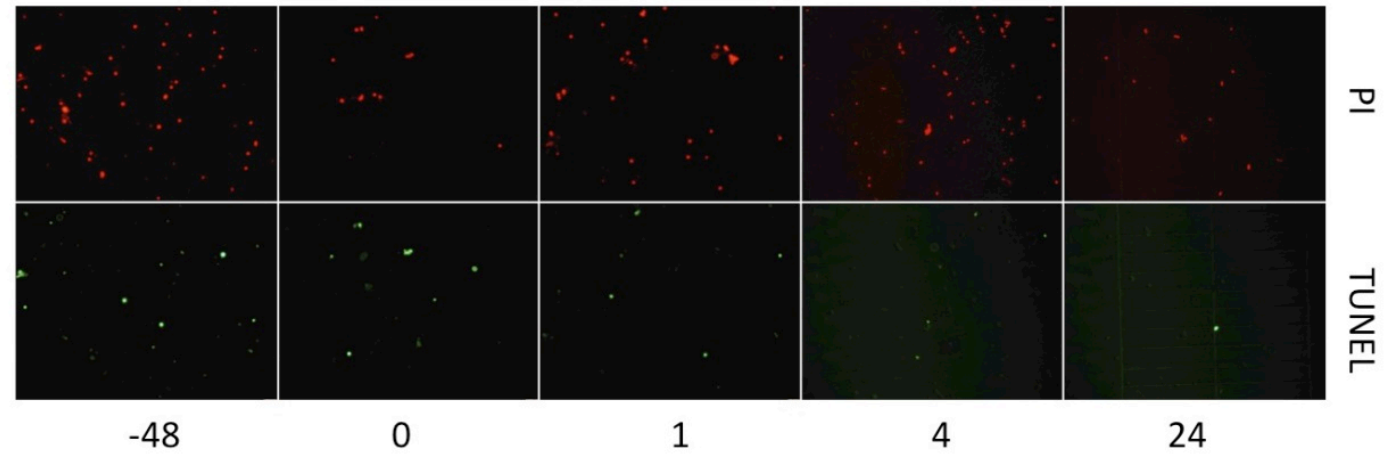

Figure 3.2. Representative images of the controls (top panel) and $16 \mathrm{dpf}$ embryos (bottom panel) used to calculate the proportion of TUNEL- and PIpositive cells. 


\section{Caspase 3/7 Activity}

The results for the caspase 3/7 assay are presented in Figure 3.3. Overall, caspase levels were low in embryos of $A$. limnaeus regardless of treatment or developmental stage when compared to the embryos treated with staurosporine. For the $16 \mathrm{dpf}$ embryos activity was low and remained unaffected by exposure to anoxia until $24 \mathrm{hr}$ of aerobic recovery where a fourfold increase was observed (one-way ANOVA, $F(4,15)=34.67, p<0.0001$, Bonferroni post hoc, $p<0.05)$. The DII embryos had low levels of caspase activity that were unaffected by exposure to anoxia even after $24 \mathrm{hr}$ of aerobic recovery (one-way ANOVA, $F(4,15)=0.31, p>0.05$ ).

Caspase activity levels were higher in post-diapause II embryos compared to the earlier stages. In fact, there was a general trend towards an increase in caspase activity as the embryos progressed through development. The regulation of caspase $3 / 7$ activity following exposure to anoxia was quite different for post-diapause II embryos compared to the earlier stages examined. Immediately following anoxic treatment there was a significantly sharp increase in caspase 3/7 activity in the 4 dpd samples (one-way ANOVA, $F(4,15)=20.31, p<0.0001$, Bonferroni post hoc, $p<0.05)$. This initial increase dropped to control levels after 1 and $4 \mathrm{hr}$ of recovery and then increased again after $24 \mathrm{hr}$ of aerobic recovery (Bonferroni post hoc, $p<0.05$ ). In contrast, 12 dpd embryos exhibited a significant reduction in caspase $3 / 7$ activity by about $50 \%$ upon anoxic exposure (one-way ANOVA, $F(4,15)=23.72, p<0.0001$, 
Bonferroni post hoc, $p<0.05$ ). Caspase $3 / 7$ activity remained at approximately this same level for $4 \mathrm{hr}$ of aerobic recovery and then increased significantly to nearly the value observed for the normoxic sample after $24 \mathrm{hr}$ of recovery (Bonferroni post hoc, $p<0.05)$. 


\section{Caspase - 3/7 Activity}
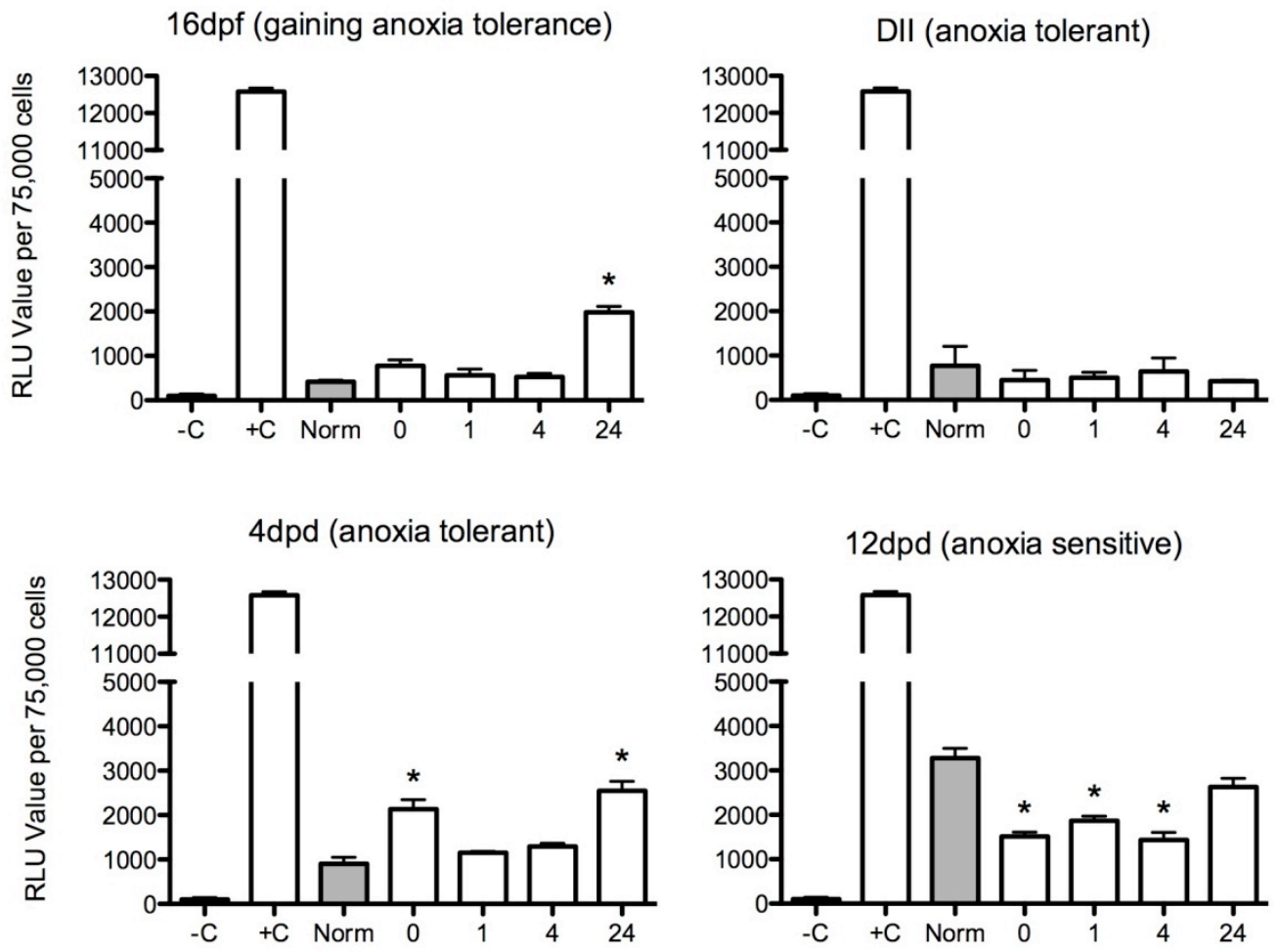

Figure 3.3. Caspase $3 / 7$ activity in relative luminescence units per 75,000 cells for each of the four developmental time points. The $x$-axis represents time of aerobic recovery from anoxic treatment in $\mathrm{hr}$. A positive control $(+\mathrm{C}, 9$ dpf embryos treated with $10 \mu \mathrm{M}$ Staurosporine for 24 hours) and a blank (-C, $50 \mu \mathrm{L}$ media and $50 \mu \mathrm{L}$ caspase reagent) were provided for each. Bars represent means \pm S.E.M. $(n=4)$. (16 dpf: one-way ANOVA, $F(4,15)=34.67$, $p<0.0001$ ) (DIl: one-way ANOVA, $F(4,15)=0.31, p>0.05)$ ( $4 \mathrm{dpd}$ : one-way ANOVA, $F(4,15)=20.31, p<0.0001)(12 \mathrm{dpd}$ : one-way ANOVA, $F(4,15)=23.72$, $p<0.0001)$. Asterisks represent values that differ significantly from normoxic control values (Bonferroni post hoc, $p<0.05$ ). 


\section{Discussion}

The embryos of A. limnaeus display varying degrees of endogenous anoxia tolerance during development that enable them to withstand anoxic conditions that would be lethal to most animals (Podrabsky et al., 2007). This state is acquired gradually as embryos develop and enter into diapause II, peaks during diapause II and is retained up to 4 days of post-diapause II development. Following this period, anoxia tolerance rapidly decreases and by $12 \mathrm{dpd}$ the embryos have lost their long-term anoxia tolerance. It is unclear whether these embryos are experiencing any cellular/DNA damage. The aim of this chapter was to observe markers of cellular damage (i.e. markers of programmed cell death) in different developmental stages of $A$. limnaeus that differ in their tolerance of anoxia in order to quantify the amount of cellular damage or death that may occur as a result of exposure to anoxia.

Two independent indicators of cell death/damage were used in this study, TUNEL staining and caspase-3/7 activity. These two methods of assessing cell death both indicate an overall lack of anoxia-induced apoptosis in embryos of A. limnaeus. Interestingly, patterns of apoptosis do not seem to correlate with anoxia tolerance, which suggests that blockage of apoptosis is only one of several mechanisms that support tolerance of anoxia in this species.

Diapause II and 16 dpf embryos exhibited very low levels of caspase- 
3/7 activity that were largely unaffected by exposure to anoxia. In addition, while the proportion of TUNEL-positive cells was reasonably high for these embryos, there was no significant effect of treatment with anoxia on these levels (see discussion below with respect to the high levels of TUNEL-positive cells). In contrast, post-diapause II embryos respond in a developmental stage-specific manner to exposure to anoxia. Embryos exposed to anoxia at 4 dpd exhibited an increase in caspase $3 / 7$ activity (Fig. 3.3), but this did not result in a large increase in apoptotic cells (Fig. 3.1). Embryos exposed to anoxia at $12 \mathrm{dpd}$ exhibit a significant decrease in caspase activity that is also not reflected in the number of apoptotic cells. The lack of a significant correlation between caspase activity and the number of presumably apoptotic cells suggest either a different response to anoxia in these two developmental stages, or the presence of other protective mechanisms that can block caspase activity. It is worth noting that the overall levels of caspase activity are low in all cases, and thus there may be small populations of cells that are induced to undergo apoptosis following anoxia that are not easily identified in the cell suspensions used for TUNEL analysis in this study. Future studies should use whole-mount embryo preparations to look for specific cells or tissues that might enter apoptosis in response to anoxia.

Reduction of caspase activity may be an overall strategy that helps to support the extreme tolerance of anoxia observed in embryos of $A$. limnaeus. While many of the stages have low levels of caspase activity that are only 
mildly affected by exposure to anoxia, embryos at $12 \mathrm{dpd}$ actually show a decrease in caspase activity. These embryos have a higher basal level of caspase-3/7 activity, and perhaps reducing this activity is critical for survival of anoxia in this stage. While $12 \mathrm{dpd}$ embryos are not tolerant of long-term anoxia, they do still have an extraordinary ability to survive over a week of anoxia, despite having well developed organ systems and a relatively high metabolic rate compared to the other embryos investigated in this study.

\section{Developmental patterns of apoptosis}

While there is an overall increase in the amount of caspase activity as development progresses, the opposite trend is observed for TUNEL-positive cells. This result suggests that either caspase-independent apoptosis is highly prevalent in $16 \mathrm{dpf}$ and DII embryos, or the TUNEL-positive cells in these embryos are some sort of false-positive. TUNEL staining has been reported in a number of studies to not correspond to apoptosis. It has been associated with gene transcription (Kockx et al., 1998), DNA repair (Kanoh et al., 1999), and non-apoptotic DNA damage (Fleck and Carey, 2005; Lesauskaite et al., 2004). Due to the consistently low numbers of TUNEL-positive cells in normoxic post-diapause II embryos (both 4 and $12 \mathrm{dpd}$ ), and a clear lack of response in TUNEL-positive cells in diapause II embryos exposed to anoxia, we feel that the high levels of TUNEL-positive cells in $16 \mathrm{dpf}$ and DII embryos are probably due to some factor other than apoptosis or cell death. The 
overall low metabolism of embryos in diapause II supports this conclusion. An alternative explanation of these data that assumes the TUNEL-positive cells are apoptotic would suggest that despite their highly depressed metabolism, DIl embryos are vulnerable to cell death. In this scenario, cellular damage and subsequent cell death is occurring during diapause. Perhaps part of the protective phenomenon associated with this developmental stage is the ability to "sacrifice" a proportion of non-essential cells in order to cut energetic/metabolic costs. While these data are interesting, additional studies are needed to gain further insight into this issue. Detailed observations on the morphology of isolated cells from $16 \mathrm{dpf}$ and DII embryos, and whole-mount staining of cells for apoptotic nuclei would both be useful in evaluating which cells might be TUNEL-positive and if they exhibit apoptotic morphology. 


\section{CHAPTER 4:}

\section{Ubiquitination and SUMOylation analysis}

\section{Background/Introduction}

The function of proteins can be regulated by posttranslational modifications. Translated gene products are subject to many modifications, such as methylation, acetylation, phosphorylation, SUMOylation or ubiquitination, etc. Such modifications can affect manifold processes such as protein-protein binding, enzyme activity, subcellular localization and protein stability. Of particular interest to this study is the use of ubiquitin and the small ubiquitin-like modifier protein (SUMO) as protein modifiers. Specifically, the aim of this chapter is to investigate their possible roles in regulating protein activity during embryonic development and after exposure to anoxia in embryos of the annual killifish Austrofundulus limnaeus.

\section{Ubiquitination of proteins}

Ubiquitin, a small, 9kDa protein, is as its name suggests, a ubiquitous protein modifier present in eukaryotic cells; recently a homologue was identified in prokaryotic cells (Pearce et al., 2008). Ubiquitin regulates several protein-protein interactions including protein translocation, signal transduction, gene transcription, and cell signaling associated with apoptosis and autophagy 
(Mukhopadhyay and Riezman, 2007). However, ubiquitin is best known for its role in the proteasomal degradation process (Ciechanover et al., 1984). The ubiquitin-proteasome system is the major cellular pathway for degradation and recycling of proteins in a cell. A single ubiquitin protein contains seven lysine residues. It is synthesized as a precursor whose C-terminus is cleaved to reveal a glycine residue. This $\mathrm{C}$-terminus glycine residue at the end of one ubiquitin moiety can then bind to any of the seven lysine residues on another ubiquitin molecule to form a poly-ubiquitin chain (Meller, 2009). The multitude of possible ubiquitin linkages enables ubiquitination to code for a more complex array of modifications as compared to other posttranslational modification mechanisms such as phosphorylation. A target protein can be mono-ubiquitinated (single ubiquitin added), poly-ubiquitinated (a chain of ubiquitin residues are added in either a simple linear or branched arrangement), or mono-ubiquitinated at multiple sites (multiple lysine residues of a single protein are ubiquitinated) (Hicke, 2001; Ikeda and Dikic, 2008). It is not yet clear what molecular signals regulate protein ubiquitination, although some studies have shown a complex crosstalk between protein ubiquitination and phosphorylation (i.e. the pro-apoptotic protein Bim) and ubiquitination and hydroxylation (i.e. the hypoxia induced transcription factor HIF-1) (Hunter, 2007).

The specific structure of the poly-ubiquitin chain can give rise to different functions. For example, lysine 48 poly-ubiquitin chains (K48 links) 
are associated with the targeting proteins to the proteasome, (Pickart and Cohen, 2004) and K63-linked polyubiquitin chains have been shown to target proteins for autophagic processing in lysosomes (Ikeda and Kerppola, 2008). Ubiquitin is conjugated to its target protein substrate via three linked reactions (Hershko, 1983). In the first step, ubiquitin is bound to an E1 ubiquitin-activating enzyme, forming a high-energy thioester bond. This is the only step that requires ATP (Pickart, 2001). Then the ubiquitin is transferred to an E2 ubiquitin-conjugating enzyme. The final step requires an E3 ubiquitin ligase enzyme that catalyzes an isopeptide bond between a lysine on the target protein and glycine residue on the C-terminus of the ubiquitin (Meller, 2009). There are two main families of E3 ligases, the HECT domain (homologous to the E6-AP carboxyl terminus) and RING (really interesting new gene). Recent studies have also identified additional E3 ligases (Jiang et al., 2001; Wertz et al., 2004). While there is only one E1 protein, there are 20 E2 conjugating enzymes, and probably hundreds of E3 ligases encoded in the human genome (Meller, 2009). Recent studies have revealed even greater complexity regarding the ubiquitination of target proteins. Distinct E2 conjugating enzymes are utilized depending on whether the target protein is to be mono-ubiquitinated or poly-ubiquitinated (Rodrigo-Brenni and Morgan, 2007; Windheim et al., 2008). In addition, a fourth class of enzyme, the E4ligase, has been suggested to regulate poly-ubiquitin chain extension (Koegl et al., 1999). The number of these enzymes present and the complexity of 
their regulation are currently unknown in annual killifish.

A number of studies have examined protein ubiquitination in response to ischemic or anoxic conditions (Meller, 2009). These studies have demonstrated that proteins are ubiquitinated following harmful ischemic conditions in rat brain (Liu et al., 2005b; Liu et al., 2004). Interestingly, they showed that proteins in the post-synaptic dendrite are ubiquitinated, which suggests a change in neuronal morphology or synaptic function following ischemia. Preconditioning the brain with a low dose of ischemia, resulted in a reduction in protein ubiquitination after a subsequent and normally harmful ischemic episode (Liu et al., 2005a). Proteasome inhibitors have been shown to be protective in models of stoke (Williams et al., 2004; Williams et al., 2003; Wojcik and Di Napoli, 2004). In contrast, a preconditioning dose of ischemia has been shown to increase protein ubiquitination in rapid ischemic tolerance models, and blocking the proteasome blocks rapid ischemic tolerance (Meller et al., 2008). Thus, the role of ubiquitination in tolerance of oxygen deprivation is likely context dependent, and different amounts of cellular stress may alter the role of protein ubiquitination in mediating cell survival.

\section{SUMOylation of proteins}

A protein related to ubiquitin, the "small ubiquitin-like modifier" or SUMO can be added to proteins to regulate a variety of processes including gene expression, chromatin structure, signal transduction, nuclear transport, cell 
signaling, plasma membrane depolarization, and maintenance of the genome (Hay, 2005; Johnson, 2004; Kerscher et al., 2006; Scheschonka et al., 2007; Wilson and Rosas-Acosta, 2005). Transcription factors are the main targets for SUMOylation and conjugation with SUMO proteins typically results in down regulation of gene expression (Girdwood et al., 2004). There are four SUMO paralogues in vertebrates, SUMO-1 through SUMO-4 (Cimarosti et al., 2008). SUMO-4 is localized mainly in the kidneys (Bohren et al., 2004), while the other three are found in the brain (Cimarosti et al., 2008). SUMO-2 and SUMO-3 share $96 \%$ homology and no difference in function has yet been identified (Hay, 2005). SUMO-1 shares only $45 \%$ homology with SUMO-2 and SUMO-3 and has distinct immunoreactivity (Lapenta et al., 1997). The activity and presence of SUMO-1 and SUMO-2/3 also differ in response to cellular stress events. Under normal (non-stressful) conditions, there is very little free SUMO-1 and a large pool of free SUMO-2/3 (Saitoh and Hinchey, 2000). In the event of cellular stress such as production of reactive oxygen species, osmotic shock, or heat shock, there is an increase in SUMO-2/3 conjugation to proteins, suggesting that SUMO-2/3 may play a role in regulating protein activity in response to cellular stress (Saitoh and Hinchey, 2000).

Some studies suggest that SUMOylation is associated with a protective phenotype in models of ischemic preconditioning. For example, an increase in protein SUMO-1-ylation in the brains of arctic ground squirrels has been reported during the torpor phase of hibernation, suggesting that SUMO-1- 
ylation may be a mechanism for neuroprotection during periods of otherwise lethally low levels of oxygen and glucose (Lee et al., 2007). Hibernation is an adaptive strategy used by many species. During torpor, hibernating animals lower their body temperature, energy consumption, and blood flow to otherwise lethal levels, but experience no cell loss or CNS damage (Carey et al., 2003; Storey, 2003). However, the exact role that protein SUMOylation may play in supporting survival during metabolic depression is currently unclear.

In contrast to the hibernation study, increased SUMO-2/3 conjugation has been reported following harmful brain ischemia, using both focal and global ischemia stroke models (Yang et al., 2008a, b). Another group investigated whether SUMO-2/3 conjugation was affected by ischemic preconditioning. They observed an increase in SUMO-2/3 conjugation following harmful ischemia that was reduced when cells were preconditioned with brief ischemia prior to the harmful ischemic insult (Loftus et al., 2009). Interestingly, they also reported that the SUMO-2/3-ylation was strongest during the harmful ischemic challenge when ATP levels were depleted, rather than in the recovery phase following ischemia. It is therefore unclear whether protein SUMO-2/3-ylation is protective or simply a consequence of a harmful cellular event, i.e. an "insult marker." 


\section{Hypotheses}

The aim for this chapter was to determine whether protein modification via ubiquitination and SUMOylation occurs following exposure to anoxia in embryos of $A$. limnaeus and to determine if anoxic preconditioning could change any observed effect.

I hypothesized that ubiquitin conjugation (presumably for targeting proteins to the proteasome) following anoxic treatment would not change in the anoxia tolerant embryos and that it would increase in the anoxia sensitive embryos. Additionally, I hypothesized that this presumed increase in protein ubiquitination following anoxic treatment would be dampened by anoxic preconditioning.

I also hypothesized that if increased SUMO conjugation is indeed a protective phenomenon, then SUMO-1 and/or SUMO-2/3 conjugation would increase in the anoxia tolerant embryos but not in the anoxia sensitive embryos in response to anoxic treatment. Additionally, I hypothesized that this presumed increase in protein SUMOylation following anoxic treatment would be heightened by anoxic preconditioning. 


\section{Materials and Methods}

\section{Immunoblot Analysis of SUMO-1, SUMO-2/3 and Ubiquitin Proteins}

To observe the role of ubiquitin, SUMO-1 and SUMO-2/3 in anoxia tolerance a western blot analysis was performed. Cells were harvested from whole embryos at the following developmental stages: diapause II (DII), 4 days post-diapause II (dpd), and $12 \mathrm{dpd}$. For the DII and $4 \mathrm{dpd}$ developmental time-points, embryos were sampled after a harmful anoxic treatment of $1 / 2$ the $\mathrm{LT}_{50}$ value for each of the stages (Podrabsky et al., 2007) and followed by 24 $\mathrm{hr}$ of normoxic recovery from the anoxic exposure. Embryos at $12 \mathrm{dpd}$ were treated with two different anoxia regimes that simulate both harmful anoxia for this developmental stage (1/2 of the $L T_{50}$; (Podrabsky et al., 2007)), and a "preconditioning" regime that has been previously shown to induce increased survival of anoxia in this stage of embryo (Riggs and Podrabsky, unpublished, Chapter 1). The sampling regime for all three developmental stages used for the western blots is presented in Figure 4.1. Three independent sample sets were prepared for each of the three developmental time points (DII, $4 \mathrm{dpd}$ and $12 \mathrm{dpd}$ ). A matched normoxic control sample was prepared for each set of anoxic samples.

To prepare samples for western blot analysis, 50 to 100 embryos were transferred to a small $24 \mathrm{~mm}, 500 \mu \mathrm{m}$-mesh basket (Netwell ${ }^{\mathrm{TM}}$, Corning Product \#3480) in a $50 \mathrm{~mm}$ Petri dish containing $2 \mathrm{ml}$ of phosphate buffered 
saline (PBS) and protease inhibitor (Roche Complete Mini, \#11836153001). Embryos were dissociated into cell suspensions by using a flat-bottom glass pestle to mash the embryos through the screen. Cell suspensions were then transferred to a $1.7 \mathrm{ml}$ microcentrifuge tube and pelleted ( $300 \times \mathrm{g}, 5 \mathrm{~min})$. The cells were then rinsed two times in PBS with protease inhibitor to remove yolk proteins. After the final rinse all the supernatant was removed and the cell pellet was snap-frozen in liquid nitrogen. Samples were stored at $-80^{\circ} \mathrm{C}$ until the day of analysis.

Embryo lysates were prepared by lysing the cells in a buffer $(0.1 \mathrm{M}$ $\mathrm{NaCl}, 0.02 \mathrm{M}$ Tris- $\mathrm{HCl}, \mathrm{pH} 7.6,1 \mathrm{mM}$ EDTA, pH 8.0, 1\% NP-40) containing protease inhibitors $(0.99 \mu \mathrm{g} / \mathrm{ml}$ aprotinin, $0.3 \mu \mathrm{g} / \mathrm{ml}$ leupeptin, $1.5 \mu \mathrm{g} / \mathrm{ml}$ pepstatin and $15 \mu \mathrm{g} / \mathrm{ml}$ PMSF and a phosphatase inhibitor cocktail $(15 \mu \mathrm{g} / \mathrm{ml}$, Sigma P2850) used as prescribed by the manufacturer. Lysates were sonicated at $15 \%$ amplitude for 10 to 15 seconds or until homogenized (Branson Digital Sonifier, S-450D). Samples were boiled for $5 \mathrm{~min}$ at $100^{\circ} \mathrm{C}$ prior to loading.

Lysates were loaded on a 10\% SDS-polyacrylamide gel and subjected to electrophoresis ( $115 \mathrm{mV}$ for $\sim 2$ hours). Proteins were transferred onto PVDF membranes (30V, overnight). The following day the membranes were blocked with $5 \%$ nonfat dried milk in Tris-buffered saline with $0.1 \%$ Tween (TBST solution) for 30 minutes on an agitator at room temperature. After blocking, the membranes were incubated on a rotator with primary antibody in 
$5 \%$ nonfat dried milk/TBST solution in a sealed plastic bag for 2 hours at room temperature [SUMO-1 primary antibody diluted 1:1000, provided by R. Meller (Loftus et al., 2009), rabbit polyclonal] [SUMO-2/3 primary antibody diluted 1:2000, provided by R. Meller (Loftus et al., 2009), rabbit polyclonal] [Ubiquitin primary antibody diluted 1:5000, Santa Cruz \#8017 Mouse monoclonal]. Membranes were removed from the plastic bag then washed for 5-10 minutes four times in TBST on an agitator at room temperature. For secondary antibody incubation, membranes were again sealed in a plastic bag and incubated with HRP conjugated secondary antibody in 5\% nonfat dried milk/TBST solution (anti-rabbit secondary antibody used for both SUMO-1 and SUMO-2/3 conjugated membranes was diluted 1:2000, Cell Signaling \#7074). Total protein was determined using a Bradford Protein Assay according to the manufacturer's instructions (Bio-rad \#500-0205). A standard curve containing $12.5,6.25,3.125,1.75$ and $0 \mu \mathrm{g}$ of BSA was used to calculate the total protein concentration in each of the samples. All samples were read on a Molecular Devices Spectramax plate reader. Lanes were loaded with equal amounts of protein (10 $\mu \mathrm{g}$ for Ubiquitin blots and $25 \mu \mathrm{g}$ for SUMO-1 and SUMO-2/3 blots). Antigen binding was determined by chemiluminescence (Visualizer ${ }^{\mathrm{TM}}$ Western Blot Detection Kit - mouse, Millipore \#64-201) and detected digitally using a digital image station (Kodak image station 2000RT) and analyzed with 1D 3.6 software. Protein levels (intensity) were determined digitally and 
expressed as OD units and normalized to a standard normoxic sample loaded onto each gel.

A. Exposure regime for diapause II embryos

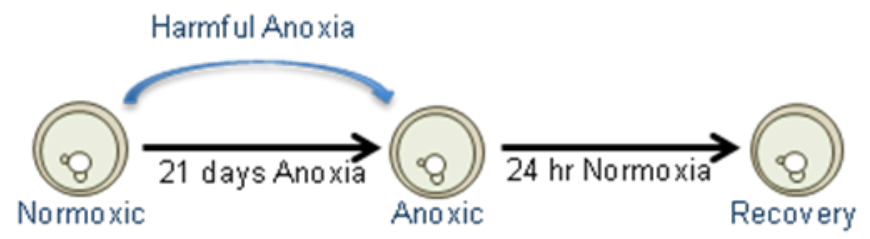

B. Exposure regime for $4 \mathrm{dpd}$ embryos

Harmful Anoxia

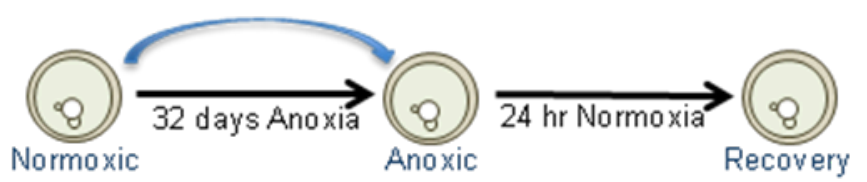

C. Exposure regime for $12 \mathrm{dpd}$ embryos with anoxic preconditioning

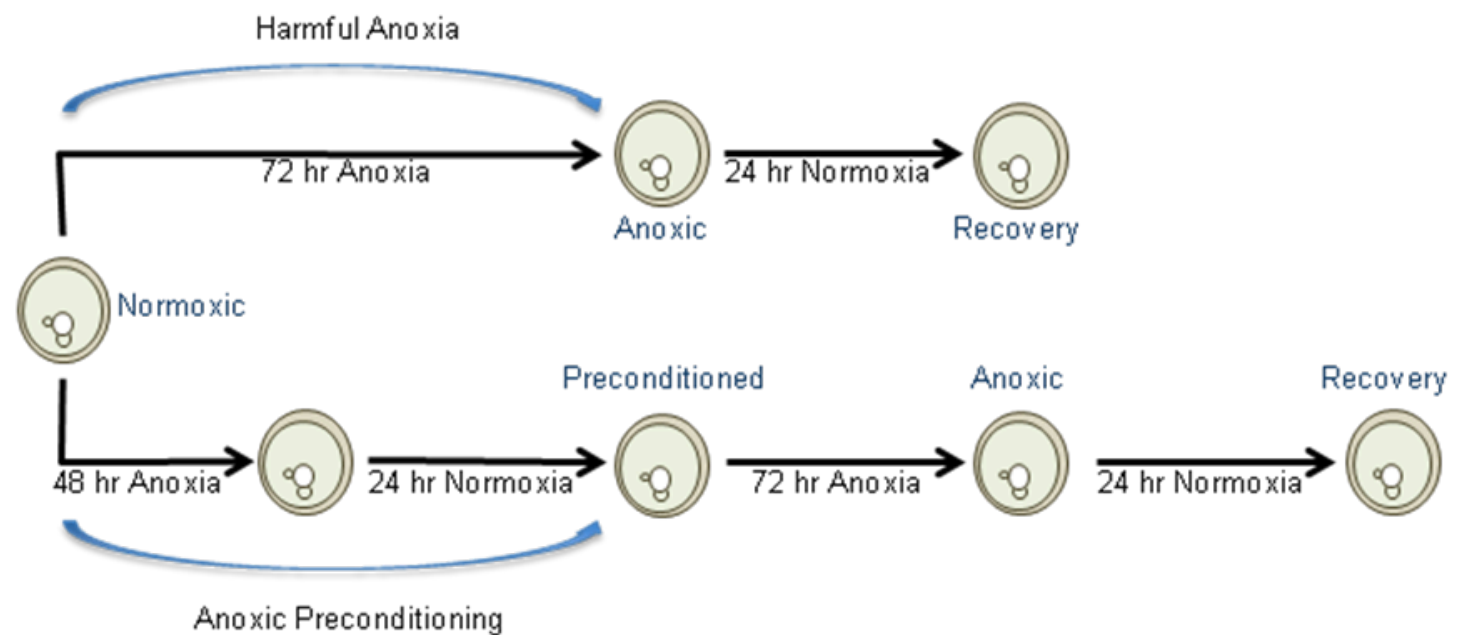

Figure 4.1. Sampling regimen for embryos exposed to anoxia and subsequent recovery from anoxia for western blot analysis. 


\section{Results}

\section{Ubiquitination of proteins}

Total protein ubiquitination for diapause II, $4 \mathrm{dpd}$ and $12 \mathrm{dpd}$ embryos was measured using western blot analysis and representative blots are provided in Figures 4.2 and 4.3. Quantification of these data by densitometry is presented in Figure 4.4 for diapause II and 4 dpd embryos and in Figure 4.5 for $12 \mathrm{dpd}$ embryos exposed to the preconditioning regimen. An analysis of protein-ubiquitination of a $23 \mathrm{kDa}$ protein band that responded uniquely to anoxia is presented in Figures 4.6 and 4.7. 


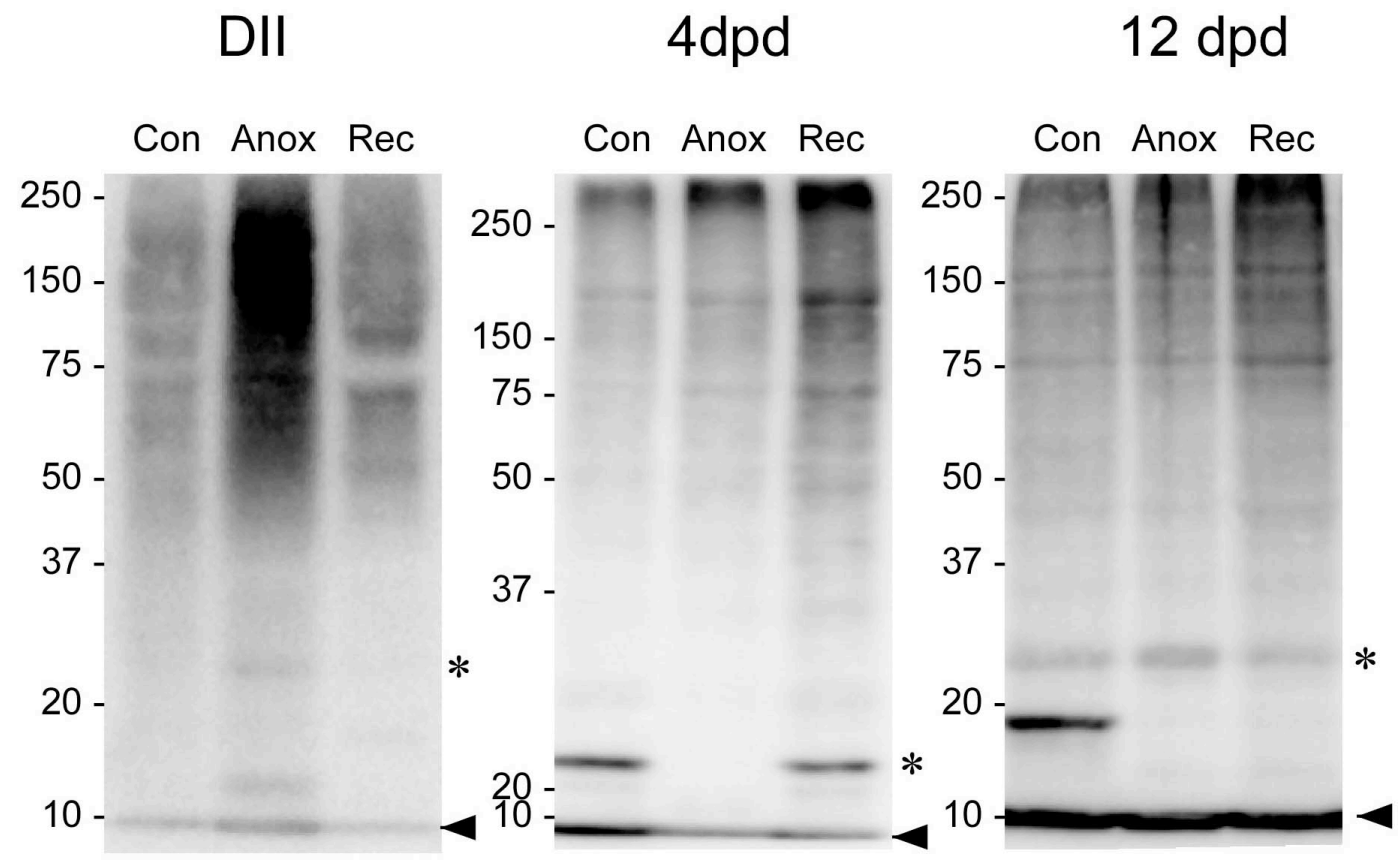

Figure 4.2. Representative western blots of ubiquitin-conjugated proteins in three different developmental stages of $A$. limnaeus exposed to normoxia (Cont), harmful anoxia (Anox=21 days for DII, 32 days for $4 \mathrm{dpd}, 72 \mathrm{hr}$ for 12 $\mathrm{dpd}$ ), and $24 \mathrm{hr}$ of normoxic recovery (Rec). The asterisk marks a $23 \mathrm{kDa}$ protein that appears to be differentially regulated during exposure to anoxia. Arrows denote free ubiquitin. 


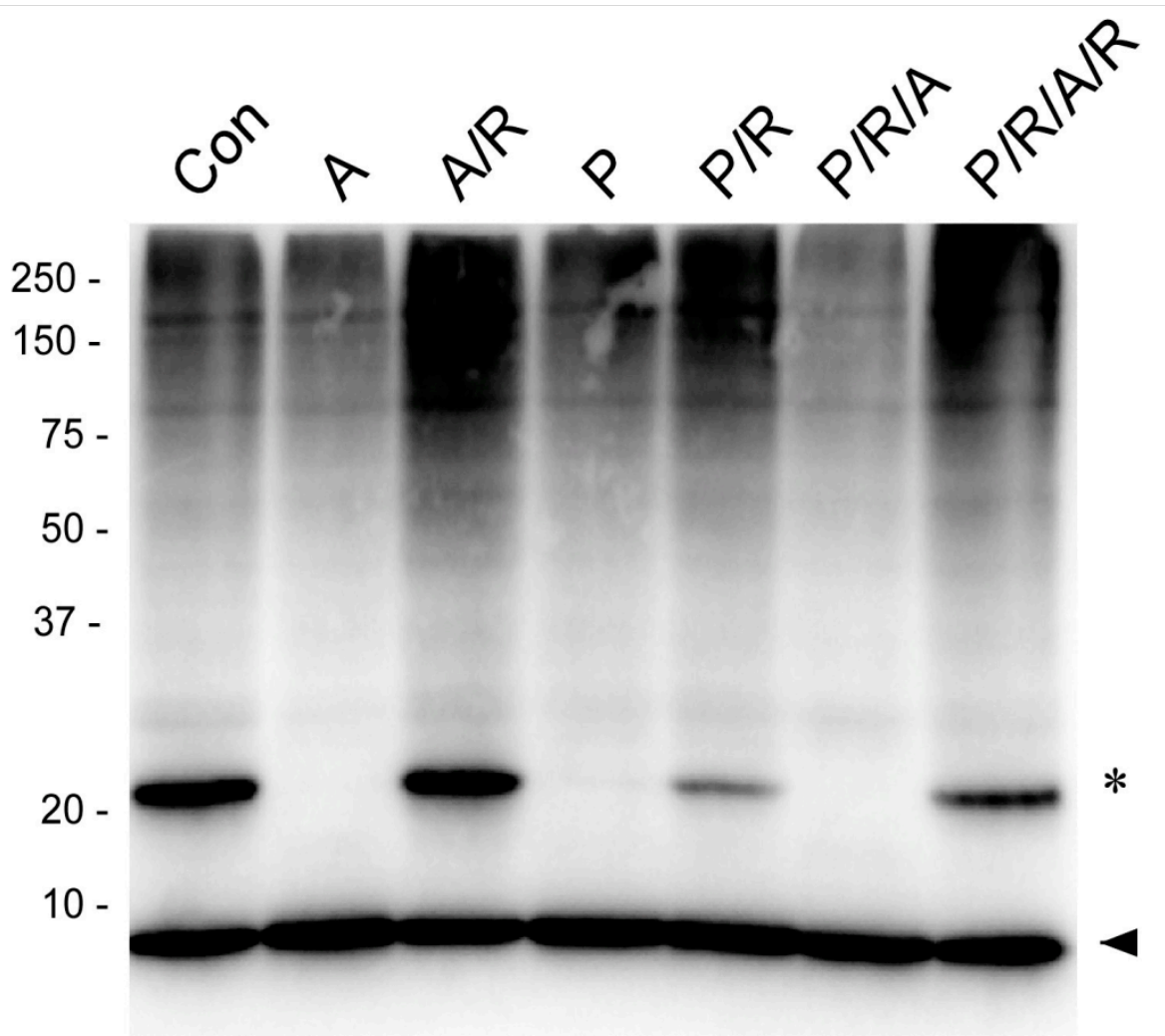

Figure 4.3. A representative blot of ubiquitin conjugated proteins in $12 \mathrm{dpd}$ embryos exposed to normoxia (Con), $72 \mathrm{hr}$ of anoxia (harmful anoxia, A) and $24 \mathrm{hr}$ of recovery from harmful anoxia (A/R). The preconditioning regimen is presented in the last 4 lanes: $48 \mathrm{hr}$ of anoxia $(P)$ followed by $24 \mathrm{hr}$ of aerobic recovery $(P / R)$, and then $72 \mathrm{hr}$ of anoxia $(P / R / A)$ followed by $24 \mathrm{hr}$ of aerobic recovery $(P / R / A / R)$. The asterisk denotes a $23 \mathrm{kDa}$ protein band that appears to be differentially regulated in response to anoxia. The arrow denotes free ubiquitin. 
Ubiquitin-conjugated proteins increased significantly from control values following harmful anoxic treatment in both of the anoxia tolerant stages. Harmful anoxia was $50 \%$ of the $L T_{50}$ value for each: 21 days for DIl embryos and 32 days for 4 dpd embryos (DII: one-way ANOVA, $F(2,6)=31.48$, $p=0.0007$, Bonferroni post hoc, $p<0.05)(4 \mathrm{dpd}$ : one-way ANOVA, $F(2,6)=8.17$, $p=0.0194$, Bonferroni post hoc, $p<0.05)$. The response was greater, over 2fold, in the diapause II embryos, and it appears that ubiquitin conjugated proteins accumulated during anoxia in this developmental stage. In $4 \mathrm{dpd}$ embryos, ubiquitin conjugates did not appear to accumulate during anoxia, but were significantly elevated (nearly 2 -fold) after $24 \mathrm{hr}$ of aerobic recovery (Figs. 4.2 and 4.4). In the $12 \mathrm{dpd}$, the opposite effect was observed (Figs. 4.2 and 4.4). There was a significant decrease of $29 \%$ (one-way ANOVA, $F(2,6)=7.69$, $p=0.0221$, Bonferroni post hoc, $p<0.05)$ in ubiquitin conjugates compared to the normoxic control. After 24 hours of aerobic recovery, ubiquitin conjugate levels returned to control values.

The $12 \mathrm{dpd}$, anoxia sensitive embryos were further tested in an anoxic preconditioning regimen. Embryos were treated with harmful anoxia alone and compared to anoxic-preconditioned embryos subsequently treated with harmful anoxia (Figs. 4.3 and 4.5). Harmful anoxia alone (72 hr) significantly decreased levels of ubiquitin conjugates by $29 \%$ (one-way ANOVA, $F(6,14)=7.48, p=0.001$, Bonferroni post hoc, $p<0.05)$ immediately following anoxia. Ubiquitin conjugation levels returned to approximately the levels of 
the normoxic controls following 24 hours of aerobic recovery. Exposure to harmful anoxia (72 hr) after anoxic preconditioning lowered the levels of protein ubiquitination by $25 \%$ relative to the normoxic control similarly to the non-preconditioned embryos but not significantly (Bonferroni post hoc, $p>0.05)$. There were no significant differences in ubiquitin conjugation following harmful anoxia or aerobic recovery between the preconditioned and non-preconditioned embryos.

As a prelude to future studies to identify potential ubiquitinated proteins, the levels of a $23 \mathrm{kDa}$ band that was consistently observed were quantified. In the diapause II samples the band was below the level of detection in the normoxic control but was visible after 48 hours of anoxia (one-way ANOVA, $F(2,6)=1573, p<0.0001$, Bonferroni post hoc, $p<0.05)$. Upon 24 hours of aerobic recovery this band once again disappeared (Figs. 4.2 and 4.6). In 4 dpd embryos the opposite pattern of expression was observed (Figs. 4.2 and 4.6). The band present in the normoxic control, dropped below detection levels upon 48 hours of anoxic treatment (one-way ANOVA, $F(2,6)=2705$, $p<0.0001$, Bonferroni post hoc, $p<0.05)$. The band was observed again after 24 hours of aerobic recovery at only $81 \%$ of the normoxic control levels (Bonferroni, post hoc, $p<0.05$ ). Embryos at $12 \mathrm{dpd}$ exhibited a similar pattern of expression to the $4 \mathrm{dpd}$ samples. The band was again present in the normoxic control but dropped below the level of detection following anoxia treatment (one-way ANOVA, $F(2,6)=7.30, p=0.0247$, Bonferroni post hoc, 
$p<0.05)$. Upon 24 hours of aerobic recovery there was an increase in band intensity to $44 \%$ of normoxic control levels. Although the harmful anoxia treatment alone was significantly different from the normoxic control (one-way ANOVA, $F(6,14)=4.26, p=0.012$, Bonferroni post hoc, $p<0.05)$., there was no significant difference between the preconditioned and non-preconditioned samples (Bonferroni post hoc, $p>0.05$ ) following anoxic treatment (Fig 4.7). 


\section{Total Protein Ubiquitination}
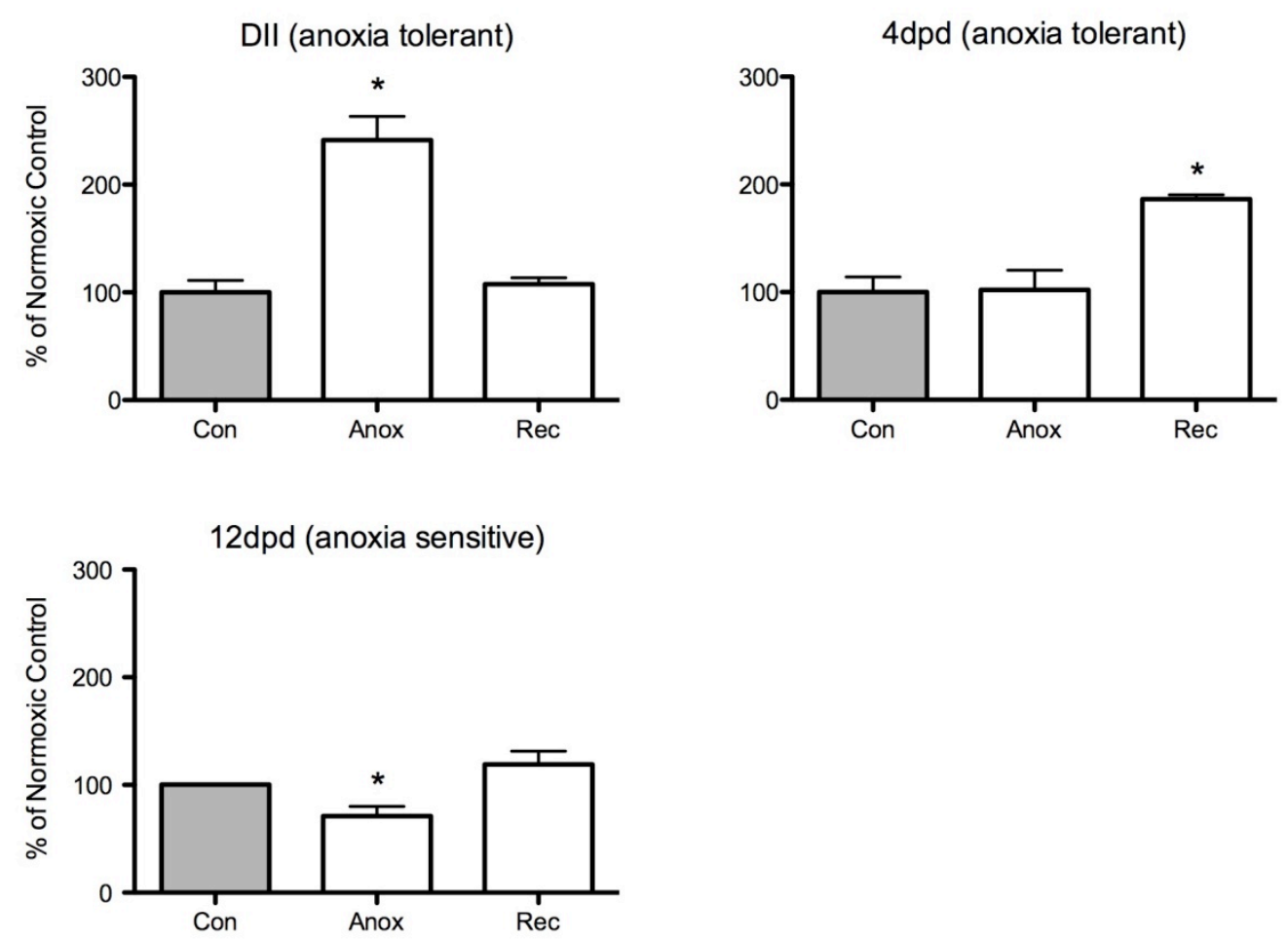

Figure 4.4. Western blot analysis of total protein ubiquitination for diapause II, $4 \mathrm{dpd}$ and $12 \mathrm{dpd}$ embryos; normoxic control (Con), exposure to harmful anoxia (Anox=21 days for DII, 32 days for $4 \mathrm{dpd}, 72 \mathrm{hr}$ for $12 \mathrm{dpd}$ ) and 24 hours of normoxic recovery $(\operatorname{Rec})$. Bars represent means and error bars are S.E.M. (n=3). (DII: one-way ANOVA, $F(2,6)=31.48, p=0.0007)(4 \mathrm{dpd}$ : one-way ANOVA, $F(2,6)=8.17, p=0.0194)(12 \mathrm{dpd}$ : one-way ANOVA, $F(2,6)=7.69$, $p=0.0221$ ). Asterisks represent values that differ significantly from normoxic control values (Bonferroni post hoc, $p<0.05$ ). Data were log transformed prior to statistical analysis in order to meet assumptions of normal distributions for one-way ANOVA. 


\section{Total protein ubiquitination}

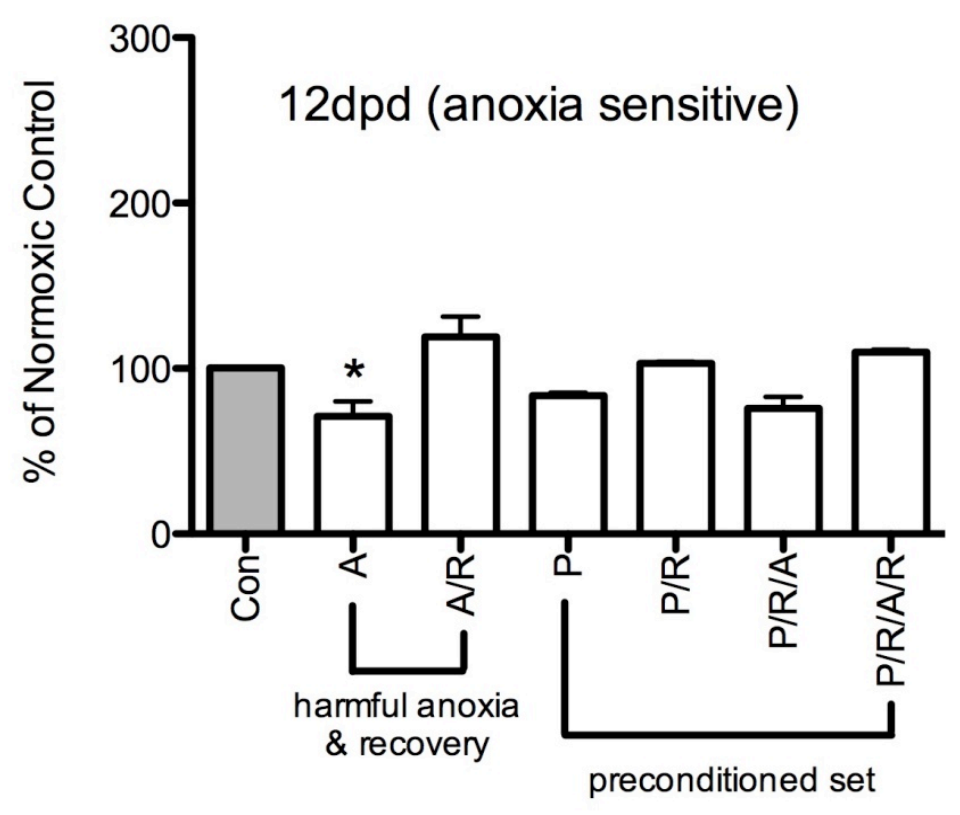

Figure 4.5. The effect of anoxic preconditioning on 12 dpd embryos. Embryos were preconditioned with a non-harmful treatment of $48 \mathrm{hr}$ of anoxia $(\mathrm{P})$ followed by $24 \mathrm{hr}$ of aerobic recovery $(\mathrm{P} / \mathrm{R})$ and then subsequently exposed to $72 \mathrm{hr}$ of anoxia $(\mathrm{P} / \mathrm{R} / \mathrm{A})$ followed by $24 \mathrm{hr}$ of aerobic recovery $(\mathrm{P} / \mathrm{R} / \mathrm{A} / \mathrm{R})$. Con=normoxic control, $A=$ harmful anoxia (72hrs anoxia). Bars represent means and error bars are S.E.M. $(n=3)$. (one-way ANOVA, $F(6,14)=7.48$, $p=0.001)$. Asterisks represent values that differ significantly from normoxic control values (Bonferroni post hoc, $p<0.05$ ). Data were log transformed prior to statistical analysis in order to meet assumptions of normal distributions for one-way ANOVA. 


\section{Protein ubiquitination at $23 \mathrm{kDa}$ band}
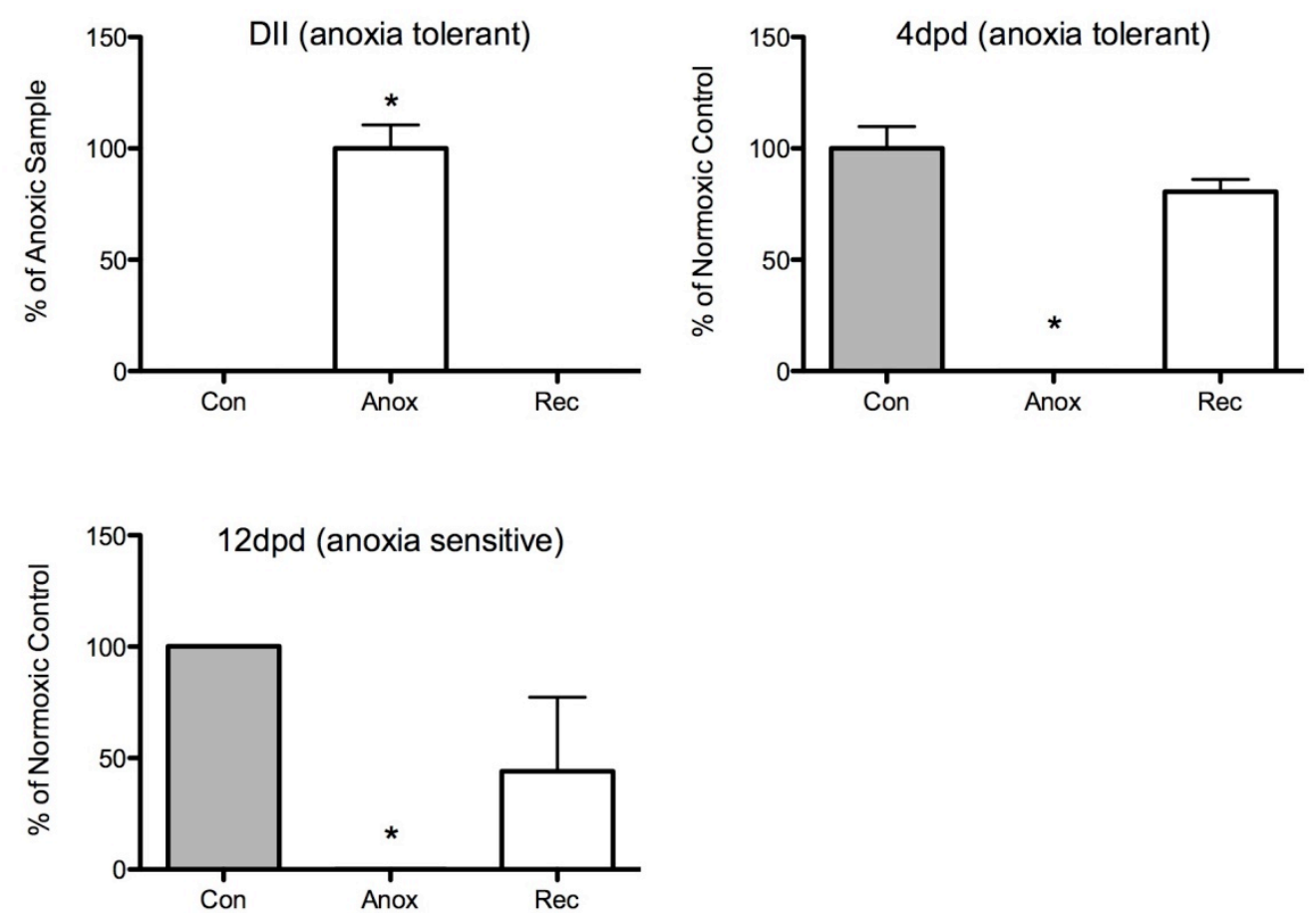

Figure 4.6. Western blot analysis of protein ubiquitination at $23 \mathrm{kDa}$ band for diapause II, $4 \mathrm{dpd}$ and $12 \mathrm{dpd}$ embryos; normoxic control (Con), harmful anoxia (Anox=21 days for DIl, 32 days for $4 \mathrm{dpd}, 72 \mathrm{hr}$ for $12 \mathrm{dpd}$ ) and 24 hours of normoxic recovery $(\operatorname{Rec})$. Bars represent means and error bars are S.E.M. (n=3). (D11: one-way ANOVA, $F(2,6)=1573, p<0.0001)$ (4 dpd: oneway ANOVA, $F(2,6)=2705, p<0.0001$ ) (12 dpd: one-way ANOVA, $F(2,6)=7.30$, $p=0.0247)$. Asterisks represent values that differ significantly from control values (Bonferroni post hoc, $p<0.05$ ). Data were log transformed prior to statistical analysis in order to meet assumptions of normal distributions for one-way ANOVA.

NOTE: in order to keep all graphs on the same scale, DIl samples were calculated as a \% of the anoxic sample because normoxic control values were below detection limits. 


\section{Protein ubiquitination at $23 \mathrm{kDa}$ band}

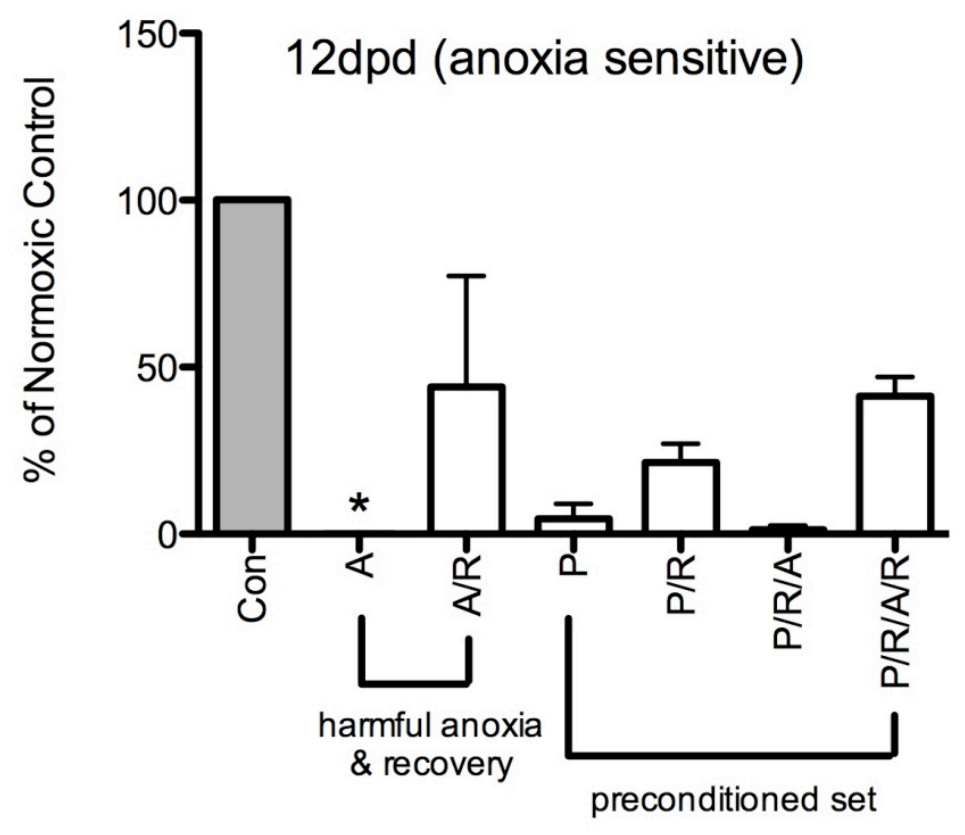

Figure 4.7. Anoxic preconditioning in 12 dpd embryos does not significantly alter the levels of a $23 \mathrm{kDa}$ ubiquitin conjugate band when compared with exposure to harmful anoxia and subsequent $24 \mathrm{hr}$ of aerobic recovery. Con=normoxic control, $A=$ harmful anoxia (72hrs anoxia), $A / R=$ harmful anoxia (72hrs) followed by 24 hrs recovery, $\mathrm{P}=$ =anoxia preconditioning treatment (48hrs), P/R=preconditioning (48hrs) followed by $24 \mathrm{hrs}$ recovery, $\mathrm{P} / \mathrm{R} / \mathrm{A}=$ preconditioning (48hrs) followed by $24 \mathrm{hrs}$ recovery followed by harmful anoxia ( $72 \mathrm{hrs}$ ), $\mathrm{P} / \mathrm{R} / \mathrm{A} / \mathrm{R}=$ preconditioning (48hrs) followed by $24 \mathrm{hrs}$ recovery followed by harmful anoxia ( $72 \mathrm{hrs}$ ) followed by $24 \mathrm{hrs} \mathrm{recovery.} \mathrm{Bars}$ represent means and error bars are S.E.M. $(n=3)$. (one-way ANOVA, $F(6,14)=4.26, p=0.012)$. Asterisks represent values that differ significantly from normoxic control values (Bonferroni post hoc, $p<0.05$ ). Data were log transformed prior to statistical analysis in order to meet assumptions of normal distributions for one-way ANOVA. 
SUMO-1 and SUMO-2/3

Total protein SUMOylation as well as individual bands for both SUMO-1 and SUMO-2/3 were measured by western blot analysis and representative blots are presented in Figures 4.8 and 4.9 (SUMO-1) and Figures 4.16 and 4.17 (SUMO-2/3). Quantifications of these results based on densitometry are presented in Figures $4.10-4.15$ (SUMO-1) and Figures 4.18 - 4.21 (SUMO2/3) below. 


\section{DII}

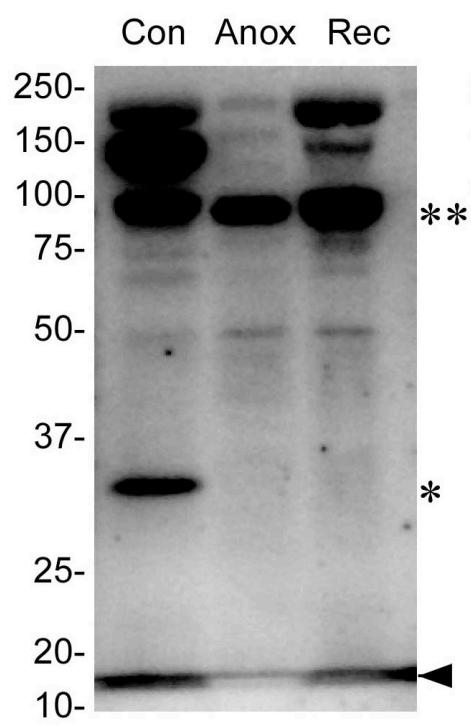

4dpd

Con Anox Rec

250-

$150-$

$100-$

$75-$

$50-$

$37-$

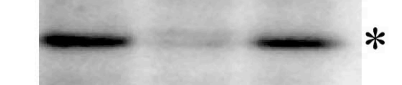

25-

$20-$
$12 \mathrm{dpd}$

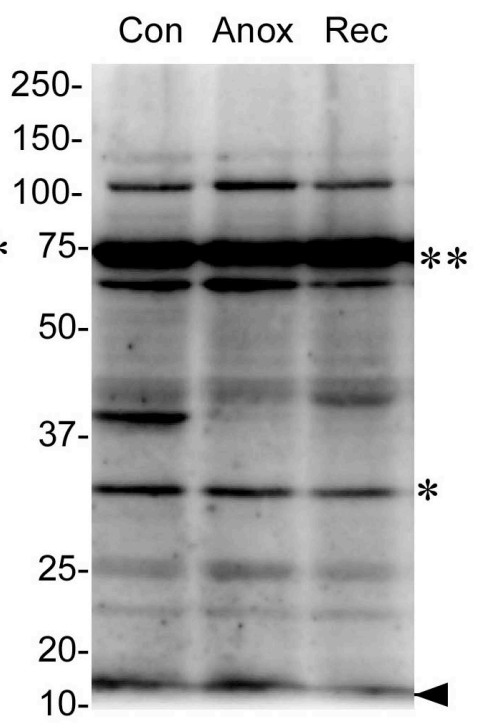

Figure 4.8. SUMO-1 conjugated proteins in 3 developmental stages of $A$. limnaeus embryos exposed to harmful anoxia (Anox=21 days for DII, 32 days for $4 \mathrm{dpd}, 72 \mathrm{hr}$ for $12 \mathrm{dpd}$ ) and allowed to recover for $24 \mathrm{hr}(\mathrm{Rec})$. Con = normoxic control embryos. The asterisks denote 30 and 75kDa protein bands that appear to be differentially regulated in response to anoxia. 


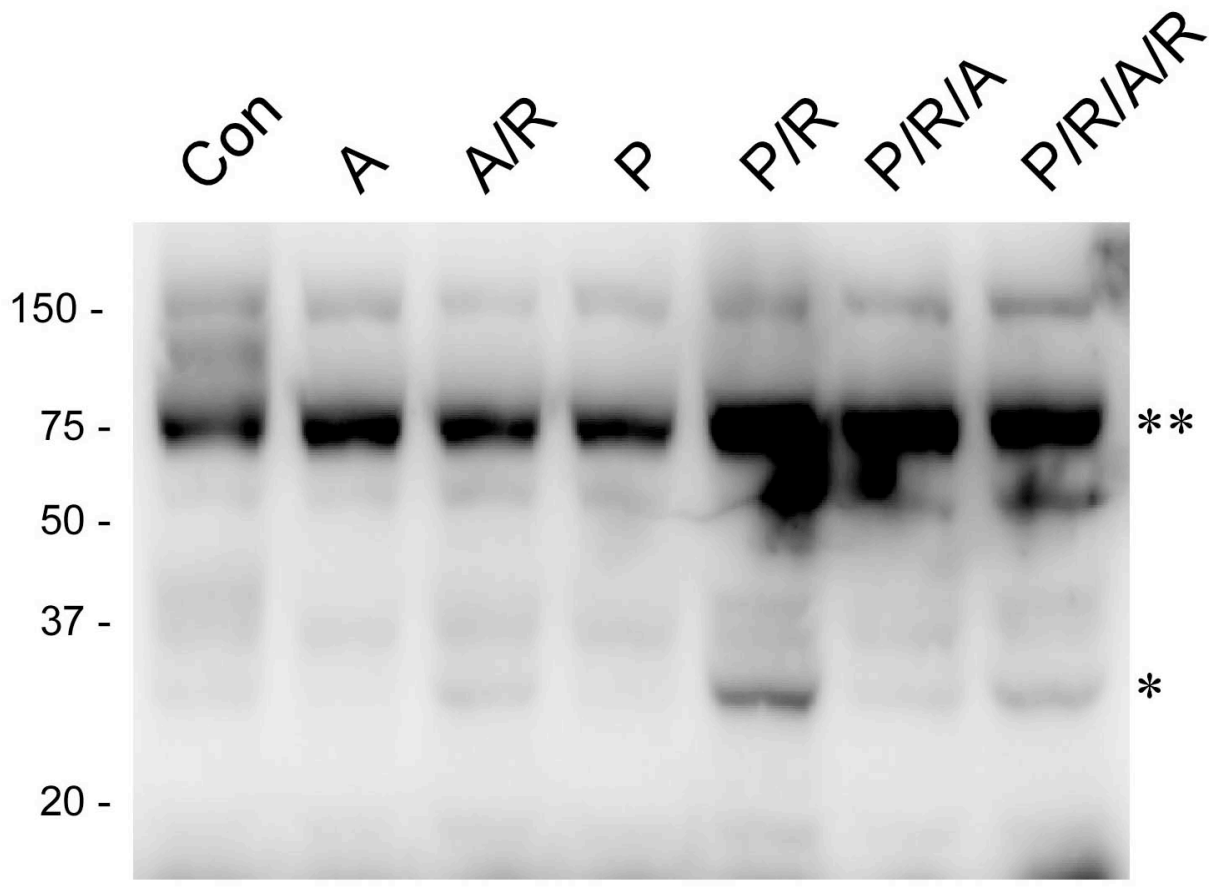

Figure 4.9. A representative blot of SUMO-1 conjugated proteins in $12 \mathrm{dpd}$ embryos exposed to normoxia (Con), $72 \mathrm{hr}$ of anoxia (harmful anoxia, A) and $24 \mathrm{hr}$ of recovery from harmful anoxia $(A / R)$. The preconditioning regimen is presented in the last 4 lanes: $48 \mathrm{hr}$ of anoxia $(\mathrm{P})$ followed by $24 \mathrm{hr}$ of aerobic recovery $(P / R)$, and then $72 \mathrm{hr}$ of anoxia $(P / R / A)$ followed by $24 \mathrm{hr}$ of aerobic recovery $(\mathrm{P} / \mathrm{R} / \mathrm{A} / \mathrm{R})$. The asterisks denote 30 and $75 \mathrm{kDa}$ protein bands that appear to be differentially regulated in response to anoxia. 
There were no significant changes in total protein SUMOylation for SUMO-1 following harmful anoxic treatment for any of the three developmental stages investigated (Fig. 4.10). The $12 \mathrm{dpd}$ embryos exposed to the preconditioning regimen also demonstrated a similar pattern. There were no significant changes in SUMO-1 conjugation following harmful anoxic treatment in either the preconditioned or non-preconditioned embryos (Fig. 4.11).

In addition to the total levels of protein SUMO-1 conjugates, two bands that were observed at $\sim 30$ (Figs 4.12 and 4.13 ) and $\sim 75 \mathrm{kDa}$ that appeared to be differentially regulated by anoxia (Figs. 4.14 and 4.15 ) were also quantified. The $30 \mathrm{kDa}$ band was observed in the normoxic control for the two developmental stages that exhibit long-term tolerance of anoxia (Fig. 4.12, DII and $4 \mathrm{dpd}$ ). In both of these stages, the band at 30kDa disappeared completely after exposure to harmful anoxia treatment, however due to sample variability it was only considered significant in the DII samples (one-way ANOVA, $F(2,6)=668.4, p<0.0001$, Bonferroni post hoc, $p<0.05)$. In $4 \mathrm{dpd}$ embryos, SUMO-1 conjugation was observed again after 24 hours of aerobic recovery. In the 12 dpd embryo samples, the SUMO-1 conjugate was present at $30 \mathrm{kDa}$ (Fig. 4.12), however there was no significant change following anoxic treatment and subsequent aerobic recovery.

The 12 dpd embryos exposed to the preconditioning regimen did not demonstrate any significant changes in SUMO-1-ylation at the $30 \mathrm{kDa}$ band (Fig. 4.13). The band was strongly present and very close in value to the 
normoxic control for all treatments.

In diapause II embryos exposed to harmful anoxia, a SUMO-1 conjugate in the $75 \mathrm{kDa}$ range appeared to exhibit differential changes in response to anoxic treatment, however, none of these changes were significant (Figs. 4.14 and 4.15). For the $12 \mathrm{dpd}$ samples exposed to the preconditioning regimen, harmful anoxia (72 hours) in the embryos did not change SUMO-1-ylation in the $75 \mathrm{kDa}$ size class area relative to the normoxic control. Anoxic preconditioning did not appear to have a large affect on SUMO-1 conjugation in this size range in $12 \mathrm{dpd}$ embryos.

For SUMOylation by SUMO-2/3 there were no significant changes in the overall levels of total SUMO conjugates for any of the treatments (Figs. $4.16-4.19)$. In addition to the total protein SUMO-2/3-ylation, a strong band that was observed at $\sim 75 \mathrm{kDa}$ was also quantified (Figs. 4.20 and 4.21 ). For the anoxia tolerant, diapause II samples, SUMO-2/3-ylation increased by $50 \%$ in this area after harmful anoxic treatment and remained elevated after 24 hours of aerobic recovery, however this change was not considered significant. Both stages of post-diapause II embryos exhibited no significant changes in SUMO-2/3-ylation at 75kDa following anoxic treatment, aerobic recovery, or following anoxic preconditioning. 


\section{Total protein SUMO-1-ylation}
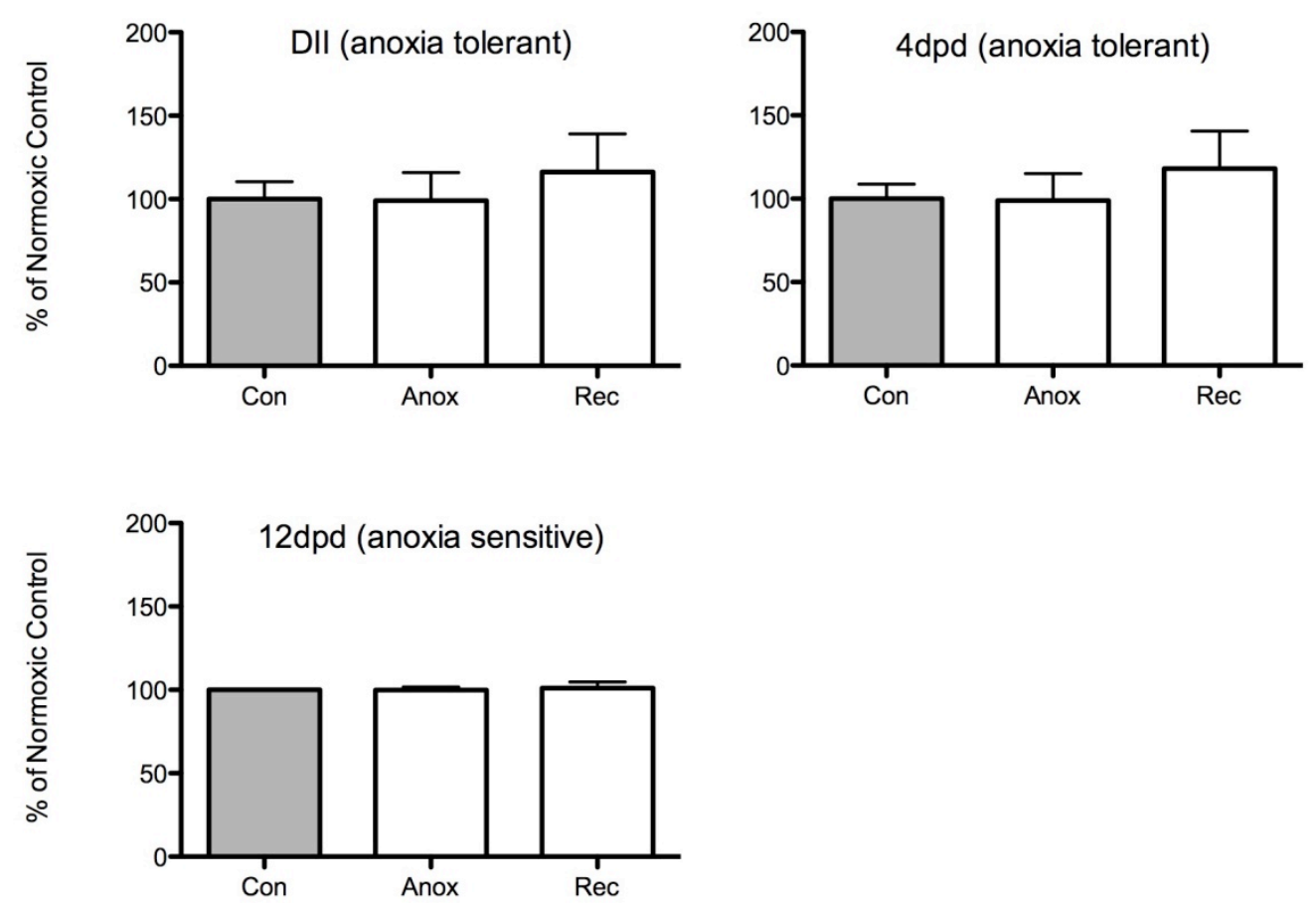

Figure 4.10. Immunoblot analysis of total protein SUMO-1-ylation for diapause II, $4 \mathrm{dpd}$ and $12 \mathrm{dpd}$ embryos; Normoxic control (Con), harmful anoxia (Anox=21 days for DII, 32 days for $4 \mathrm{dpd}, 72 \mathrm{hr}$ for $12 \mathrm{dpd}$ ) and 24 hours of normoxic recovery (Rec). Bars represent means and error bars are S.E.M. $(n=3)$. One-way ANOVA analysis revealed no significant changes from Normoxic control values, $p>0.05$. Data were log transformed prior to statistical analysis in order to meet assumptions of normal distributions for one-way ANOVA. 


\section{Total SUMO-1-ylation}

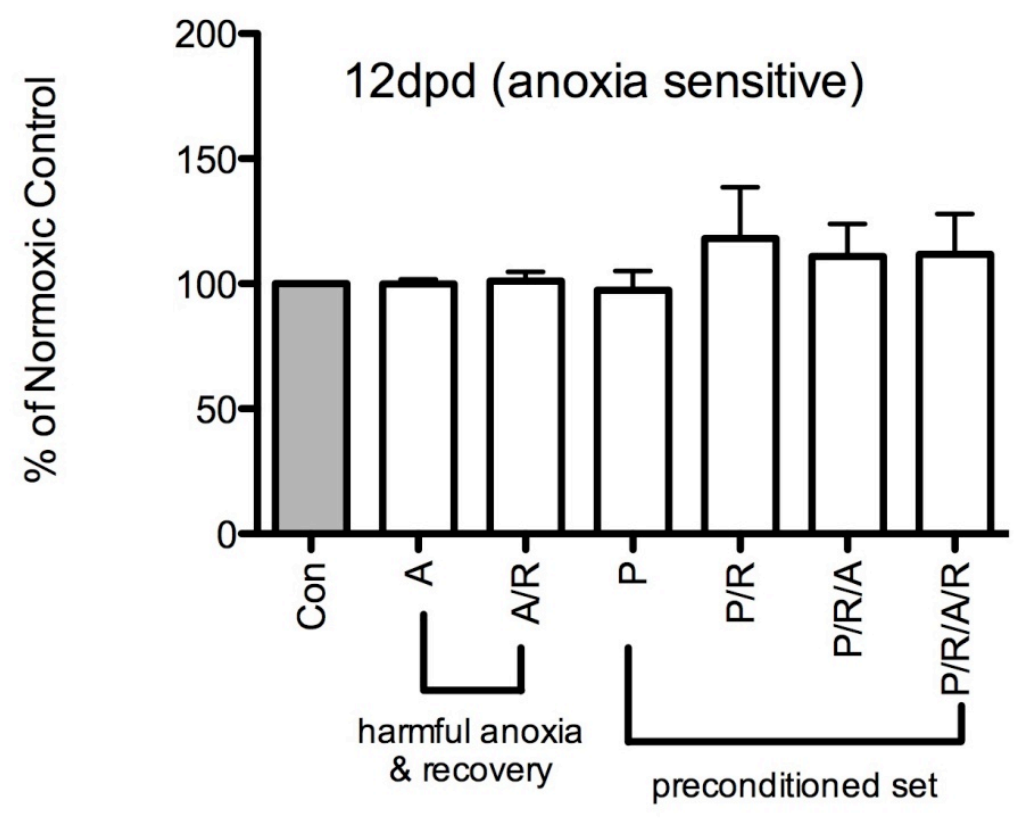

Figure 4.11. 12 dpd embryos were preconditioned with a non-harmful treatment of 48 hours of anoxia and then subsequently exposed to harmful anoxia (72 hrs). Con=normoxic control, A=harmful anoxia ( $72 \mathrm{hrs}$ anoxia), $\mathrm{A} / \mathrm{R}=$ harmful anoxia $(72 \mathrm{hrs}$ ) followed by $24 \mathrm{hrs}$ recovery, $\mathrm{P}=$ anoxia preconditioning treatment (48hrs), $\mathrm{P} / \mathrm{R}=$ preconditioning (48hrs) followed by $24 \mathrm{hrs}$ recovery, $\mathrm{P} / \mathrm{R} / \mathrm{A}=$ =preconditioning (48hrs) followed by $24 \mathrm{hrs}$ recovery followed by harmful anoxia ( $72 \mathrm{hrs}$ ), P/R/A/R=preconditioning (48hrs) followed by $24 \mathrm{hrs}$ recovery followed by harmful anoxia (72hrs) followed by $24 \mathrm{hrs}$ recovery. Bars represent means and error bars are S.E.M. $(n=3)$. One way ANOVA analysis revealed no significant changes from normoxic control values, $p>0.05$. Data were log transformed prior to statistical analysis in order to meet assumptions of normal distributions for one-way ANOVA. 


\section{Protein SUMO-1-ylation at 30kDa band}
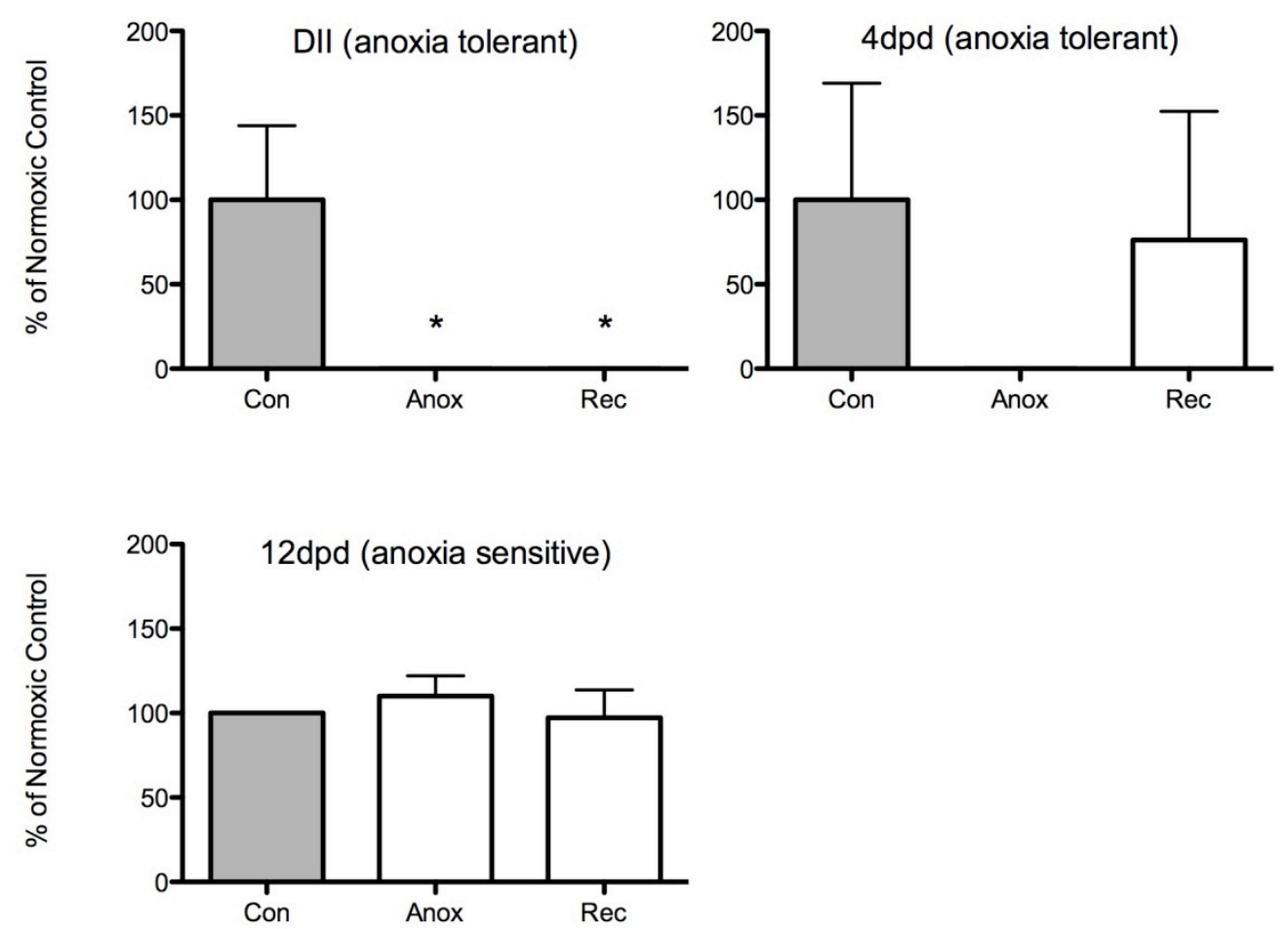

Figure 4.12. Immunoblot analysis of protein SUMO-1-ylation at 30kDa band for diapause II, $4 \mathrm{dpd}$ and 12 dpd embryos; normoxic control (Con), harmful anoxia (Anox=21 days for DII, 32 days for $4 \mathrm{dpd}, 72 \mathrm{hr}$ for $12 \mathrm{dpd}$ ) and 24 hours of normoxic recovery $(\operatorname{Rec})$. Bars represent means and error bars are S.E.M. $(n=3)$. (DII: one-way ANOVA, $F(2,6)=668.4, p<0.0001)(4 \mathrm{dpd}$ : one-way ANOVA, $F(2,6)=1.36, p>0.05$ ) (12 dpd: one-way ANOVA, $F(2,6)=0.32$, $p>0.05)$. Asterisks represent values that differ significantly from normoxic control values (Bonferroni post hoc, $p<0.05$ ). Data were log transformed prior to statistical analysis in order to meet assumptions of normal distributions for one-way ANOVA. 


\section{Protein SUMO-1-ylation at 30kDa band}

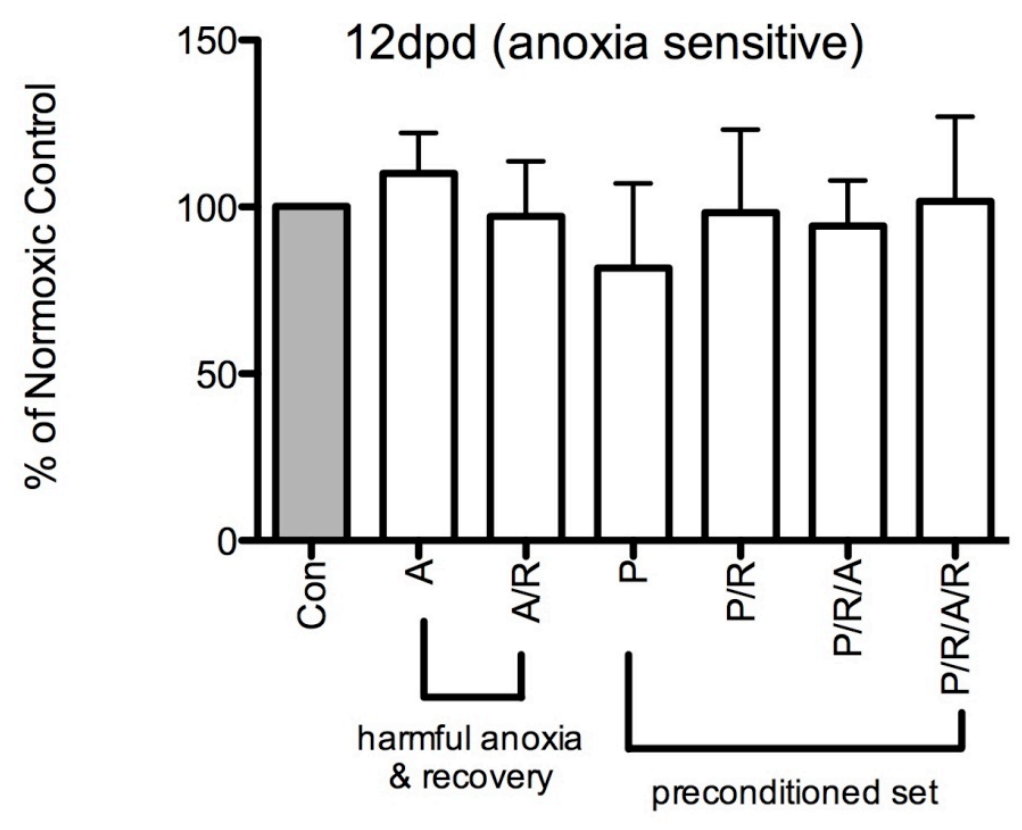

Figure 4.13. 12 dpd embryos were preconditioned with a non-harmful treatment of 48 hours of anoxia and then subsequently exposed to harmful anoxia (72 hrs). Con=normoxic control, $A=$ harmful anoxia ( $72 \mathrm{hrs}$ anoxia), $\mathrm{A} / \mathrm{R}=$ harmful anoxia $(72 \mathrm{hrs}$ ) followed by 24 hrs recovery, $\mathrm{P}=$ anoxia preconditioning treatment (48hrs), $\mathrm{P} / \mathrm{R}=$ preconditioning (48hrs) followed by $24 \mathrm{hrs}$ recovery, $\mathrm{P} / \mathrm{R} / \mathrm{A}=$ preconditioning (48hrs) followed by $24 \mathrm{hrs}$ recovery followed by harmful anoxia (72hrs), P/R/A/R=preconditioning (48hrs) followed by $24 \mathrm{hrs}$ recovery followed by harmful anoxia (72hrs) followed by $24 \mathrm{hrs}$ recovery. Bars represent means and error bars are S.E.M. $(n=3)$. One way ANOVA analysis revealed no significant changes from normoxic control values, $p>0.05$. Data were log transformed prior to statistical analysis in order to meet assumptions of normal distributions for one-way ANOVA. 


\section{Protein SUMO-1-ylation at 75kDa band}
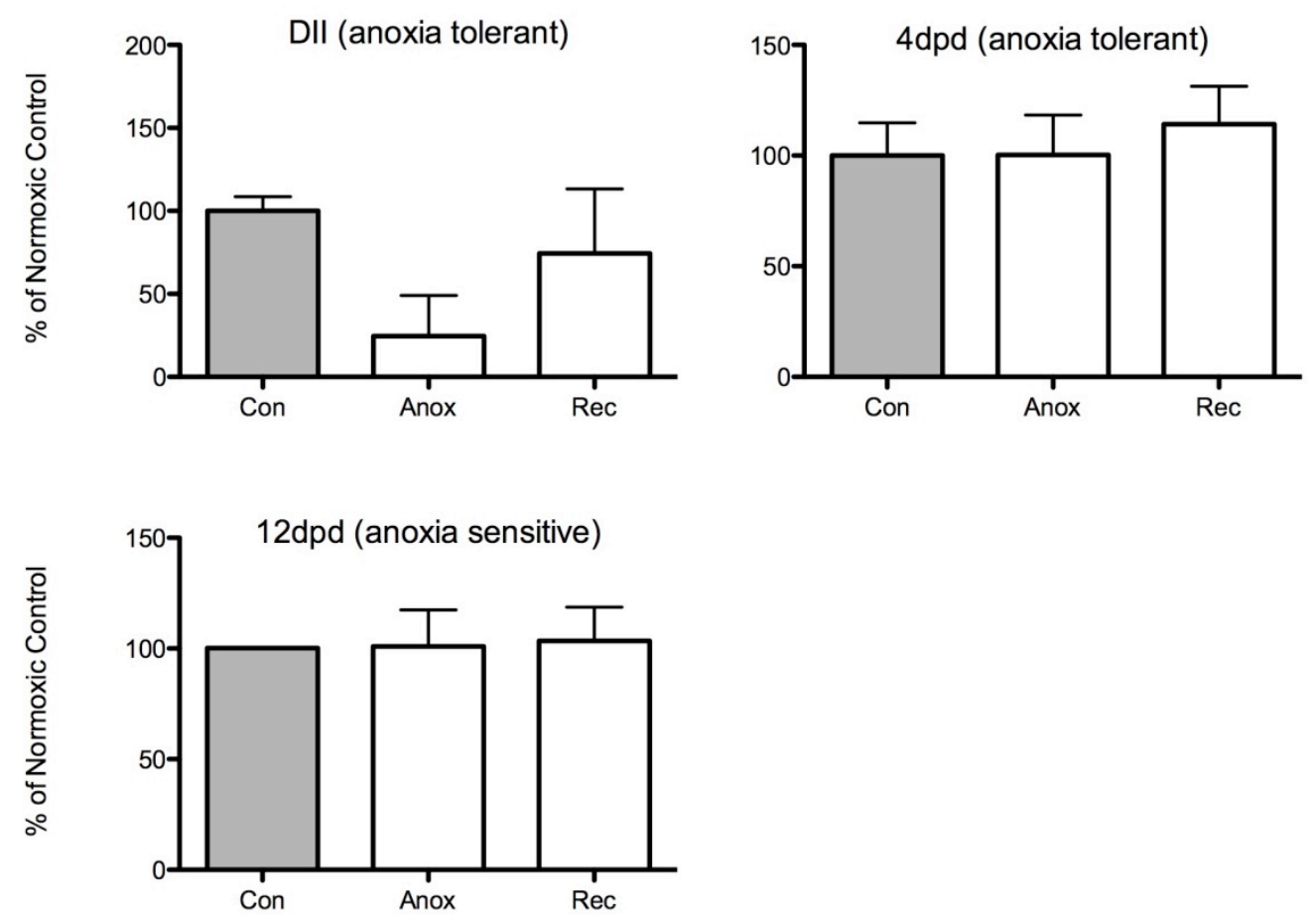

Figure 4.14. Immunoblot analysis of protein SUMO-1-ylation at $75 \mathrm{kDa}$ band for diapause II, $4 \mathrm{dpd}$ and $12 \mathrm{dpd}$ embryos; Normoxic control (Con), harmful anoxia (Anox=21 days for DII, 32 days for $4 \mathrm{dpd}, 72 \mathrm{hr}$ for $12 \mathrm{dpd}$ ) and 24 hours of normoxic recovery (Rec). Bars represent means and error bars are S.E.M. $(n=3)$. One way ANOVA analysis revealed no significant changes from Normoxic control values, $p>0.05$. Data were log transformed prior to statistical analysis in order to meet assumptions of normal distributions for one-way ANOVA. 


\section{Protein SUMO-1-ylation at 75kDa band}

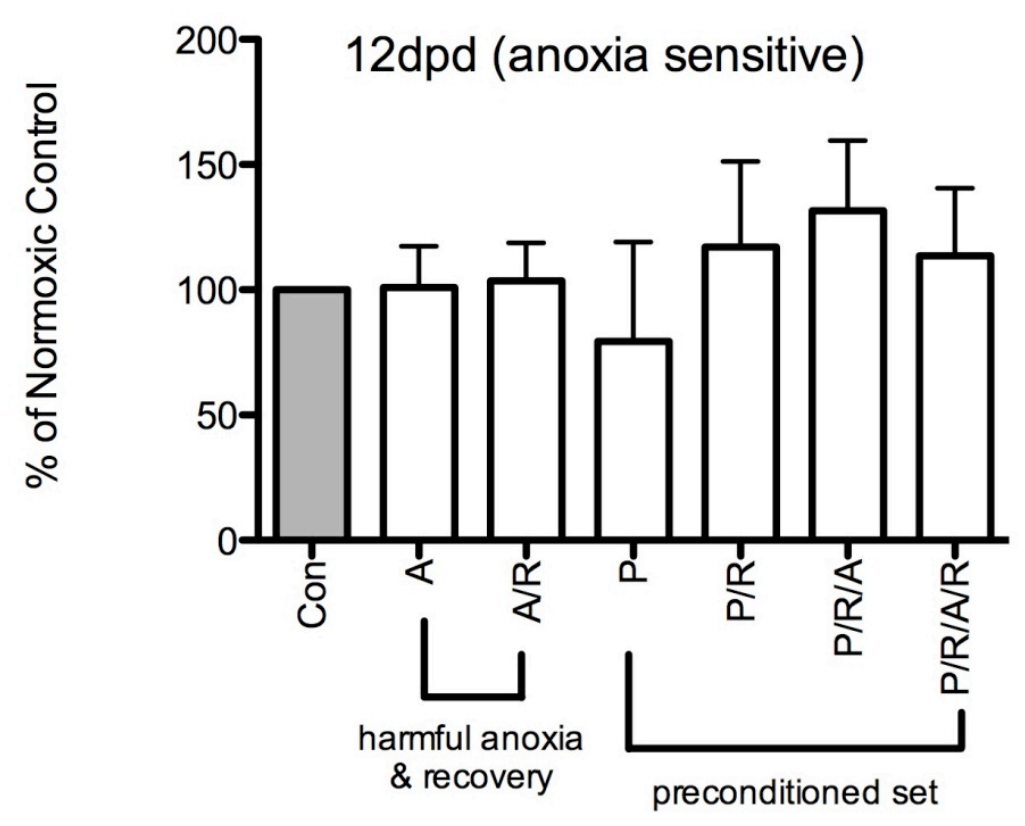

Figure 4.15. 12 dpd embryos were preconditioned with a non-harmful treatment of 48 hours of anoxia and then subsequently exposed to harmful anoxia (72 hrs). Con=normoxic control, $A=$ harmful anoxia ( $72 \mathrm{hrs}$ anoxia), $\mathrm{A} / \mathrm{R}=$ harmful anoxia $(72 \mathrm{hrs}$ ) followed by $24 \mathrm{hrs}$ recovery, $\mathrm{P}=$ anoxia preconditioning treatment (48hrs), $\mathrm{P} / \mathrm{R}=$ preconditioning (48hrs) followed by $24 \mathrm{hrs}$ recovery, $\mathrm{P} / \mathrm{R} / \mathrm{A}=$ =preconditioning (48hrs) followed by $24 \mathrm{hrs}$ recovery followed by harmful anoxia (72hrs), P/R/A/R=preconditioning (48hrs) followed by $24 \mathrm{hrs}$ recovery followed by harmful anoxia ( $72 \mathrm{hrs}$ ) followed by $24 \mathrm{hrs}$ recovery. Bars represent means and error bars are S.E.M. $(n=3)$. One way ANOVA analysis revealed no significant changes from normoxic control values, $p>0.05$. Data were log transformed prior to statistical analysis in order to meet assumptions of normal distributions for one-way ANOVA. 


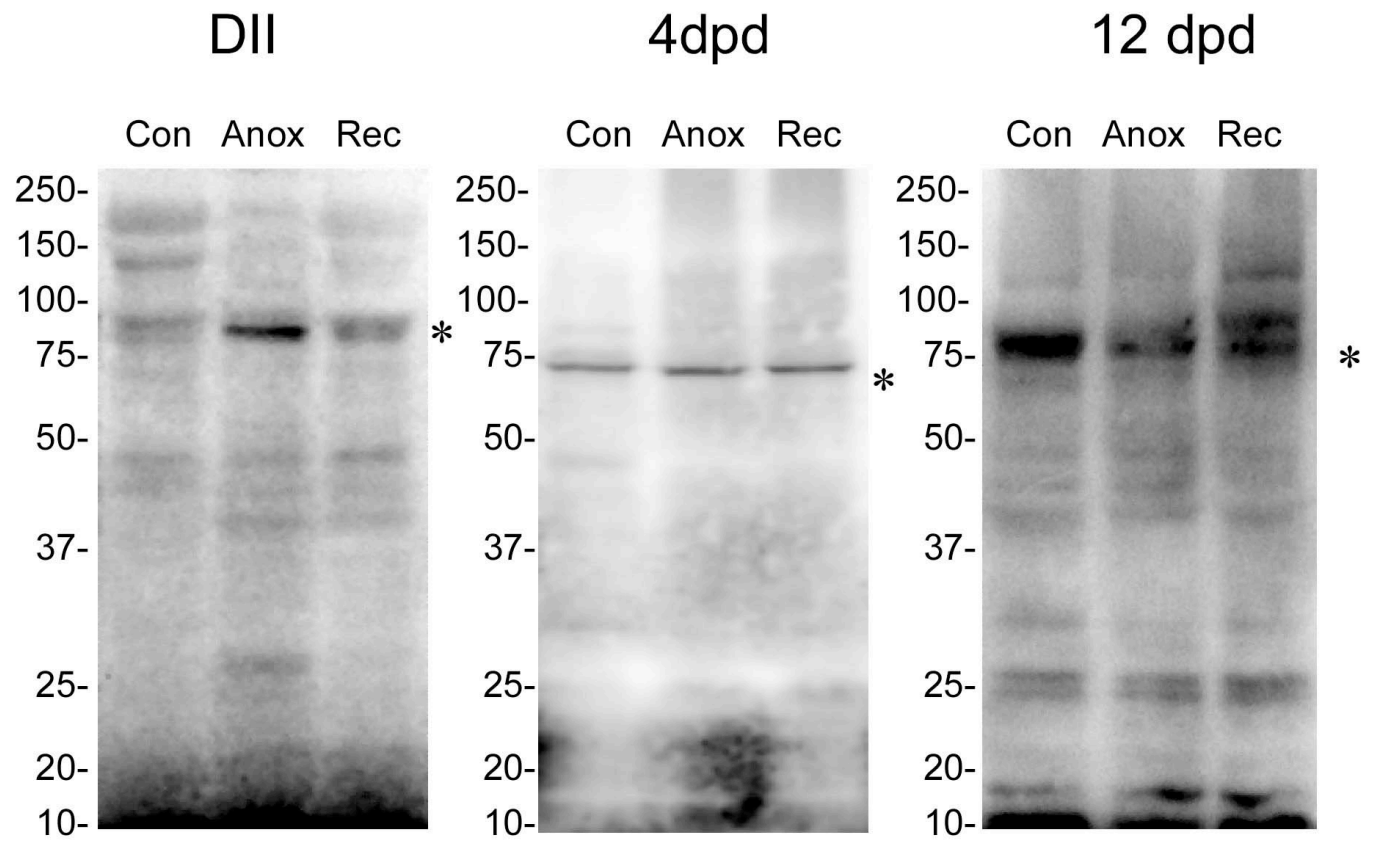

Figure 4.16. Representative blots of SUMO 2/3 conjugated proteins in 3 developmental stages of $A$. limnaeus embryos exposed to harmful anoxia (Anox=21 days for DIl, 32 days for $4 \mathrm{dpd}, 72 \mathrm{hr}$ for $12 \mathrm{dpd}$ ) and allowed to recover for $24 \mathrm{hr}(\mathrm{Rec})$. Con = normoxic control embryos. The asterisk denotes a $75 \mathrm{kDa}$ protein band that appears to be differentially regulated in response to anoxia. 


\section{SUMO $2 / 3$}

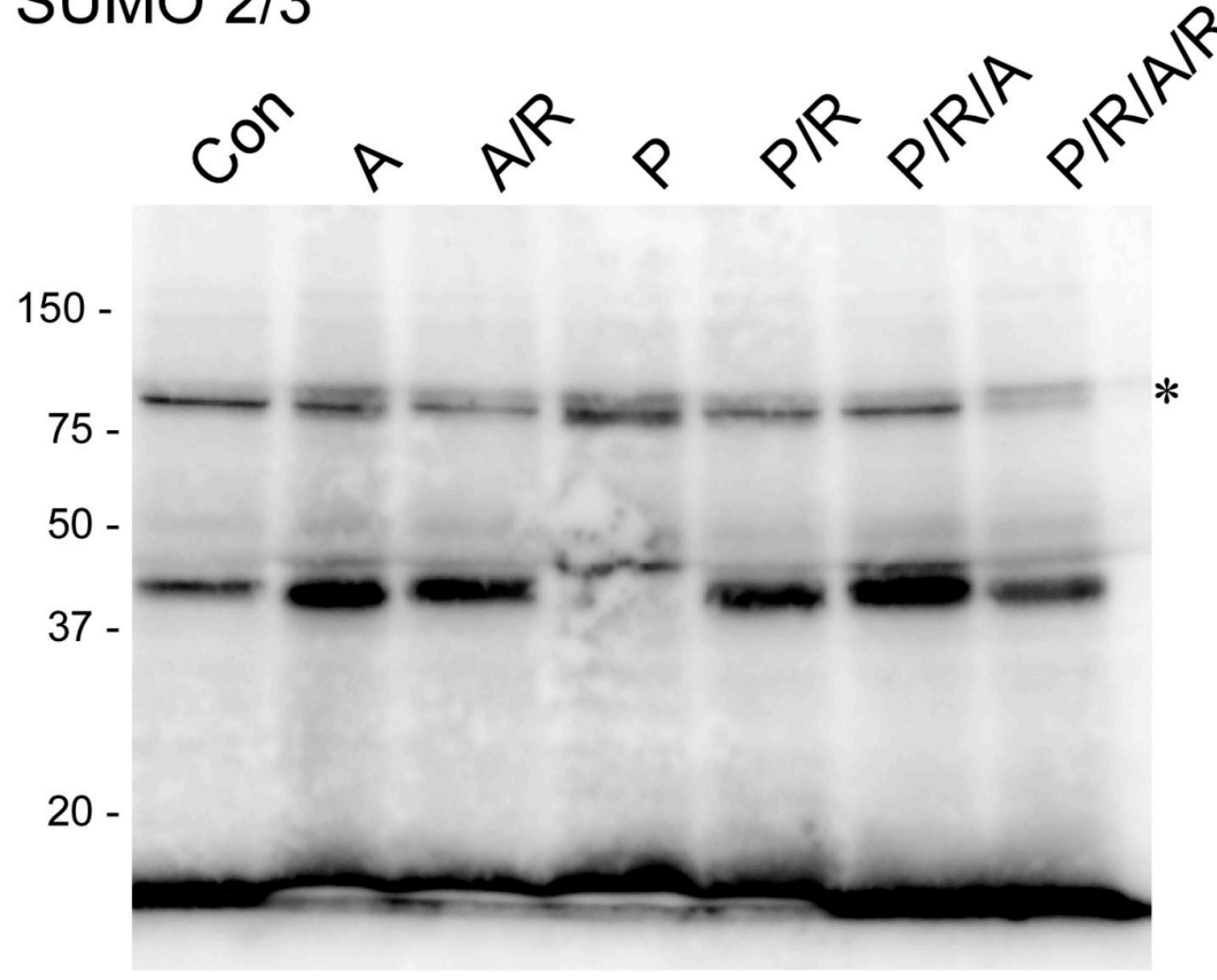

Figure 4.17. A representative blot of SUMO-2/3 conjugated proteins in $12 \mathrm{dpd}$ embryos exposed to normoxia (Con), $72 \mathrm{hr}$ of anoxia (harmful anoxia, A) and $24 \mathrm{hr}$ of recovery from harmful anoxia $(A / R)$. The preconditioning regimen is presented in the last 4 lanes: $48 \mathrm{hr}$ of anoxia $(\mathrm{P})$ followed by $24 \mathrm{hr}$ of aerobic recovery $(P / R)$, and then $72 \mathrm{hr}$ of anoxia $(P / R / A)$ followed by $24 \mathrm{hr}$ of aerobic recovery $(\mathrm{P} / \mathrm{R} / \mathrm{A} / \mathrm{R})$. The asterisk denotes a $75 \mathrm{kDa}$ protein band that appears to be differentially regulated in response to anoxia. 


\section{Total protein SUMO-2/3-ylation}
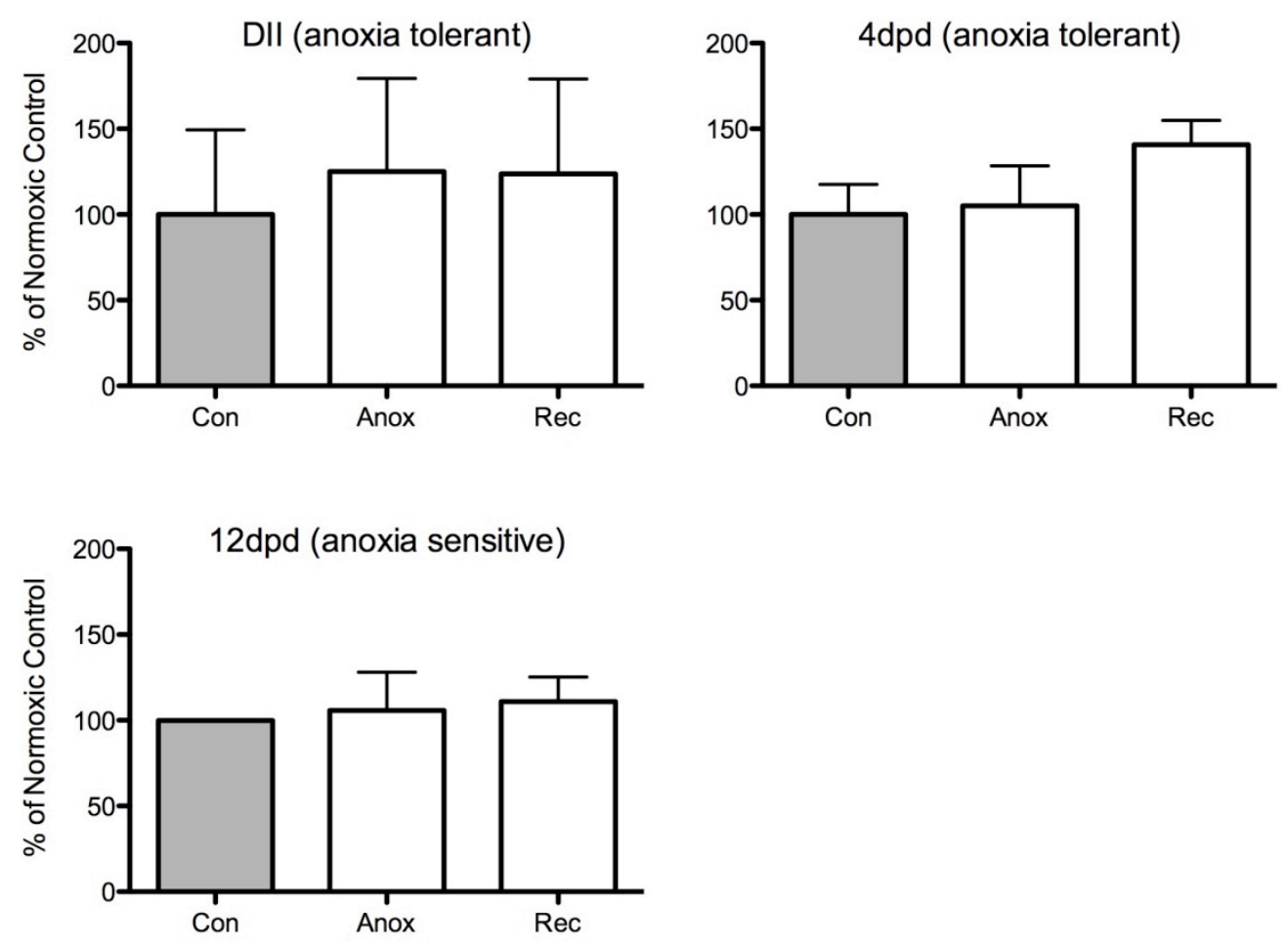

Figure 4.18. Immunoblot analysis of total protein SUMO-2/3-ylation for diapause II, $4 \mathrm{dpd}$ and $12 \mathrm{dpd}$ embryos; normoxic control (Con), harmful anoxia (Anox=21 days for DII, 32 days for $4 \mathrm{dpd}, 72 \mathrm{hr}$ for $12 \mathrm{dpd}$ ) and 24 hours of normoxic recovery $(\operatorname{Rec})$. Bars represent means and error bars are S.E.M. $(n=3)$. One way ANOVA analysis revealed no significant changes from normoxic control values, $p>0.05$. Data were log transformed prior to statistical analysis in order to meet assumptions of normal distributions for one-way ANOVA. 


\section{Total protein SUMO-2/3-ylation}

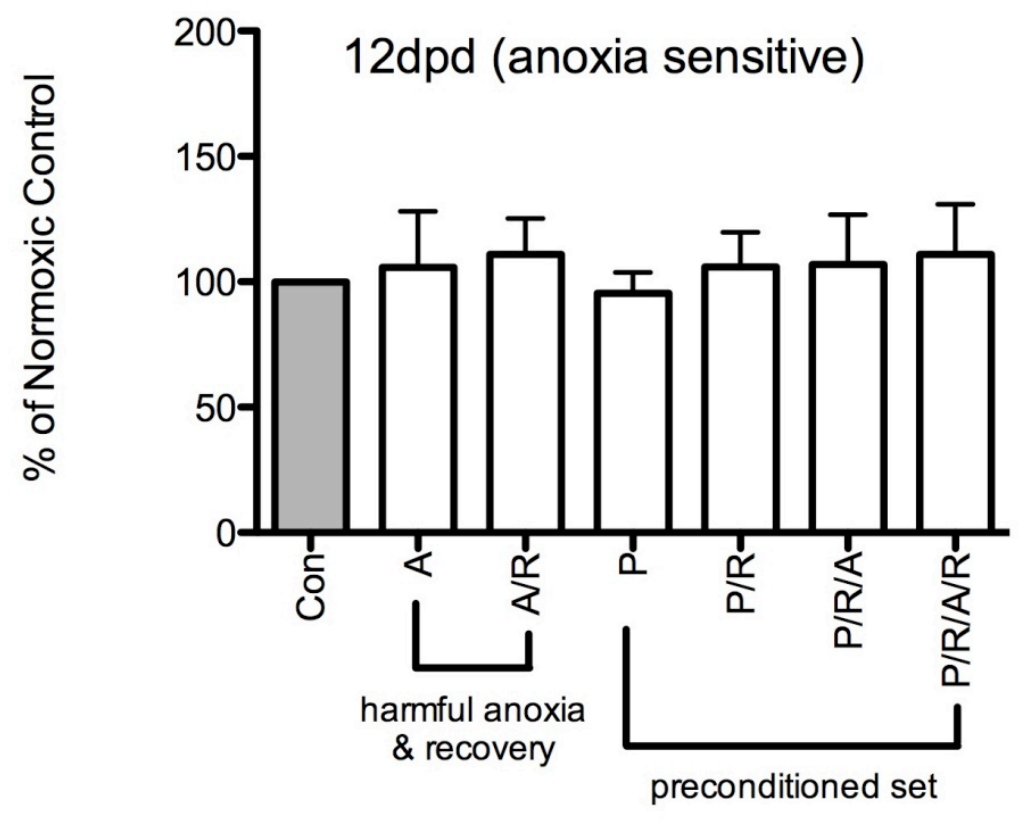

Figure 4.19. 12 dpd embryos were preconditioned with a non-harmful treatment of 48 hours of anoxia and then subsequently exposed to harmful anoxia (72 hrs). Con=normoxic control, A=harmful anoxia ( $72 \mathrm{hrs}$ anoxia), $\mathrm{A} / \mathrm{R}=$ harmful anoxia $(72 \mathrm{hrs}$ ) followed by $24 \mathrm{hrs}$ recovery, $\mathrm{P}=$ anoxia preconditioning treatment (48hrs), $\mathrm{P} / \mathrm{R}=$ preconditioning (48hrs) followed by 24hrs recovery, $\mathrm{P} / \mathrm{R} / \mathrm{A}=$ preconditioning (48hrs) followed by $24 \mathrm{hrs}$ recovery followed by harmful anoxia (72hrs), P/R/A/R=preconditioning (48hrs) followed by $24 \mathrm{hrs}$ recovery followed by harmful anoxia (72hrs) followed by $24 \mathrm{hrs}$ recovery. Bars represent means and error bars are S.E.M. $(n=3)$. One way ANOVA analysis revealed no significant changes from normoxic control values, $p>0.05$. Data were log transformed prior to statistical analysis in order to meet assumptions of normal distributions for one-way ANOVA. 


\section{Protein SUMO-2/3-ylation at 75kDa band}
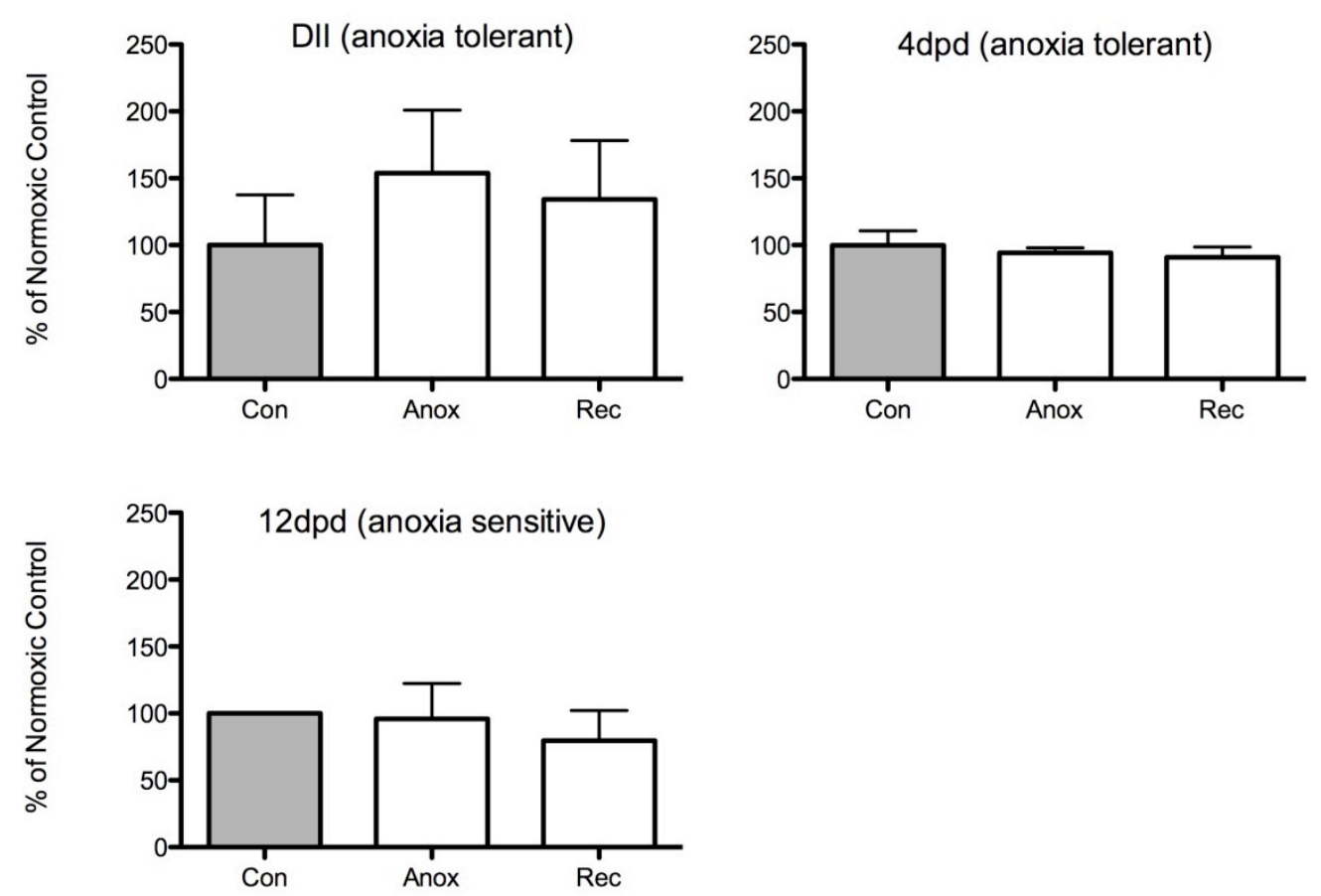

Figure 4.20. Immunoblot analysis of protein SUMO-2/3-ylation at 75kDa band for diapause II, $4 \mathrm{dpd}$ and $12 \mathrm{dpd}$ embryos; normoxic control (Con), harmful anoxia (Anox=21 days for DII, 32 days for $4 \mathrm{dpd}, 72 \mathrm{hr}$ for $12 \mathrm{dpd}$ ) and 24 hours of normoxic recovery (Rec). Bars represent means and error bars are S.E.M. $(n=3)$. One way ANOVA analysis revealed no significant changes from normoxic control values, $p>0.05$. Data were log transformed prior to statistical analysis in order to meet assumptions of normal distributions for one-way ANOVA. 


\section{Protein SUMO-2/3-ylation at 75kDa band}

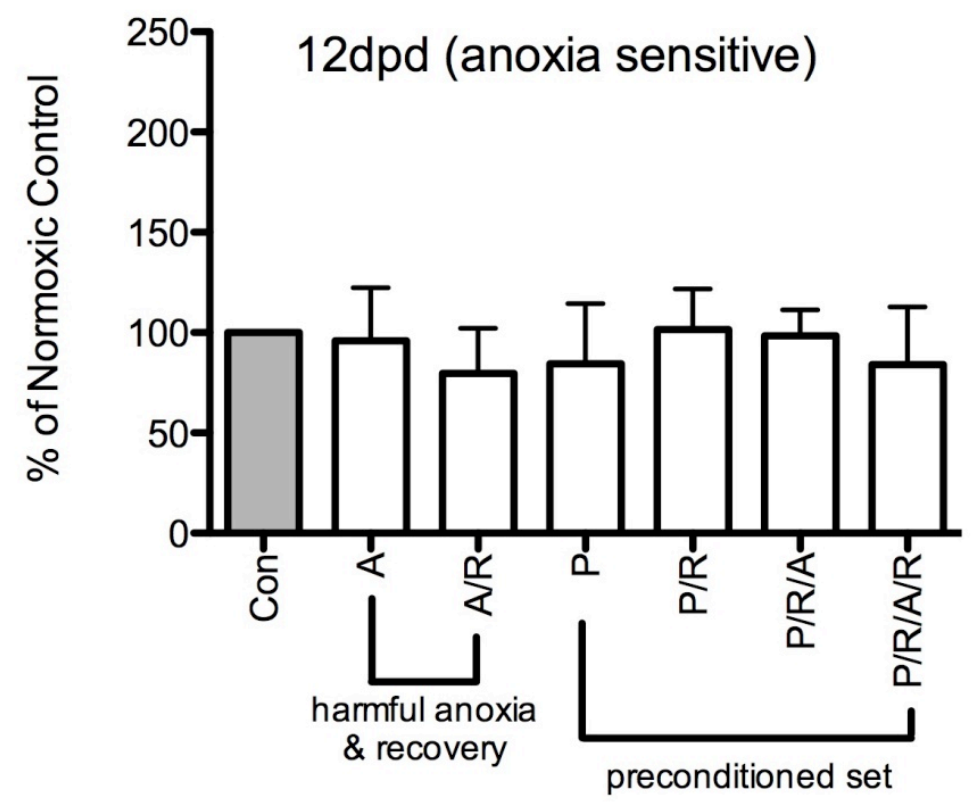

Figure 4.21. 12 dpd embryos were preconditioned with a non-harmful treatment of 48 hours of anoxia and then subsequently exposed to harmful anoxia (72 hrs). Con=normoxic control, $A=$ harmful anoxia ( $72 \mathrm{hrs}$ anoxia), $\mathrm{A} / \mathrm{R}=$ harmful anoxia $(72 \mathrm{hrs}$ ) followed by $24 \mathrm{hrs}$ recovery, $\mathrm{P}=$ anoxia preconditioning treatment (48hrs), $\mathrm{P} / \mathrm{R}=$ preconditioning (48hrs) followed by 24hrs recovery, $\mathrm{P} / \mathrm{R} / \mathrm{A}=$ preconditioning (48hrs) followed by $24 \mathrm{hrs}$ recovery followed by harmful anoxia (72hrs), P/R/A/R=preconditioning (48hrs) followed by $24 \mathrm{hrs}$ recovery followed by harmful anoxia (72hrs) followed by $24 \mathrm{hrs}$ recovery. Bars represent means and error bars are S.E.M. $(n=3)$. One way ANOVA analysis revealed no significant changes from normoxic control values, $p>0.05$. Data were log transformed prior to statistical analysis in order to meet assumptions of normal distributions for one-way ANOVA. 


\section{Discussion}

A number of studies have examined protein ubiquitination and SUMOylation in response to ischemic, anoxic conditions and following ischemic preconditioning. There is still a discrepancy as to the nature of ubiquitin and SUMO conjugation in response to these cellular stressors. It is unclear whether the observed changes confer a protective phenotype or whether they are simply responses or "markers" of harmful cellular stress. The embryos of Austrofundulus limnaeus, which possess a unique period of endogenous anoxia tolerance as well as periods of anoxia sensitivity provide an excellent model for gaining greater insight into this developing story.

The aim for this chapter was to determine whether there were changes in ubiquitin and/or SUMO conjugation of proteins following anoxia treatment in killifish embryos and whether or not anoxic preconditioning could change any observed effect in response to anoxia.

\section{Ubiquitination}

Changes in protein ubiquitination following anoxic treatment were clearly evident and were different in stages that exhibit long-term tolerance of anoxia as compared to those with relatively less anoxia tolerance. In the two anoxia tolerant stages, ubiquitin conjugation was significantly increased following anoxia treatment. In the earlier diapause II stage, this increase was 
observed immediately following exposure to harmful anoxia. In the $4 \mathrm{dpd}$ embryos a similar increase was observed, however, it occurred following 24 hours of aerobic recovery after the anoxic treatment. The opposite pattern of expression was observed in the anoxia sensitive, $12 \mathrm{dpd}$ embryos. There was a significant decrease in ubiquitin conjugation observed following anoxia treatment.

The individual band quantified at $23 \mathrm{kDa}$ also showed some interesting changes following anoxic treatment. The dormant, diapause II embryos exhibited non-detectable levels of this ubiquitin conjugate during normoxia. Following harmful anoxic treatment (21 days), however, a significant increase in this ubiquitin conjugate was observed. The two post diapause stages exhibited the opposite pattern of expression. This ubiquitin conjugate was constitutively expressed in both of these later embryonic stages and was reduced to non-detectable levels upon harmful anoxic treatment, suggesting that this ubiquitin conjugate is indeed responding to anoxic treatment in a developmentally specific manner that is related to the degree of endogenous anoxia tolerance exhibited by each stage. Identification of this target of ubiquitin conjugation will be an important follow-up study for further investigating this phenomenon.

Taken together, these data suggest that there is an anoxia related change in protein ubiquitination occurring in killifish embryos. During the periods of development when the embryos are at the peak of their 
endogenous anoxia tolerance, proteins are labeled in far greater numbers in response to anoxic conditions. When this endogenous tolerance diminishes/disappears, proteins are instead being de-ubiquitinated or degraded. This difference in ubiquitination may be explained in two ways. First, it is possible that in the embryos that exhibit long-term tolerance of anoxia, protein degradation is controlled at the level of the 26S proteasome, and thus ubiquitin conjugates accumulate during exposure to anoxia. In the much less tolerant 12 dpd embryos, ubiquitin conjugates may be degraded more quickly due to less stringent control over the $26 \mathrm{~S}$ proteasome under oxygen stress, or alternatively rates of ubiquitin conjugation may be reduced. We cannot discern between these two options without further experimentation and manipulation of the system.

The second reason for this difference in ubiquitination expression between the anoxia tolerant and anoxia sensitive stages may not have anything to do with a protective phenotype. The increase in ubiquitination of proteins in the diapause II and 4 dpd embryos exposed to anoxia may simply be due to a build up of proteins labeled for degradation that are accumulated during this energetically limited period. Degradation of proteins and recycling of the ubiquitin molecules requires additional energy, which may not be in sufficient supply during anoxic conditions. The $12 \mathrm{dpd}$ embryos that have resumed development and are metabolically active may have sufficient energy to degrade proteins via the proteasome system. An interesting follow-up study 
might include an investigation of proteasome inhibitors in each of these sample sets to see if these changes in ubiquitination are affected by blocking proteasomal degradation.

Preconditioning did not appear to have an effect on protein ubiquitination. There was no significant difference between the preconditioned and non-preconditioned embryos treated with harmful anoxia. These data taken together with those from the previous sample sets, indicate that changes in the overall levels of total ubiquitin conjugates are not related to a protective phenotype but rather are indications of cellular stress in this system.

\section{SUMOylation}

Previous studies have shown increases in SUMO conjugation following periods of ischemia or anoxia. In some cases the increases appear following natural states of anoxia tolerance such as in torpor during hibernation in arctic ground squirrels (Lee et al., 2007). In other cases the increase follows periods of harmful ischemia such as in modeled stroke (Cimarosti et al., 2008; Yang et al., 2008a, b). Therefore the aim was to observe any changes in SUMOylation following anoxia treatment in both anoxia tolerant and anoxia sensitive stages of $A$. limnaeus embryos and to determine if anoxic preconditioning had any affect on any observed changes.

This study did not indicate any significant changes in total levels of 
either SUMO-1 or SUMO-2/3 conjugates following anoxia treatment. This was true for both the anoxia tolerant as well as the anoxia sensitive embryos tested. Further, there were no significant differences in preconditioned embryos as compared to the non-preconditioned embryos in their response to harmful anoxia treatment. There were however, some changes in the individual band analyses for SUMO-1 but not for SUMO-2/3. Individual SUMO-1 conjugates at 30 and $75 \mathrm{kDa}$ showed some significant changes in response to harmful anoxic treatment. The $30 \mathrm{kDa}$ SUMO-1 conjugate was constitutively expressed in all three embryonic stages. Following anoxic treatment, however, it dropped to undetectable levels in the two anoxia tolerant stages, diapause II and $4 \mathrm{dpd}$. In the anoxia sensitive, $12 \mathrm{dpd}$ embryos the levels were unaffected by anoxic treatment. Similarly, the $75 \mathrm{kDa}$ SUMO-1 conjugate was constitutively expressed in all three embryonic stages. It also decreased following anoxic treatment but only in the diapause II embryos and the change was not statistically significant. Taken together these data suggest that while widespread total protein SUMOylation might not play a significant role in response to anoxia, there are perhaps a few specific targets of SUMOylation that may be involved in this phenomenon. Again, identification of these specific SUMO conjugates is an important follow-up study for further investigating this trend. 


\section{CHAPTER 5:}

\section{Summary and future directions}

The aim of this project was to observe and analyze molecular changes associated with anoxia both during quiescence and under conditions of induced tolerance in the embryos of Austrofundulus limnaeus. Embryos of this species exhibit both anoxia tolerant and anoxia sensitive stages of development, which make them an excellent model for characterizing and quantifying such changes. Understanding the molecular mechanisms promoting A. limnaeus anoxia tolerance is expected to aid in identifying novel therapeutic targets to reduce cell death following periods of anoxia or ischemia in heart, brain or other tissues.

Several different methods were utilized in this study to elucidate the mechanisms for anoxia tolerance in the embryos of $A$. limnaeus including a cell cycle analysis, immunoblot analyses of two cell cycle regulators, cell death analysis using TUNEL and caspase assays and finally an analysis of protein post-translational modification. 


\section{Major findings from Chapter 2: Cell cycle and cell cycle arrest}

\section{Flow cytometry analysis of cell cycle arrest}

Cell cycle arrest was investigated using flow cytometry. I hypothesized that the anoxia-tolerant stages of embryonic development would be composed of cells arresting mostly in $G_{1}$. This study showed that nearly all stages of embryonic development were composed almost exclusively of cells in $\mathrm{G}_{1}$ and that these cells arrested exactly where they were in the cell cycle when treated with anoxia. This strategy could be considered adaptive for several reasons. First, $\mathrm{G}_{1}$ cells have only one copy of their genome to maintain during this energy-limited state. Second, when recovering from anoxic conditions the amount of DNA damage that has accumulated during anoxia will be far less to repair in a single copy than in two copies.

These findings differ from those of zebrafish. Zebrafish embryos exposed to anoxia arrest mostly in $\mathrm{S}(77.7 \%)$ and $\mathrm{G}_{2} / \mathrm{M}(22.3 \%)$ (Padilla and Roth, 2001). Wild zebrafish embryos may not be routinely exposed to anoxic conditions and as such are not necessarily adapted for hypoxic or anoxic conditions. On the other hand, annual killifish are routinely exposed to such conditions. 


\section{Immunoblot analysis of Cyclin D1 levels}

As a second component of the cell cycle analysis in A. limnaeus embryos the roles of two known regulators of the cell cycle, Cyclin D1, a positive regulator, and $\mathrm{p} 53$, a transcription factor that can negatively regulate cell cycle progression were investigated. Western blot analysis was used to measure the levels of each of these proteins in A. limnaeus embryos from different developmental stages.

It was expected that cyclin D1, a positive regulator of cell cycle progression would decrease under anoxic conditions; however, no significant trends in response to anoxia treatment or with anoxic preconditioning were observed. It should be noted though that cyclin D1 is only one of several subunits that regulate the cyclin dependent kinases (CDK's) throughout cell cycle progression through $\mathrm{G}_{1}$. From this study it appears that a reduction in cyclin D1 is not a mechanism for regulating cell cycle arrest. There are of course numerous other components to the cell cycle machinery that could be screened as possible regulators of cell cycle arrest that play a major role during anoxic conditions in A. limnaeus cells.

\section{Immunoblot analysis of p53 levels}

The second cell cycle regulator investigated was $p 53$, which acts as a cellular stress sensor to halt cell cycle progression under conditions of cellular stress such as anoxia or when DNA damage is present. I hypothesized that 
p53 levels would increase following anoxic treatment, thereby negatively regulating cell cycle progression. This hypothesis held true for the diapause II samples in which p53 expression was nearly undetectable in normoxic embryos and increased significantly following harmful anoxic treatment (21 days). These data suggest that p53 is indeed acting to arrest cell cycle in response to harmful anoxia in this stage of embryo as hypothesized. Interestingly the above pattern was reversed in the $4 \mathrm{dpd}$ and $12 \mathrm{dpd}$ embryos counter to the hypothesis. p53 was constitutively expressed in the normoxic control for both of these sets of embryos, which have resumed development. Although the changes were not statistically significant, there was a noteworthy trend in both sets of embryos following harmful anoxic treatment. The high,p53 levels were reduced by $\sim 50 \%$ in both sets of embryos following harmful anoxic treatment and had returned to approximately the normoxic values following 24 hours of aerobic recovery. These data indicate that p53 is not acting as a negative regulator of cell cycle progression in response to harmful anoxia during the post-diapause II developmental stages.

Typically when cells are deprived of oxygen or exposed to other DNA damaging treatments such as ultraviolet light or gamma rays, they raise their levels of p53 by blocking its degradation (Alberts et al., 2008). During diapause II, this was the case. As embryos rapidly lose their endogenous anoxia tolerance following diapause, endogenous p53 levels may act as a 
protective mechanism that leaves cells essentially "primed" for anoxic stress through higher basal (normoxic) p53 expression. The elevated basal (normoxic control) levels of p53 observed in the two post diapause stage sample sets may, however, be attributed to p53's role in DNA repair (Sarasin and Dessen, 2010; Smith et al., 1995; Wang et al., 1995). This alternate function of p53 may be an important mechanism for repairing damage that accumulated during diapause II. The half-life of p53 is very short and as such, unstressed cells do not typically express constitutive levels of p53. However, one study has reported elevated levels of unique subspecies of human wildtype p53 in normal cells (Rivas et al., 1992). Depending on the degree of DNA damage accrued during the anoxic period, p53 may act to halt cell cycle progression, or if the damage is too great, induce apoptosis once normoxic conditions are established.

\section{Major findings from Chapter 3: Cell death analysis}

Embryos of A. limnaeus are able to withstand long periods of oxygen deprivation as well as many other forms of cellular stresses. It is unclear whether the cells of these organisms experience significant DNA damage in response to stressors but are able to repair the damage or whether they are able to prevent DNA damage from accruing in the first place. One of the aims of this study was to determine whether any such damage was occurring by 
measuring two known markers of DNA damage that typically lead to programmed cell death.

\section{TUNEL analysis}

The first marker for DNA damage that I used, Terminal deoxynucleotide transferase dUTP Nick End Labeling (TUNEL), is a well-known technique for detecting DNA breaks or damaged DNA in relation to total cellular DNA. TUNEL staining was measured in four different embryonic developmental stages representing both anoxia tolerant and anoxia sensitive embryos. Staining was quantified using fluorescent microscopy.

Although none of the changes observed in TUNEL staining were significant there were some interesting trends. It was clear that that the anoxia sensitive group of embryos tested (12 dpd) exhibited the greatest degree of TUNEL-positive cells in response to anoxia treatment. For the other three groups of embryos, $16 \mathrm{dpf}$, diapause II and $4 \mathrm{dpd}$, all associated with increasing or peak anoxia tolerance, there was a decrease in TUNEL positive cells in response to anoxia treatment, indicating that these embryos are perhaps able to prevent DNA damage during periods of anoxia.

Another notable finding was that the highest basal level of TUNEL positive cells (i.e. normoxic control samples) was observed in the diapause II samples. These embryos are in a state of suspended animation and are at the peak of their endogenous anoxia tolerance. They are also, however, 
severely energy-limited. This lack of energy may partly account for the accumulation of TUNEL positive cells observed in these samples. However, even in this energy-limited state, the proportion of TUNEL positive cells still decreased (as did the other two anoxia tolerant stages of embryos) albeit not to a significant degree.

These interesting trends warrant further investigation with larger sample sizes to improve statistical power.

\section{Caspase-3/7 analysis}

DNA fragmentation due to nuclease activity (i.e. TUNEL staining assays) cannot be used as an exclusive means to define apoptosis but it is often associated with apoptosis. For this reason, it is typically used in combination with other criteria as a marker of cell death. Another indicator of apoptosis used in this study was caspase-3/7 activity. There are two classes of caspases involved in apoptosis. Initiator caspases, or apical caspases, activate pro-forms of effector caspases by proteolysis. Effector caspases, or executioner caspases, cleave other protein substrates within the cell to begin the cascade of reactions that lead to programmed cell death. The effector caspases are specific players in the apoptotic pathway and can therefore be

used as markers of this process. Both caspase 3 and caspase 7 are members of the effector caspase family and were evaluated together for their role in caspase-dependent apoptosis in A. limnaeus embryos in response to anoxic 
treatment. Caspase-3/7 activity was measured in four different embryonic developmental stages representing both anoxia tolerant and anoxia sensitive embryos.

For the three stages of anoxia tolerant embryos (16 dpf, diapause II, and $4 \mathrm{dpd}$ ) the basal or normoxic control levels of caspase-3/7 were low, indicating very little caspase-dependent apoptosis. In response to anoxia, the diapause II embryos, which are in a state of suspended development and are at the peak of their endogenous anoxia tolerance, exhibited no significant change in their already low levels of caspase. In the other two anoxia tolerant stages of embryos, both the $16 \mathrm{dpf}$ (prior to entering diapause II) and the 4 dpd (just exiting diapause II), basal levels of caspase activity were also low but showed a significant increase with anoxic treatment. These increases occurred either immediately following anoxic treatment (4 dpd) or after 24 hours of subsequent aerobic recovery (16 dpf). Although both of these increases were statistically significant they were still much lower ( 5 fold lower) than the positive control (i.e. a sample treated with Staurosporine, a known apoptosis inducer). Taken together, these data suggest that the naturally anoxia tolerant stage embryos that are not in diapause II are possibly vulnerable to some caspase dependent apoptosis in response to anoxic conditions. However, given the magnitude of caspase activity in a sample treated with a known apoptotic-inducing agent (i.e. the Staurosporine treated 
positive control) it is unlikely that observed caspase activity leads to significant amounts of cell death in $A$. limneaus.

In the 12 dpd embryos, which were the most anoxia sensitive stage tested, basal caspase levels in the normoxic samples were higher, although they were still nearly 4-fold lower than the positive control. In response to anoxic treatment these levels initially decreased but rose again to the higher normoxic levels following 24 hours of subsequent aerobic recovery. Not surprisingly, these data indicate that these anoxia-sensitive embryos are indeed more vulnerable to caspase-dependent apoptosis during anoxic conditions than the other, earlier-stage and more anoxic tolerant embryos tested. Despite the slightly heightened vulnerability to anoxic treatment in these 12 dpd embryos, it should be noted that these embryos still retain a remarkable ability to withstand anoxia $\left(L T_{50}=7.4 \pm 0.7\right.$ days, Fig 2.2$)$, which is reflected by the overall low caspase activity relative to the positive control.

\section{Major findings from Chapter 4: Ubiquitination and SUMOylation analysis}

The function of proteins can be regulated by post-translational modifications. Changes in SUMO (small ubiquitin-like modifier) and ubiquitin modifications to proteins have been associated with ischemia and anoxia in several studies. It is still unclear whether these changes are protective or simply markers of cellular stress and damage. 
The final aim of this study was to observe post-translational protein modifications in A. limnaeus embryos in response to anoxic treatment. Immunoblot analysis was used to measure the levels of ubiquitin, SUMO-1 and SUMO-2/3 in three different embryonic developmental stages representing both anoxia tolerant and anoxia sensitive embryos.

\section{Immunoblot analysis of Ubiquitin}

Of the three post-translational modifiers tested, ubiquitin showed the greatest response to anoxic treatment. In the anoxia tolerant diapause II samples there was a significant increase in total ubiquitinated protein immediately following anoxic treatment. Additionally, there was a significant increase in a specific $23 \mathrm{kDa}$ ubiquitin conjugate in the diapause II embryos following harmful anoxia. In the 4 dpd embryos, which still retain their peak anoxia tolerance, there was also a significant increase in total protein ubiquitination following anoxic treatment, however, this increase was only evident following 24 hours of aerobic recovery. The anoxia sensitive $12 \mathrm{dpd}$ embryos exhibited the opposite pattern of expression with a significant decrease in total protein ubiquitination following anoxic treatment. The $23 \mathrm{kDa}$ ubiquitin conjugate also exhibited a significant decrease following harmful anoxia in both the 4 and $12 \mathrm{dpd}$ embryos. These results may indicate that embryos in diapause II allow damaged proteins to accumulate during diapause and process them upon exit from dormancy, while embryos at 4 and 
$12 \mathrm{dpd}$ block ubiquitination of proteins during exposure to anoxia in order to conserve cellular ATP stores for processes that immediately contribute to the survival of the cell.

Taken together these data suggest that posttranslational protein modification by ubiquitin is occurring in the anoxia tolerant embryos of $A$. limnaeus. Perhaps an adaptive strategy for surviving anoxic conditions is to label all non-critical cellular components for proteasomal degradation.

\section{Immunoblot analysis of SUMO-1 and SUMO-2/3}

Total protein conjugation by both SUMO-1 and SUMO-2/3 showed very little response to anoxic treatment in each of the three stages of embryos. There were a few individual SUMO-1 protein conjugates however, that did respond differentially to anoxic treatment. A 30kDa SUMO-1 conjugate decreased significantly following harmful anoxic treatment in the diapause II embryos. Another 75kDa SUMO-1 conjugate also demonstrated a decrease, albeit not significant, following harmful anoxic treatment in the diapause II embryos. These data indicate that while widespread SUMO-1-ylation is not responsive to harmful anoxia there may be some specific SUMO-1 targets involved in responding to anoxic stress in A. limnaeus embryos. The specific SUMO targets affected by the anoxic treatments in this study represent potentially interesting avenues to pursue in future studies and identifying them 
may help to better elucidate the role of SUMOylation in response to cellular stress.

\section{Final thoughts and future directions}

The overall findings from this study indicate that the embryos of $A$. limnaeus do indeed experience some degree of cellular stress (i.e. increase in ubiquitinated proteins, increase in p53 expression, evidence of DNA damage from TUNEL staining and increases in caspase activity) in response to anoxic treatment, even in their most protective state of diapause II. However, despite these observations, the whole organisms are still able to recover from anoxia and do not succumb to death. The overall low levels of TUNEL-positive cells and caspase activity relative to the positive controls indicates that the damage accrued in response to anoxic treatment is minimal. It appears that embryos are able to either "sacrifice" a certain portion of cells or they are able to repair the damage required for resumed development following anoxia.

One important follow up study would be to investigate the role of the proteasome in this system. For instance, are the increases in protein ubiquitination indeed targets for proteasomal degradation or do they play a different role? What are the specific target proteins of this observed increase? Are they mono- or poly-ubiquitinated?

Another interesting follow up study would be to repeat the TUNEL experiment. There were several interesting trends suggesting that the 
embryos are able to block DNA damage, however, none of these changes were significant. Further studies with larger samples or more repeats may shed light on these observed trends. Additionally, a morphological analysis for apoptotic cells following TUNEL staining in both dissociated cells and whole mount embryos would be an important study.

This study only touches the surface of the question as to how these amazing animals survive such extreme environmental conditions that would be lethal to most eukaryotes. There is of course a multitude of molecular machinery that may be involved and it is exciting to imagine the discoveries that are yet to be made using this remarkable model species. 


\section{CHAPTER 6:}

\section{Establishing an embryonic cell line from Austrofundulus limnaeus}

\section{Background/Introduction}

Embryonic stem cells are undifferentiated cells derived from early embryos that have the potential to develop into any adult cell phenotype. Embryonic stem cells (ESCs) have piqued intense scientific interest due to their enormous potential as both a research tool and as a mechanism for disease therapy. ESCs have been isolated from a number of vertebrates including mammals, birds and fish (Alvarez et al., 2007; Bejar et al., 2002; Chen et al., 2003a; Chen et al., 2003b; Chen et al., 2004; Evans and Kaufman, 1981; First et al., 1994; Hong and Schartl, 1996; lannaccone et al., 1994; Martin, 1981; Pain et al., 1996; Piedrahita et al., 1990; Sukoyan et al., 1993; Thomson et al., 1995; Wheeler, 1994). Specifically, fish ESCs offer several advantages to other vertebrate stem cell lines. Fish embryos are large and transparent, develop rapidly, can be produced in large quantities and are simple to harvest in contrast to mammalian and avian species. Fish models for vertebrate development and physiology such as the zebrafish (Danio rerio; (Fishman, 2001)) and medakafish (Oryzias latipes) (Wittbrodt et al., 2002)) are comparable to the widely used mouse models for gene function studies. Fish embryonic stem cell cultures have also been shown to be advantageous for their independence of differentiating inhibitors (Alvarez et al., 2007). 
Annual killifish species have many unique developmental qualities that would make them an ideal vertebrate model for the study of development and gene function. Their ability to enter diapause during embryonic development and sustain a variety of harsh environment conditions as well as their unique dispersion-reaggregation phase that is interposed between cleavage and embryogenesis, makes this species an excellent source for an in vitro comparative model. The aim of this project was to isolate and characterize an embryonic stem cell line from the Annual killifish species, Austrofundulus limnaeus and to determine the environmental parameters in which this cell line can survive.

\section{Austrofundulus limnaeus' unique development}

The annual killifish, Austrofundulus limnaeus is a cyprinodont fish endemic to ephemeral ponds in regions of northern South America where it is most commonly found in the Maracaibo basin of Venezuela (Lilyestrom and Taborn, 1982; Taborn and Thomerson, 1978) a region that has been described as having extreme fluctuations in temperature and drought (Podrabsky et al., 1998). The adult and juvenile forms die out on a seasonal basis when their ponds desiccate during dry seasons (Nico and Thomerson, 1989). This severe and unpredictable climate has given rise to several unique developmental adaptations, including the ability to enter a profound state of metabolic dormancy, which allows populations of $A$. limnaeus to persist under 
conditions that are lethal to almost all other species of fish (Myers, 1952;

Wourms, 1972a, b). During this period of developmental arrest, or diapause, the embryos are extremely resistant to a variety of harsh environmental conditions. Rainy periods cause the ponds to refill and the embryos resume development, hatch and continue the life cycle (Wourms, 1972a).

Embryonic diapause in annual killifish was discovered in the 1960's by Wourms (Wourms, 1963, 1964) and Peters (Peters, 1963, 1965) who described two unique characteristics of annual killifish development that differed substantially from that of all other vertebrates and more specifically from all other teleost fish. The first major difference is the ability of annual killifish embryos to undergo developmental arrest at specific and well-defined morphological stages (Wourms, 1972c). The second is a unique stage of early development that includes the complete dispersion and subsequent reaggregation of the cells that will generate the embryo (Wourms, 1972b).

Embryonic diapause is a state of profound developmental and metabolic arrest in annual killifish (Podrabsky and Hand, 1999). Diapause can be described loosely as obligate or facultative in annual killifish, although it appears that all stages of diapause are in some way responsive to environmental influences. In general, there are three distinct stages at which the embryo may enter diapause. The first, Diapause I, is a facultative arrest. It occurs during stage 20 of embryonic development when the deep blastomeres are in dispersed phase I and occurs only when environmental 
conditions are suboptimal (Wourms, 1972c). Diapause II has been described as an obligate developmental arrest period although some embryos may bypass this stage depending on the temperature (Podrabsky et al., 2010). It commences during stage 32 to 33 and at $25^{\circ} \mathrm{C}$ almost $70-90 \%$ of the embryos will arrest at this stage (Wourms, 1972c). The third period of developmental arrest, Diapause III, occurs during stage 43 , just prior to hatching and can also be initiated by sub-optimal environmental conditions, although it appears to be obligate in our laboratory stock of $A$. limnaeus (Wourms, 1972c).

Another unique developmental distinction of annual killifish is a stage of complete dispersion and subsequent reaggregation that occurs during epiboly and has been termed the dispersion-reaggregation process (Wourms, 1963, 1964, 1965, 1967, 1972a, b). Normal teleost development begins with a series of cleavages that produce two populations of blastomeres: peripheral blastomeres become multinucleate and flatten to form the enveloping cell layer (ECL) which is shed at hatching, and deep blastomeres which form an immediate aggregate and proceed through embryogenesis. The embryos of annual killifish differ significantly during development by means of a unique phase termed the dispersion-reaggregation phase that is interposed between cleavage and embryogenesis (Wourms, 1972a). During this period, the deep blastomeres disperse as amoeboid-like cells; there is no embryonic axis, embryo, or any distinct mass of tissue (Wourms, 1972a). 

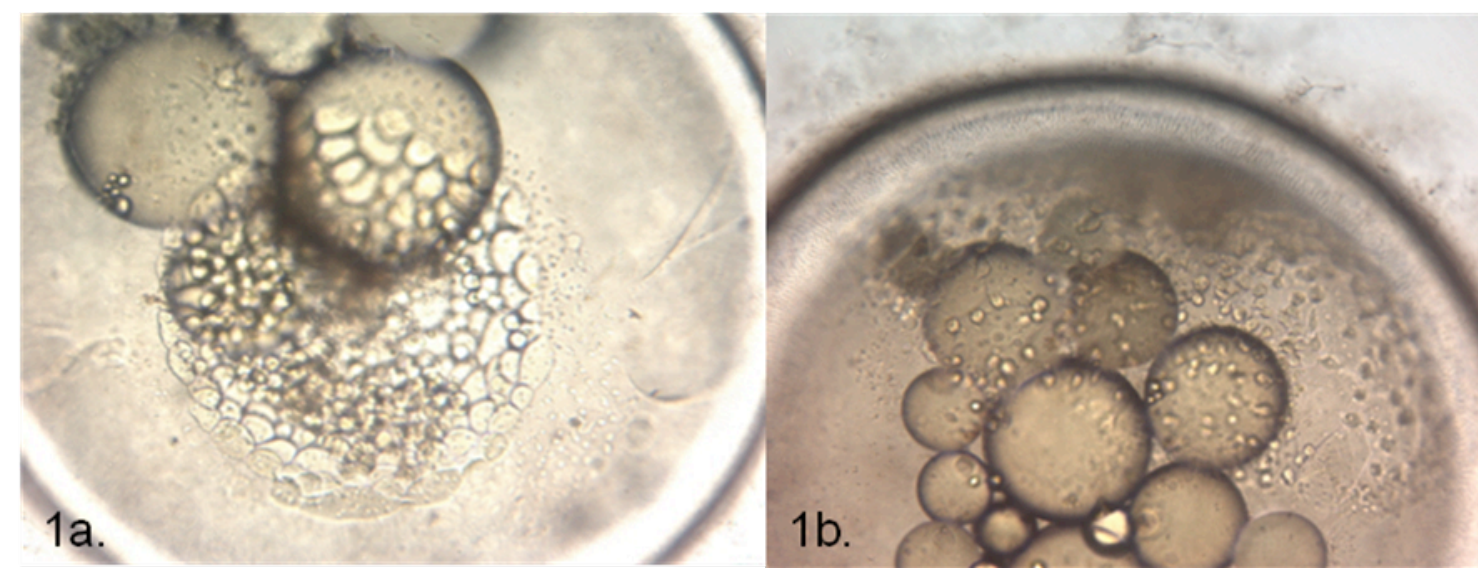

Figure 6.1a. Two populations of blastomeres evident; flat, multinucleate enveloping layer cells on surface and round, deep blastomeres beginning to disperse.

Figure 6.1b. Deep blastomeres further dispersed in an expanding hollow blastula stage embryo. 
The amoeboid-like, deep blastomeres are randomly distributed and increase in number, due almost entirely to mitotic divisions and rarely from recruitment of peripheral blastomeres (Wourms, 1972a). At the completion of epiboly, the deep blastomeres are randomly dispersed and remain so for approximately four days (Wourms, 1972a). At approximately four days post fertilization (stage 22) the blastomeres begin to aggregate, typically below the equator and form a mass that is shaped like a lenticular disc, wider in the center and as thin as a single cell layer on the periphery (Wourms, 1972a). This aggregate eventually forms the embryonic axis and at this stage annual killifish embryos follow normal teleost development (Wourms, 1972a).

It is unknown whether the deep blastomeres of annual killifish have undergone gastrulation and differentiated into the three primary germ layers. The deep blastomeres are randomly distributed during the dispersed phase and do not appear to be organized into any cell layers. There is no embryonic axis or any distinct cell aggregate at this stage. Wourms (Wourms, 1972a) hypothesized that this phenomenon arose as a developmental adaptation. With this adaptation, the embryo would be capable of sustaining a tremendous loss of progenitor cells during this period but would remain viable with only a single surviving totipotent stem cell. Although it has not been tested, it is the reigning hypothesis (Murphy and Collier, 1997; Wourms, 1972a)as well as our belief that these deep blastomeres remain either toti- or pluripotent stem cells 
until the reaggregation phase at stage 22 of development where they coalesce to form the embryonic axis.

\section{Embryonic stem cell research}

Tissue culture arose at the beginning of the $20^{\text {th }}$ century as a means of studying animal cells free from the variations that might arise during in vivo experimentation (Freshney, 2005). Early on, tissue explants dominated the field until the early 1950's when defined media and enzymatic techniques for passaging cells were developed, thereby facilitating the technique of dissociated cell culture (Freshney, 2005). Cell culture has become an invaluable tool for numerous fields of scientific research including pharmacology, immunology, genomics, developmental biology, cell physiology, tissue engineering, toxicology, cancer research, and a myriad of others. Culturing cells in vitro has several advantages such as a reduction in animal use, easy preservation, as well as providing a microenvironment for defined and controlled conditions (Freshney, 2005).

New cell lines are continually being developed and remain a vital part of scientific research today. Stem cells in particular, are advantageous for studying the biological function of genes (Cecconi and Meyer, 2000; Muller, 1999) and due to their enormous potential as a research tool a great deal of attention has been focused on the development of protocols for stem cell research. 
In addition to human ESCs, isolates have also been successfully cultured from a number of vertebrates including mammals, birds and fish. The establishment of embryonic stem cells from mice in the 1980's (Evans and Kaufman, 1981; Martin, 1981) paved the way for the development of several other vertebrate stem cell lines. Similar, ESC cultures have been successfully established from sheep (Piedrahita et al., 1990), mink (Sukoyan et al., 1993), rat (lannaccone et al., 1994), pig (Wheeler, 1994), cow (First et al., 1994), monkey (Thomson et al., 1995), and chicken (Pain et al., 1996).

Initially, embryonic stem cells from most species required growth on a feeder-layer of cells to avoid differentiation (Evans and Kaufman, 1981). The first attempts to culture fish ESCs centered on establishing growth conditions that avoided spontaneous differentiation (Alvarez et al., 2007). Culturing attempts in medaka and zebrafish showed the necessity of using rich media including fish embryo extract, and bovine fibroblast growth factor (bFGF) (Alvarez et al., 2007). ESCs from both model species were cultured successfully using the non-differentiating strategies used for murine cells such as feeder layers (Evans and Kaufman, 1981), conditioning media (Martin, 1981), and linfocine leukemia inhibitory factor (LIF). These cultures were successful on a short-term basis. However, the results were not satisfactory for long-term cultures (Alvarez et al., 2007; Hong et al., 2000).

More recently, human, mouse and some fish species have been cultured successfully without feeder layers. Hong and Schartl (Hong and 
Schartl, 1996) developed feeder-free culture conditions for medakafish, Oryzias latipes, that have been successfully applied to a handful of other fish species including gilthead seabream, Sparus aurata (Bejar et al., 2002), red seabream, Pagrosomus major (Chen et al., 2003a), sea perch, Lateolabrax japonicus (Chen et al., 2003b), flounder, Paralichthys olivaceus (Chen et al., 2004) and zebrafish, Danio rerio (as cited in (Alvarez et al., 2007).

Specifically, fish ESCs offer several advantages when compared to other vertebrate stem cell lines. In contrast to mammalian and avian species, it is relatively easy to harvest cells from fish embryos because fish embryos are large and transparent, develop rapidly, and can be produced in large quantities. Additionally, fish models for vertebrate development and physiology such as the zebrafish (Fishman, 2001) and medakafish (Wittbrodt et al., 2002) are comparable to the mouse for use in gene function studies (Alvarez et al., 2007). Additionally, fish ESCs offer an appreciable advantage over non-piscine species due to their independence from growth conditions requiring inhibitory differentiation factors or the need to be grown on feeder layers (Alvarez et al., 2007).

\section{Materials and Methods}

The successful model for establishing feeder-free primary cultures from medakafish embryos (Hong and Schartl, 1996) was employed in isolation, 
expansion and developmental progression of stem cells from A. limnaeus embryos. This protocol has been successfully applied to other diverse species of fish (Bejar et al., 2002; Chen et al., 2003a; Chen et al., 2003b; Chen et al., 2004; Hong and Schartl, 1996) thereby demonstrating the feasibility of these techniques. The protocol for isolating primary embryonic stem cells from $A$. limnaeus involves three major steps, 1) bleaching, 2) chorion removal and 3) plating of the cells.

The first step, bleaching of the embryos, was conducted in a clean room inside of a laminar flow hood. The concentration of sodium hypochlorite solution as well as the time in the solution were both optimized. The optimal concentration settled upon was $0.2 \%$ sodium hypochlorite solution in embryo medium for 2 minutes.

After the various bleaching conditions were tested, the final optimized protocol reads as follows: Using a transfer pipette, embryos were transferred to a sterile $24 \mathrm{~mm}, 500 \mu \mathrm{m}$-mesh basket (Netwell ${ }^{\mathrm{TM}}$, Corning Product \#3480) resting in a well of a six-well plate containing embryo medium with $10 \mathrm{mg} / \mathrm{l}$ gentamycin sulfate. The Netwell ${ }^{\mathrm{TM}}$ basket was transferred to the second well of the six-well plate containing a solution of $0.2 \%$ bleach (prepared fresh). A sterile transfer pipette was used to pipette the bleach solution over the entire basket and all the embryos inside for 2 minutes. This step ensured continuous movement of the embryos to all allow all surface areas of the embryos as well as the basket to be exposed to the bleach solution. After 2 minutes in the 
bleach solution, the Netwell ${ }^{\mathrm{TM}}$ basket was transferred to the third and fourth wells of the six-well plate successively, both containing sterile calcium-free Ringer solution. This step was used to remove a majority of the bleach solution. The Netwell ${ }^{\mathrm{TM}}$ basket containing the bleached embryos was then transferred to the fifth well of the six-well plate containing a sterile solution of $1 \%$ Sodium Thiosulfate in 1x Hank's Balanced Salt Solution to neutralize any remaining bleach. The Netwell ${ }^{\mathrm{TM}}$ basket containing embryos was finally placed in the sixth well of the plate, containing sterile cell culture medium. 


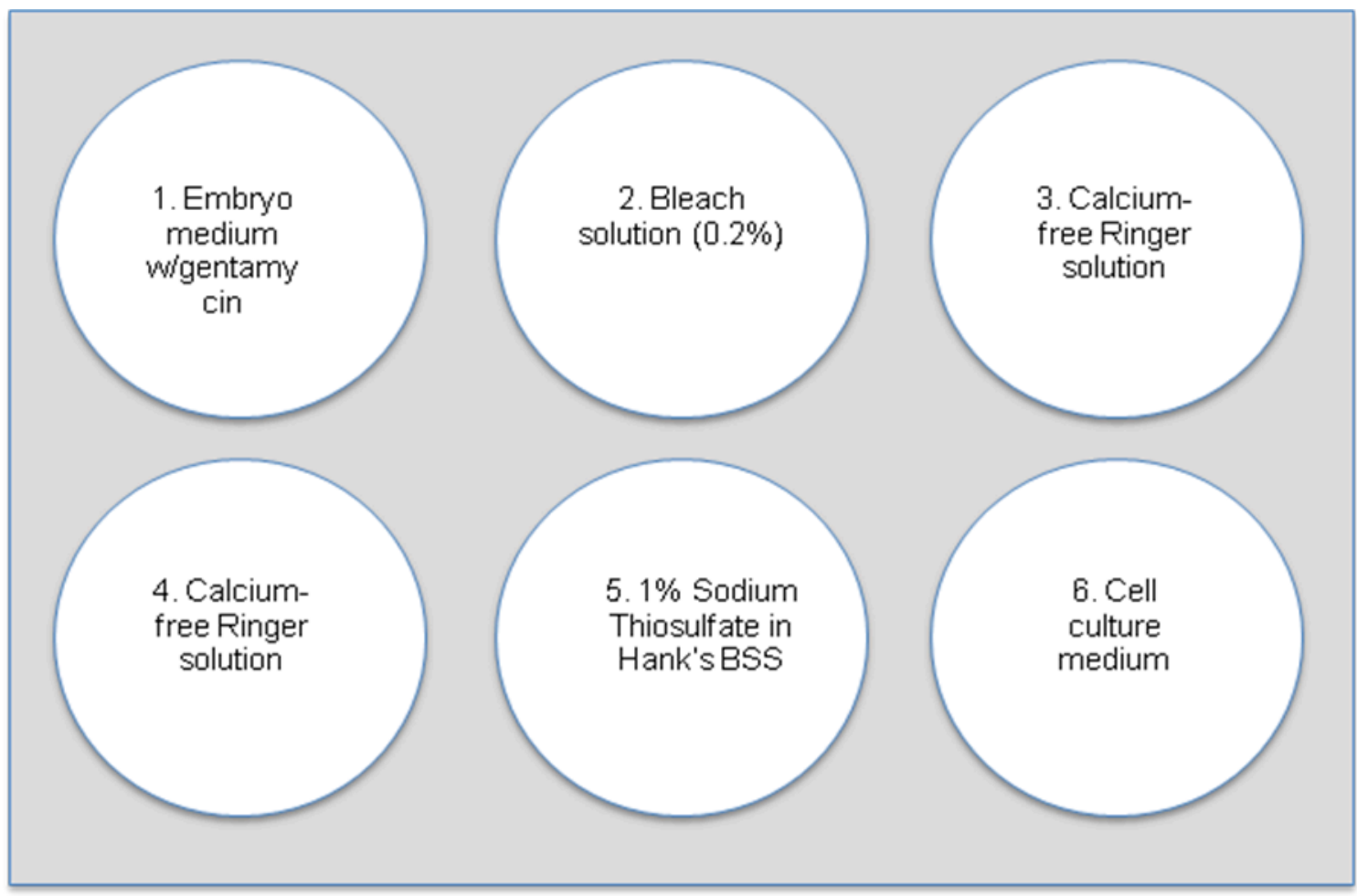

Figure 6.2. Series of solutions used in the embryo bleaching protocol carried out in a sterile six-well tissue culture plate. 
The second step, removing the chorion, was also conducted in a HEPA-filtered, tissue-culture room. Embryos were dechorinated mechanically with sterile fine-tipped forceps using a dissecting scope or they were ground with a glass pestle. The embryos ground with the glass pestle were either plated directly after rinsing or they were sieved through a mesh screen to remove any large pieces of chorion.

After the various conditions for chorion removal were tested, the final optimized protocol reads as follows: The Netwell ${ }^{\mathrm{TM}}$ basket resting in the sixth well of the culture plate containing cell culture medium was used to dissociate the cells. A sterile glass pestle was used to gently push the embryos through the mesh of the basket (embryos were popped but not ground with the pestle and the basket was rinsed in media to aid in rinsing out cells).

The suspension of cells was triturated through a sterile $200 \mu \mathrm{L}$ pipette tip several times to further dissociate cells. The cell suspension was transferred to a sterile microcentrifuge tube. Cells were rinsed 2 times in cell culture medium by centrifugation ( $300 \mathrm{xg}$ for 3 to 5 minutes) to remove excess yolk protein. After rinsing, the cell suspension was plated directly into tissue culture slides, Petri dishes or plates containing the appropriate amount of cell culture medium.

The third step, plating the cells, was also conducted in a HEPA-filtered, tissue-culture room inside a laminar flow hood. Several different plating 
methods and techniques were employed and are presented in Figure 6.3

below.

Figure 6.3. List of the plating techniques tested for optimization of cell culture with embryonic cells isolated from A. limnaeus.

Regular, untreated tissue culture plastic

Regular tissue culture plastic treated with $0.1 \%$ gelatin

Lab-Tek $®$ II CC2 - treated chamber slide

Permanox® Plastic Lab-Tek $\circledast$ Chamber slide

Permanox® Plastic Lab-Tek $\circledast$ Chamber slide treated with $0.1 \%$ gelatin

Permanox $\circledast$ Plastic Lab-Tek $\circledast$ Chamber slide with $5 \mu \mathrm{g} / \mathrm{mL}$ Laminin added to the cell culture medium 
Figure 6.4. A. limnaeus deep blastomeres isolated from embryos 4 days post fertilization and grown in an in vitro culture.

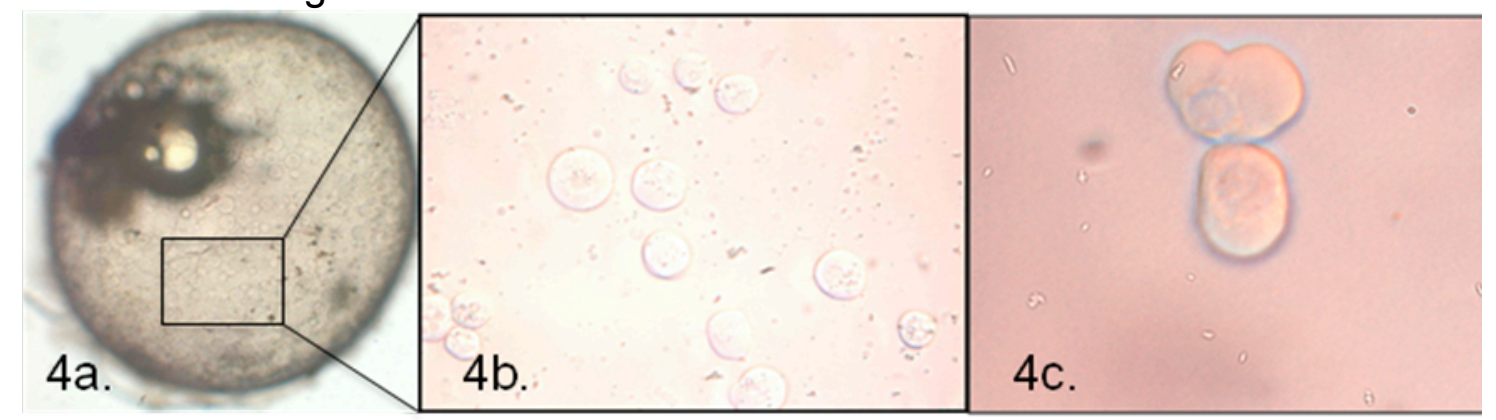

Figure 6.4a. Intact embryo

Figure 6.4b. Dissociated cells

Figure 6.4c. Amoeboid cells 
Figure 6.5. Embyronic cells isolated from A. limnaeus embryos in diapause II at 29 days post-fertilization.

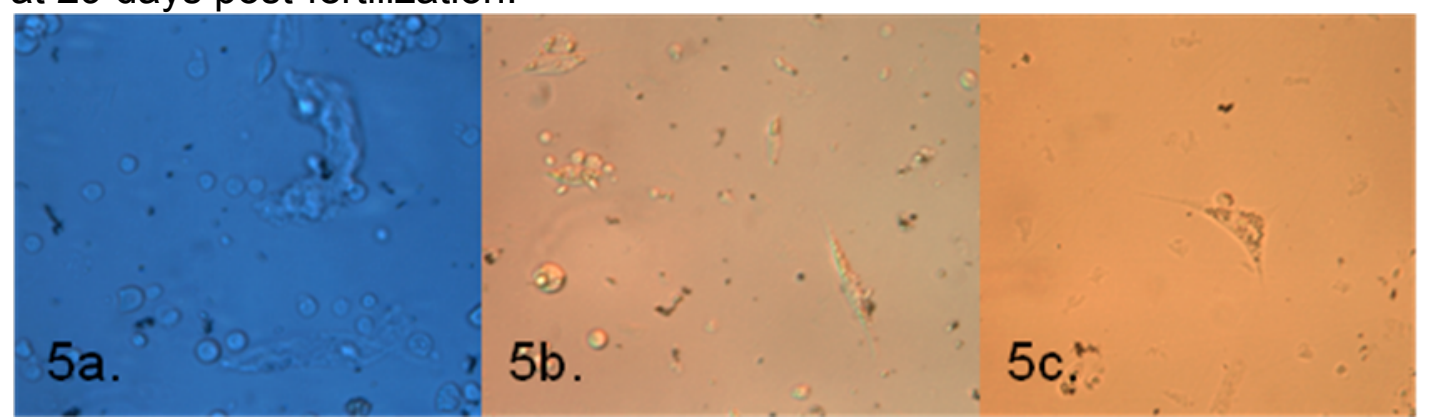

Figure 6.5a. Day 0 in culture Figure 6.5b. Day 2 in culture

Figure 6.5c. Day 3 in culture 


\section{Optimization of culture conditions}

Primary cultures were established on numerous occasions. Optimal growth conditions were never achieved due to time constraints as well as facility unavailability. Primary cell cultures were maintained for up to a month and a half, however, they did not divide adequately for passage. Ideally, each component of the in vitro system would be titrated for optimum viability including media composition, incubation temperature, humidity, gas composition, and cell monolayer density. Growth medium has been provisionally formulated but not optimized. Formulations were based on the media compositions developed for zebrafish (Westerfield, 1995) and medakafish (Hong and Schartl, 1996) embryonic stem cell cultures. (See Figure 6.6 for the current formulation of growth medium.) 


\begin{tabular}{|l|}
\hline $\begin{array}{l}\text { Figure 6.6. Complete growth medium for } A \text {. limnaeus cell culture } \\
\text { (in } 500 \mathrm{~mL} \mathrm{~L}-15)\end{array}$ \\
\hline glucose $(4.5 \mathrm{~g} / \mathrm{L})$ \\
\hline HEPES $(20 \mathrm{mM})$ \\
\hline 2-mercaptoethanol $(100 \mu \mathrm{M})$ \\
\hline fetal Bovine Serum $(15 \%)$ \\
\hline fish Serum $(1 \%)$ \\
\hline L-glutamine $(2 \mathrm{mM})$ \\
\hline nonessential amino acids $(1 \mathrm{mM})$ \\
\hline sodium pyruvate $(1 \mathrm{mM})$ \\
\hline sodium selenite $(1 \mathrm{mM})$ \\
\hline bFGF $(2 \mathrm{ng} / \mathrm{mL})$ \\
\hline$A$. limnaeus Embryo Extract $(0.5$ embyros $/ \mathrm{mL})$ \\
\hline penicillin $(50 \mathrm{U} / \mathrm{mL})$ \\
\hline streptomycin $(50 \mu \mathrm{gg} / \mathrm{mL})$ \\
\hline gentamycin $(50 \mu \mathrm{g} / \mathrm{mL})$ \\
\hline fungizone $(1 \mathrm{~mL} / 100 \mathrm{~mL})$ \\
\hline pH adjusted to 7.4 \\
\hline osmolality adjusted to $296 \mathrm{mOs} / \mathrm{kg}$ \\
\hline Sterile-filtered through a $0.22 \mu \mathrm{m}$ vacuum filter \\
\hline
\end{tabular}


Figure 6.7. Examples of $A$. limnaeus cells maintained in culture. Cells were isolated from $12 \mathrm{dpd}$ embryos and maintained in culture for 25 days at $25^{\circ} \mathrm{C}$.

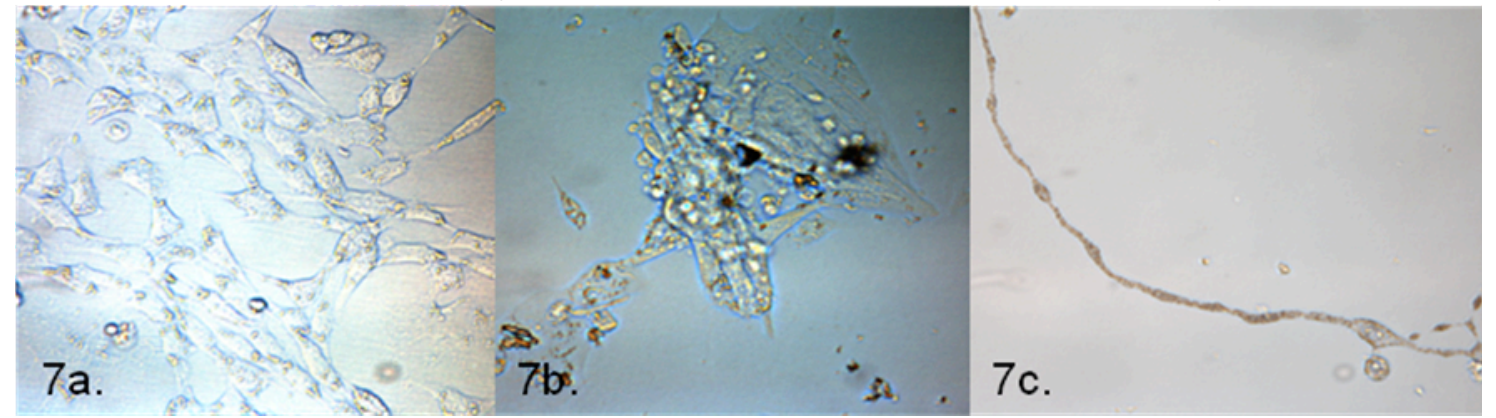

Figure 6.7a. Fibroblast-like cells

Figure 6.7b. Contractile cardiac tissue which actively contracted for 19 days in culture.

Figure 6.7c. Example of a neuronal cell in culture. 
Figure 6.8. Examples of embryoid bodies formed in culture from embryonic $A$. limnaeus cells.

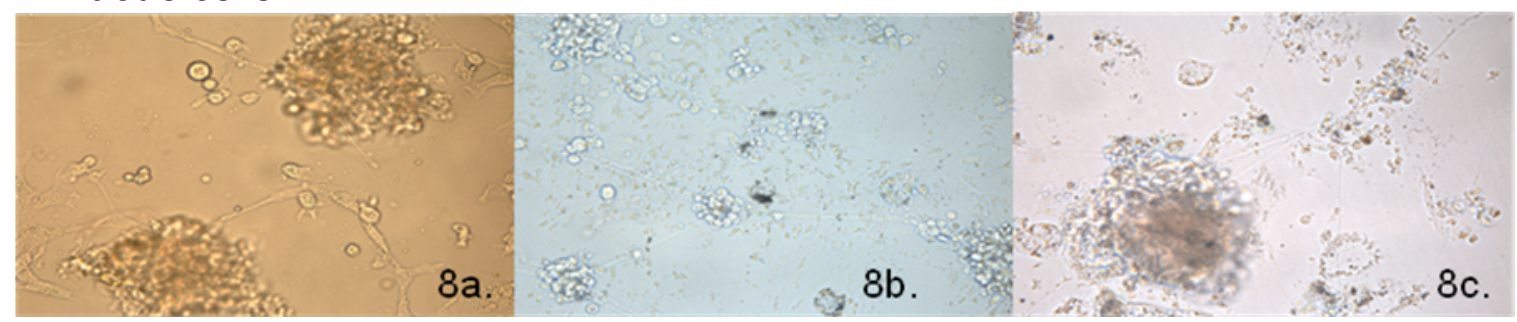

Figure 6.8a. Embryoid bodies formed from cells isolated from $4 \mathrm{dpf}$ embryos.

Figure 6.8b. Embryoid bodies formed from cells isolated from $36 \mathrm{dpf}$ embryos.

Figure 6.8c. A close-up view of embryoid bodies formed from $36 \mathrm{dpf}$ embryonic cells. 
Figure 6.9. Examples of $A$. limnaeus cells maintained in culture.

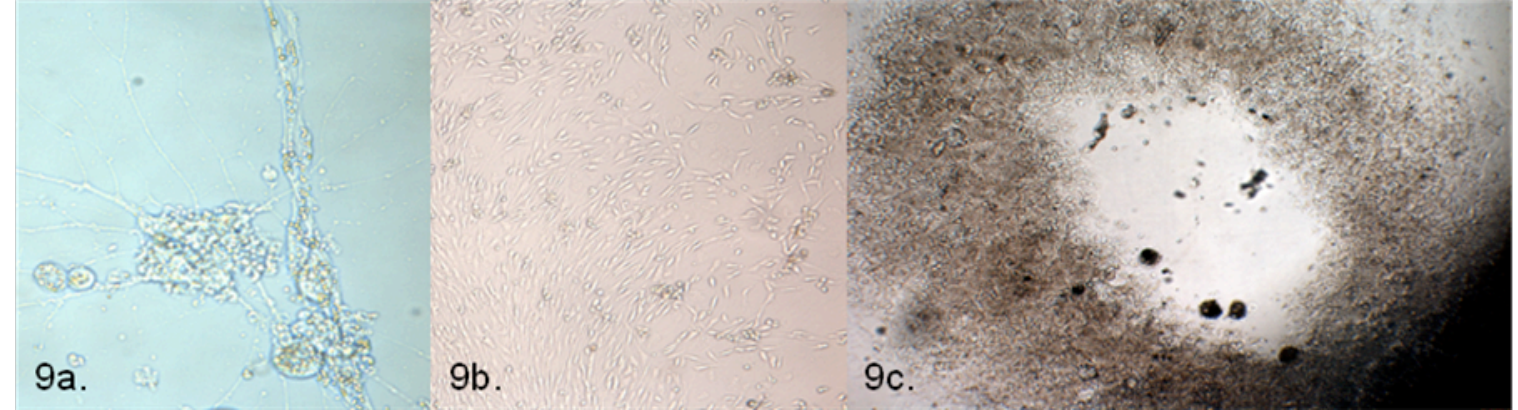

Figure 6.9a. Neuronal-like cells after 25 days in culture that were initially isolated from embryos at $36 \mathrm{dpf}$.

Figure 6.9 b. Fibroblast-like cells after 25 days in culture that were initially isolated from $36 \mathrm{dpf}$ embryos.

Figure 6.9c. Growth ring formed after 31 days in culture. Cells were initially isolated from embryos at $5 \mathrm{dpf}$. 


\section{Assessment ESC's for toti- or pluripotency}

Undifferentiated stem cells express specific lineage markers, which allow for their identification. Additionally, the role of specific transcription factors in regulating early gene expression can be measured and correlated to developmental stage. In order to maintain that a cell line that is indeed an embryonic stem cell line, the cells must be characterized. Initially it was our aim to use three universally accepted markers of pluripotency expressed in undifferentiated cells to determine the nature of the embryonic cells in culture: 1) Alkaline phosphatase activity, 2) OCT-4 expression and 3) SSEA expression. Once it was determined that the establishing the embryonic cell line would be temporarily placed on hold, these experiments also were temporarily suspended. Below are some preliminary data that were collected on Alkaline phosphatase expression in A. limnaeus embryos.

\section{Alkaline Phosphatase Activity}

Alkaline phosphatase is highly expressed in undifferentiated cells and is often used as a stem cell marker (Familari and Selwood, 2006). The in vitro alkaline phosphatase assay was performed using a commercial kit designed to measure alkaline phosphatase activity in embryonic stem cells (Chemicon International, Catalog No. SCR004). The in vivo portion of this work has been completed and clearly denotes the presence of undifferentiated cells in the embryo at various stages. At five days post fertilization the deep blastomeres 
are in the dispersed phase. Many of these cells appear blue indicating they are indeed expressing alkaline phosphatase (Figure 6.10a). At twelve days post fertilization, the deep blastomeres have started to reaggregate, while some remain dispersed. Many of these cells also appear blue indicating that they are still expressing alkaline phosphatase activity (Figure 6.10b). 
Figure 6.10. Alkaline phosphatase staining in whole A. limnaeus embryos

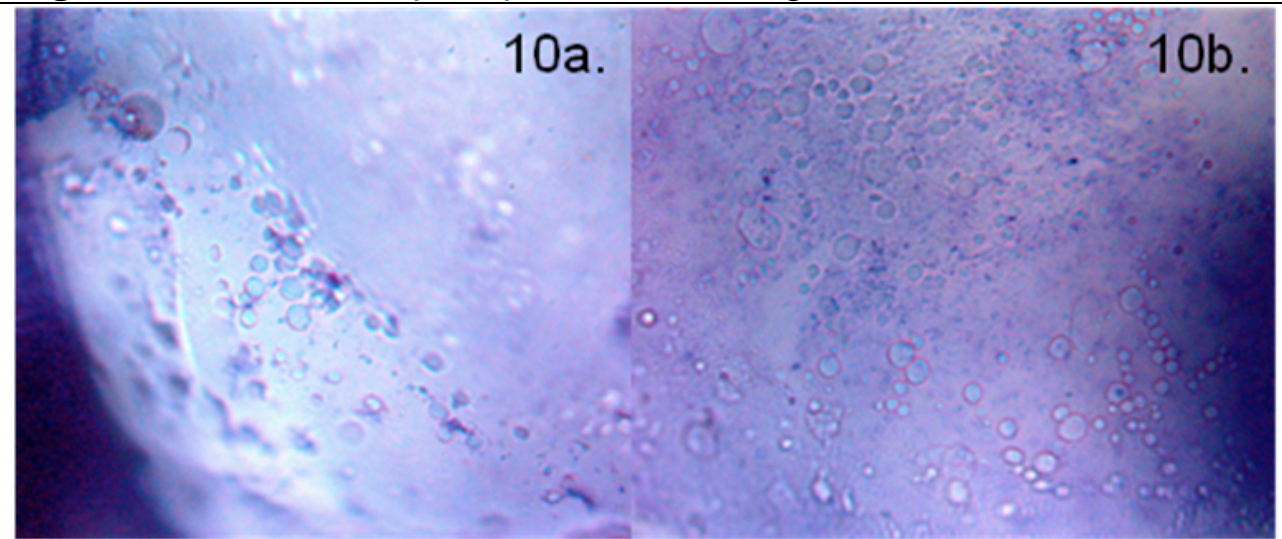

Figure 6.10a. Deep blastomeres in a $5 \mathrm{dpf}$ embryo (dispersed phase).

Figure 6.10b. Aggregation of deep blastomeres in a 12 dpf embryo.

Somites in medakafish are also known to stain positively for alkaline phosphatase activity (The Medaka Book 4.5.1. Alkaline phosphatase staining, http://www.shigen.nig.ac.jp/medaka/medakabook/). A. limnaeus embryos at 19 days post fertilization were stained for alkaline phosphatase activity as a positive control and appear deep purple in color (Figure 6.11). The color is clearly a different hue from the earlier embryonic cells but could possibly be attributed to high concentrations alkaline phosphatase activity. 
Figure 6.11. Alkaline phosphatase staining of somites in whole $A$. limnaeus embryos.

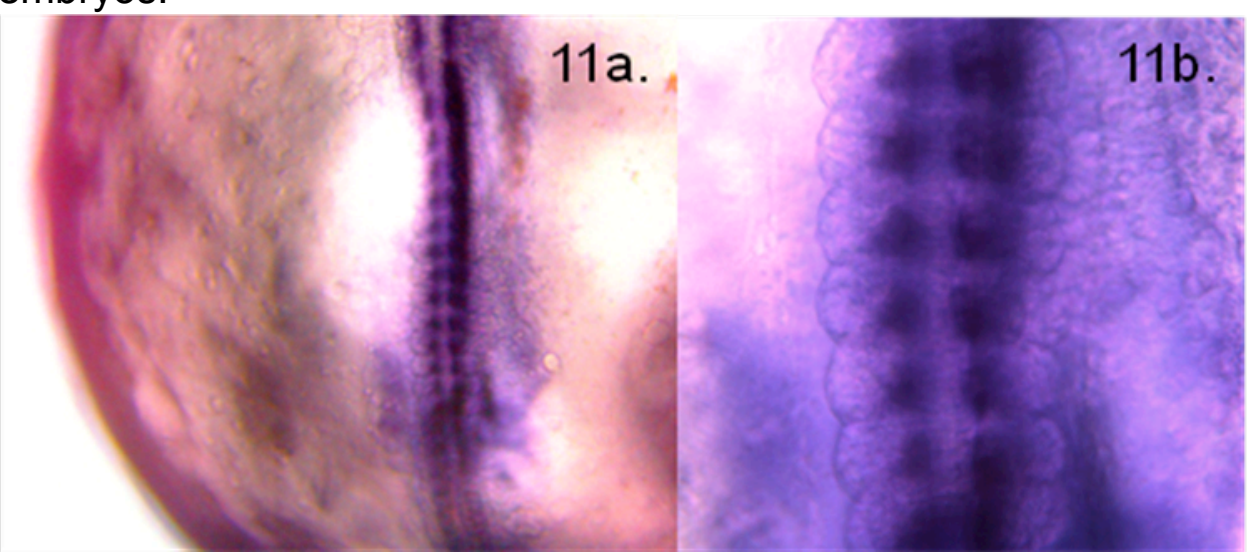

Figure 6.11a. Somites stained in a $19 \mathrm{dpf}$ embryo.

Figure 6.11b. Close-up of somite staining in a $19 \mathrm{dpf}$ embryo. 


\section{Significance of this study}

Work on human embryonic stem cell lines has been hindered by their notorious fragility. Maintaining these cells in culture is both tedious and laborintensive (Institute, 2010). Although recent studies have identified two novel compounds (Thiazovivin and Pyrintegrin) that acted to significantly increase cell survival by more than 30 fold, many obstacles still remain for using human stem cells in scientific research (Xu et al., 2010).

With the current moratorium on federal funding of embryonic stem cell research in humans, additional cell sources such as fish models for embryonic stem cells may offer alternative avenues for the scientific study of these types of cells and may lead to the development of new protocols for their use. The technical advantages to using fish ESCs in addition to the distinct and very unique characteristics of annual killifish development make Austrofundulus limnaeus an excellent model for vertebrate development. The distinctive dispersion-reaggregation phase and their ability to enter diapause during embryonic development and subsequently survive a range of harsh environmental conditions make this species a unique candidate for a comparative in vitro system.

Another advantage to establishing an embryonic stem cell line from a fish species is that fish are one of the most distantly related groups of vertebrates to the more widely used mammalian lines and therefore provide an excellent reference to vertebrate studies. Finally, annual killifish embryos are 
able to sustain a range of extreme environmental conditions such as anoxia/hypoxia and severe temperature fluctuations. If pluri- or totipotent stem cells from Austrofundulus limnaeus retain the ability to survive such conditions this cell line has the potential to be a very powerful model for vertebrate research as well as for the delivery of stem cell therapy.

Finally, the convenience of cell culture allows for controlled in vitro studies that can be compared to the in vivo models. Cell culture also reduces the number of animals needed for each study and eliminates ethical concerns when experimental conditions are considered damaging. 


\section{References}

Alberts, B., Johnson, A., Lewis, J., Raff, M., Roberts, K., and Walter, P., eds. (2008). Molecular Biology of the Cell, 5 edn (New York, Garland Science, Taylor and Francis Group, LLC).

Alvarez, M.C., Bejar, J., Chen, S., and Hong, Y. (2007). Fish ES cells and applications to biotechnology. Mar Biotechnol (NY) 9, 117-127.

Amarante-Mendes, G.P., Finucane, D.M., Martin, S.J., Cotter, T.G., Salvesen, G.S., and Green, D.R. (1998). Anti-apoptotic oncogenes prevent caspasedependent and independent commitment for cell death. Cell Death Differ 5 , 298-306.

Bejar, J., Hong, Y., and Alvarez, M.C. (2002). An ES-like cell line from the marine fish Sparus aurata: characterization and chimaera production. Transgenic Res 11, 279-289.

Blazka (1958). The Anaerobic Metabolism of Fish. Physoiological Zoology, 117-128.

Bohren, K.M., Nadkarni, V., Song, J.H., Gabbay, K.H., and Owerbach, D. (2004). A M55V polymorphism in a novel SUMO gene (SUMO-4) differentially activates heat shock transcription factors and is associated with susceptibility to type I diabetes mellitus. J Biol Chem 279, 27233-27238.

Brunet, C.L., Gunby, R.H., Benson, R.S., Hickman, J.A., Watson, A.J., and Brady, G. (1998). Commitment to cell death measured by loss of clonogenicity is separable from the appearance of apoptotic markers. Cell Death Differ 5, 107-115.

Cande, C., Cohen, I., Daugas, E., Ravagnan, L., Larochette, N., Zamzami, N., and Kroemer, G. (2002). Apoptosis-inducing factor (AIF): a novel caspaseindependent death effector released from mitochondria. Biochimie 84, 215222. 
Candi, E., Schmidt, R., and Melino, G. (2005). The cornified envelope: a model of cell death in the skin. Nat Rev Mol Cell Biol 6, 328-340.

Carey, H.V., Andrews, M.T., and Martin, S.L. (2003). Mammalian hibernation: cellular and molecular responses to depressed metabolism and low temperature. Physiol Rev 83, 1153-1181.

Cecconi, F., and Meyer, B.I. (2000). Gene trap: a way to identify novel genes and unravel their biological function. FEBS Lett 480, 63-71.

Chen, S., Sha, Z., and Ye, H. (2003a). Establishment of a pluripotent embryonic cell line from sea perch (Lateoabrax japonicus) embryos. Aquaculture, 141-151.

Chen, S., Ye, H., Sha, Q., and Xhi, C. (2003b). Derivation of a pluripotent embryonic cell line from red seabream blastulas. Journal of Fish Biology, 795805.

Chen, S.L., Ren, G.C., Sha, Z.X., and Shi, C.Y. (2004). Establishment of a continuous embryonic cell line from Japanese flounder Paralichthys olivaceus for virus isolation. Dis Aquat Organ 60, 241-246.

Ciechanover, A., Finley, D., and Varshavsky, A. (1984). Ubiquitin dependence of selective protein degradation demonstrated in the mammalian cell cycle mutant ts85. Cell 37, 57-66.

Cimarosti, H., Lindberg, C., Bomholt, S.F., Ronn, L.C., and Henley, J.M. (2008). Increased protein SUMOylation following focal cerebral ischemia. Neuropharmacology 54, 280-289.

Clegg, J. (1997). Embryos of Artemia franciscana survive four years of continuous anoxia: the case for complete metabolic rate depression. $J$ Exp Biol 200, 467-475.

Cohen, G.M. (1997). Caspases: the executioners of apoptosis. Biochem J 326 (Pt 1), 1-16.

Counis, M.F., Chaudun, E., Arruti, C., Oliver, L., Sanwal, M., Courtois, Y., and Torriglia, A. (1998). Analysis of nuclear degradation during lens cell differentiation. Cell Death Differ 5, 251-261. 
de Graaf, A.O., van den Heuvel, L.P., Dijkman, H.B., de Abreu, R.A., Birkenkamp, K.U., de Witte, T., van der Reijden, B.A., Smeitink, J.A., and Jansen, J.H. (2004). Bcl-2 prevents loss of mitochondria in CCCP-induced apoptosis. Exp Cell Res 299, 533-540.

De Maria, R., Lenti, L., Malisan, F., d'Agostino, F., Tomassini, B., Zeuner, A., Rippo, M.R., and Testi, R. (1997). Requirement for GD3 ganglioside in CD95and ceramide-induced apoptosis. Science 277, 1652-1655.

dos Santos, N.M., do Vale, A., Reis, M.I., and Silva, M.T. (2008). Fish and apoptosis: molecules and pathways. Curr Pharm Des 14, 148-169.

Ellerby, H.M., Martin, S.J., Ellerby, L.M., Naiem, S.S., Rabizadeh, S., Salvesen, G.S., Casiano, C.A., Cashman, N.R., Green, D.R., and Bredesen, D.E. (1997). Establishment of a cell-free system of neuronal apoptosis: comparison of premitochondrial, mitochondrial, and postmitochondrial phases. J Neurosci 17, 6165-6178.

Evans, M.J., and Kaufman, M.H. (1981). Establishment in culture of pluripotential cells from mouse embryos. Nature 292, 154-156.

Fadok, V.A., Voelker, D.R., Campbell, P.A., Cohen, J.J., Bratton, D.L., and Henson, P.M. (1992). Exposure of phosphatidylserine on the surface of apoptotic lymphocytes triggers specific recognition and removal by macrophages. J Immunol 148, 2207-2216.

Familari, M., and Selwood, L. (2006). The potential for derivation of embryonic stem cells in vertebrates. Mol Reprod Dev 73, 123-131.

Fergusson-Kolmes, L., and Podrabsky, J.E. (2007). Differential effects of anoxia on heart rate in developmental stages of the annual killifish Austrofundulus limnaeus that differ in their tolerance of anoxia. J Exp Zool A Ecol Genet Physiol 307, 419-423.

Ferri, K.F., and Kroemer, G. (2001). Organelle-specific initiation of cell death pathways. Nat Cell Biol 3, E255-263.

Festjens, N., Vanden Berghe, T., and Vandenabeele, P. (2006). Necrosis, a well-orchestrated form of cell demise: signalling cascades, important mediators and concomitant immune response. Biochim Biophys Acta 1757, 1371-1387. 
First, N.L., Sims, M.M., Park, S.P., and Kent-First, M.J. (1994). Systems for production of calves from cultured bovine embryonic cells. Reprod Fertil Dev $6,553-562$.

Fishman, M.C. (2001). Genomics. Zebrafish--the canonical vertebrate. Science 294, 1290-1291.

Fleck, C.C., and Carey, H.V. (2005). Modulation of apoptotic pathways in intestinal mucosa during hibernation. Am J Physiol Regul Integr Comp Physiol 289, R586-R595.

Freshney, R. (2005). Culture of Animal Cells (Hoboken, NJ, John Wiley \& Sons, Inc.).

Galluzzi, L., Joza, N., Tasdemir, E., Maiuri, M.C., Hengartner, M., Abrams, J.M., Tavernarakis, N., Penninger, J., Madeo, F., and Kroemer, G. (2008). No death without life: vital functions of apoptotic effectors. Cell Death Differ 15, 1113-1123.

Garrido, C., and Kroemer, G. (2004). Life's smile, death's grin: vital functions of apoptosis-executing proteins. Curr Opin Cell Biol 16, 639-646.

Girdwood, D.W., Tatham, M.H., and Hay, R.T. (2004). SUMO and transcriptional regulation. Semin Cell Dev Biol 15, 201-210.

Golstein, P., and Kroemer, G. (2007). Cell death by necrosis: towards a molecular definition. Trends Biochem Sci 32, 37-43.

Graeber, T.G., Osmanian, C., Jacks, T., Housman, D.E., Koch, C.J., Lowe, S.W., and Giaccia, A.J. (1996). Hypoxia-mediated selection of cells with diminished apoptotic potential in solid tumours. Nature 379, 88-91.

Green, D., and Kroemer, G. (1998). The central executioners of apoptosis: caspases or mitochondria? Trends Cell Biol 8, 267-271.

Green, D.R., and Kroemer, G. (2004). The pathophysiology of mitochondrial cell death. Science 305, 626-629.

Hand, S.C., and Menze, M.A. (2008). Mitochondria in energy-limited states: mechanisms that blunt the signaling of cell death. J Exp Biol 211, 1829-1840. 
Hay, R.T. (2005). SUMO: a history of modification. Mol Cell 18, 1-12.

Hershko, A. (1983). Ubiquitin: roles in protein modification and breakdown. Cell 34, 11-12.

Hicke, L. (2001). Protein regulation by monoubiquitin. Nat Rev Mol Cell Biol 2, 195-201.

Hirsch, T., Marchetti, P., Susin, S.A., Dallaporta, B., Zamzami, N., Marzo, I., Geuskens, M., and Kroemer, G. (1997). The apoptosis-necrosis paradox. Apoptogenic proteases activated after mitochondrial permeability transition determine the mode of cell death. Oncogene 15, 1573-1581.

Holler, N., Zaru, R., Micheau, O., Thome, M., Attinger, A., Valitutti, S., Bodmer, J.L., Schneider, P., Seed, B., and Tschopp, J. (2000). Fas triggers an alternative, caspase-8-independent cell death pathway using the kinase RIP as effector molecule. Nat Immunol 1, 489-495.

Holopainen, I.J., and Hyvarinen, H. (1985). Ecology and physiology of crucian carp (Carassius carassius L.) in small Finnish ponds with anoxic conditions in winter. Verh Int Ver Limnol, 2566-2570.

Hong, Y., Chen, S., and Schartl, M. (2000). Embryonic stem cells in fish: current status and perspectives. Fish Physiol Biochem, 165-170.

Hong, Y., and Schartl, M. (1996). Establishment and growth responses of early medakafish (Oryzias latipes) embryonic cells in feeder layer-free cultures. Molecular Marine Biology and Biotechnology, 93-104.

Hunter, T. (2007). The age of crosstalk: phosphorylation, ubiquitination, and beyond. Mol Cell 28, 730-738.

lannaccone, P.M., Taborn, G.U., Garton, R.L., Caplice, M.D., and Brenin, D.R. (1994). Pluripotent embryonic stem cells from the rat are capable of producing chimeras. Dev Biol 163, 288-292.

Ikeda, F., and Dikic, I. (2008). Atypical ubiquitin chains: new molecular signals. 'Protein Modifications: Beyond the Usual Suspects' review series. EMBO Rep 9, 536-542. 
Ikeda, H., and Kerppola, T.K. (2008). Lysosomal localization of ubiquitinated Jun requires multiple determinants in a lysine-27-linked polyubiquitin conjugate. Mol Biol Cell 19, 4588-4601.

Institute, S.R. (2010). Scientists Solve Mystery of Fragile Stem Cells; New Findings to Speed Research on Potential Therapy (Science Daily).

Jiang, J., Ballinger, C.A., Wu, Y., Dai, Q., Cyr, D.M., Hohfeld, J., and Patterson, C. (2001). CHIP is a U-box-dependent E3 ubiquitin ligase: identification of Hsc70 as a target for ubiquitylation. J Biol Chem 276, 4293842944.

Johnson, E.S. (2004). Protein modification by SUMO. Annu Rev Biochem 73, 355-382.

Kane, D.A., and Kimmel, C.B. (1993). The zebrafish midblastula transition. Development 119, 447-456.

Kanoh, M., Takemura, G., Misao, J., Hayakawa, Y., Aoyama, T., Nishigaki, K., Noda, T., Fujiwara, T., Fukuda, K., Minatoguchi, S., et al. (1999). Significance of myocytes with positive DNA in situ nick end-labeling (TUNEL) in hearts with dilated cardiomyopathy: not apoptosis but DNA repair. Circulation 99, 27572764.

Kerscher, O., Felberbaum, R., and Hochstrasser, M. (2006). Modification of proteins by ubiquitin and ubiquitin-like proteins. Annu Rev Cell Dev Biol 22, 159-180.

Kluck, R.M., Bossy-Wetzel, E., Green, D.R., and Newmeyer, D.D. (1997). The release of cytochrome $\mathrm{c}$ from mitochondria: a primary site for $\mathrm{Bcl}-2$ regulation of apoptosis. Science 275, 1132-1136.

Kockx, M.M., Muhring, J., Knaapen, M.W., and de Meyer, G.R. (1998). RNA synthesis and splicing interferes with DNA in situ end labeling techniques used to detect apoptosis. Am J Pathol 152, 885-888.

Koegl, M., Hoppe, T., Schlenker, S., Ulrich, H.D., Mayer, T.U., and Jentsch, S. (1999). A novel ubiquitination factor, E4, is involved in multiubiquitin chain assembly. Cell 96, 635-644. 
Koff, A., Giordano, A., Desai, D., Yamashita, K., Harper, J.W., Elledge, S., Nishimoto, T., Morgan, D.O., Franza, B.R., and Roberts, J.M. (1992). Formation and activation of a cyclin E-cdk2 complex during the G1 phase of the human cell cycle. Science 257, 1689-1694.

Kroemer, G., Galluzzi, L., Vandenabeele, P., Abrams, J., Alnemri, E.S., Baehrecke, E.H., Blagosklonny, M.V., El-Deiry, W.S., Golstein, P., Green, D.R., et al. (2009). Classification of cell death: recommendations of the Nomenclature Committee on Cell Death 2009. Cell Death Differ 16, 3-11.

Kroemer, G., Petit, P., Zamzami, N., Vayssiere, J.L., and Mignotte, B. (1995). The biochemistry of programmed cell death. FASEB J 9, 1277-1287.

Kroemer, G., and Reed, J.C. (2000). Mitochondrial control of cell death. Nat Med 6, 513-519.

Lapenta, V., Chiurazzi, P., van der Spek, P., Pizzuti, A., Hanaoka, F., and Brahe, C. (1997). SMT3A, a human homologue of the S. cerevisiae SMT3 gene, maps to chromosome 21qter and defines a novel gene family. Genomics 40, 362-366.

Lavoie, J.N., Nguyen, M., Marcellus, R.C., Branton, P.E., and Shore, G.C. (1998). E4orf4, a novel adenovirus death factor that induces p53-independent apoptosis by a pathway that is not inhibited by zVAD-fmk. J Cell Biol 140, 637645.

Lee, Y.J., Miyake, S., Wakita, H., McMullen, D.C., Azuma, Y., Auh, S., and Hallenbeck, J.M. (2007). Protein SUMOylation is massively increased in hibernation torpor and is critical for the cytoprotection provided by ischemic preconditioning and hypothermia in SHSY5Y cells. J Cereb Blood Flow Metab 27, 950-962.

Lesage, S., Steff, A.M., Philippoussis, F., Page, M., Trop, S., Mateo, V., and Hugo, P. (1997). CD4+ CD8+ thymocytes are preferentially induced to die following CD45 cross-linking, through a novel apoptotic pathway. J Immunol $159,4762-4771$.

Lesauskaite, V., Epistolato, M.C., Ivanoviene, L., and Tanganelli, P. (2004). Apoptosis of cardiomyocytes in explanted and transplanted hearts. Comparison of results from in situ TUNEL, ISEL, and ISOL reactions. Am J Clin Pathol 121, 108-116. 
Levine, A.J. (1997). p53, the cellular gatekeeper for growth and division. Cell 88, 323-331.

Lew, D.J., Dulic, V., and Reed, S.I. (1991). Isolation of three novel human cyclins by rescue of $\mathrm{G} 1$ cyclin (Cln) function in yeast. Cell 66, 1197-1206.

Li, P., Nijhawan, D., Budihardjo, I., Srinivasula, S.M., Ahmad, M., Alnemri, E.S., and Wang, X. (1997). Cytochrome $c$ and dATP-dependent formation of Apaf-1/caspase-9 complex initiates an apoptotic protease cascade. Cell 91, 479-489.

Lilyestrom, C., and Taborn, D. (1982). El control biologico de mosquitos mediante peces en la cuenca del Lago de Maricaibo, Venezuela. Informe Tecnico del Vice - Rectorado de Produccion Agricola, 1-38.

Lippens, S., Denecker, G., Ovaere, P., Vandenabeele, P., and Declercq, W. (2005). Death penalty for keratinocytes: apoptosis versus cornification. Cell Death Differ 12 Suppl 2, 1497-1508.

Liu, C., Chen, S., Kamme, F., and Hu, B.R. (2005a). Ischemic preconditioning prevents protein aggregation after transient cerebral ischemia. Neuroscience $134,69-80$.

Liu, C.L., Ge, P., Zhang, F., and Hu, B.R. (2005b). Co-translational protein aggregation after transient cerebral ischemia. Neuroscience 134, 1273-1284.

Liu, C.L., Martone, M.E., and Hu, B.R. (2004). Protein ubiquitination in postsynaptic densities after transient cerebral ischemia. J Cereb Blood Flow Metab 24, 1219-1225.

Liu, X., Kim, C.N., Yang, J., Jemmerson, R., and Wang, X. (1996). Induction of apoptotic program in cell-free extracts: requirement for dATP and cytochrome c. Cell 86, 147-157.

Lloyd-Jones, D., Adams, R.J., Brown, T.M., Carnethon, M., Dai, S., De Simone, G., Ferguson, T.B., Ford, E., Furie, K., Gillespie, C., et al. (2010). Heart disease and stroke statistics--2010 update: a report from the American Heart Association. Circulation 121, e46-e215.

Loftus, L.T., Gala, R., Yang, T., Jessick, V.J., Ashley, M.D., Ordonez, A.N., Thompson, S.J., Simon, R.P., and Meller, R. (2009). Sumo-2/3-ylation 
following in vitro modeled ischemia is reduced in delayed ischemic tolerance. Brain Res 1272, 71-80.

Lorenzo, H.K., Susin, S.A., Penninger, J., and Kroemer, G. (1999). Apoptosis inducing factor (AIF): a phylogenetically old, caspase-independent effector of cell death. Cell Death Differ 6, 516-524.

Lutz, P.L., and Nilsson, G.E. (2004). Vertebrate brains at the pilot light. Respir Physiol Neurobiol 141, 285-296.

Machado, B.E., and Podrabsky, J.E. (2007). Salinity tolerance in diapausing embryos of the annual killifish Austrofundulus limnaeus is supported by exceptionally low water and ion permeability. J Comp Physiol B 177, 809-820.

Martin, G.R. (1981). Isolation of a pluripotent cell line from early mouse embryos cultured in medium conditioned by teratocarcinoma stem cells. Proc Natl Acad Sci U S A 78, 7634-7638.

Marzo, I., Brenner, C., Zamzami, N., Susin, S.A., Beutner, G., Brdiczka, D., Remy, R., Xie, Z.H., Reed, J.C., and Kroemer, G. (1998). The permeability transition pore complex: a target for apoptosis regulation by caspases and bcl2-related proteins. J Exp Med 187, 1261-1271.

McCall, K., and Steller, H. (1997). Facing death in the fly: genetic analysis of apoptosis in Drosophila. Trends Genet 13, 222-226.

McCarthy, N.J., Whyte, M.K., Gilbert, C.S., and Evan, G.I. (1997). Inhibition of Ced-3/ICE-related proteases does not prevent cell death induced by oncogenes, DNA damage, or the Bcl-2 homologue Bak. J Cell Biol 136, 215227.

Melino, G. (2001). The Sirens' song. Nature 412, 23.

Meller, R. (2009). The role of the ubiquitin proteasome system in ischemia and ischemic tolerance. Neuroscientist 15, 243-260.

Meller, R., Thompson, S.J., Lusardi, T.A., Ordonez, A.N., Ashley, M.D., Jessick, V., Wang, W., Torrey, D.J., Henshall, D.C., Gafken, P.R., et al. (2008). Ubiquitin proteasome-mediated synaptic reorganization: a novel mechanism underlying rapid ischemic tolerance. J Neurosci 28, 50-59. 
Mukhopadhyay, D., and Riezman, H. (2007). Proteasome-independent functions of ubiquitin in endocytosis and signaling. Science 315, 201-205.

Muller, U. (1999). Ten years of gene targeting: targeted mouse mutants, from vector design to phenotype analysis. Mech Dev 82, 3-21.

Murphy, W.J., and Collier, G.E. (1997). A molecular phylogeny for aplocheiloid fishes (Atherinomorpha, Cyprinodontiformes): the role of vicariance and the origins of annualism. Mol Biol Evol 14, 790-799.

Myers, G. (1952). Annual Fishes. Aquarium Journal (San Francisco), 125-141.

Nicholson, D.W., and Thornberry, N.A. (1997). Caspases: killer proteases. Trends Biochem Sci 22, 299-306.

Nico, L., and Thomerson, J. (1989). Ecology, food habits and spatial interactions of Orinoco Basin annual killifish. Acta Biologica (Venezuela), 106120.

Ohta, T., Kinoshita, T., Naito, M., Nozaki, T., Masutani, M., Tsuruo, T., and Miyajima, A. (1997). Requirement of the caspase-3/CPP32 protease cascade for apoptotic death following cytokine deprivation in hematopoietic cells. J Biol Chem 272, 23111-23116.

Padilla, P.A., and Roth, M.B. (2001). Oxygen deprivation causes suspended animation in the zebrafish embryo. Proc Natl Acad Sci U S A 98, 7331-7335.

Pain, B., Clark, M.E., Shen, M., Nakazawa, H., Sakurai, M., Samarut, J., and Etches, R.J. (1996). Long-term in vitro culture and characterisation of avian embryonic stem cells with multiple morphogenetic potentialities. Development 122, 2339-2348.

Pardee, A.B. (1989). G1 events and regulation of cell proliferation. Science 246, 603-608.

Pearce, M.J., Mintseris, J., Ferreyra, J., Gygi, S.P., and Darwin, K.H. (2008). Ubiquitin-like protein involved in the proteasome pathway of Mycobacterium tuberculosis. Science 322, 1104-1107.

Peters, N. (1963). Embryonale Anpassungen oviparer Zahnkarpfen aus periodisch austrocknenden Gewassern. Int Rev Ges Hydrobiol, 257-313. 
Peters, N. (1965). Diapause und embryonale missbildung bei eierlegenden zahnkarpfen. Roux' Archiv fur Entwicklungsmechanik, 75-87.

Pickart, C.M. (2001). Mechanisms underlying ubiquitination. Annu Rev Biochem 70, 503-533.

Pickart, C.M., and Cohen, R.E. (2004). Proteasomes and their kin: proteases in the machine age. Nat Rev Mol Cell Biol 5, 177-187.

Piedrahita, J.A., Anderson, G.B., and Bondurant, R.H. (1990). On the isolation of embryonic stem cells: Comparative behavior of murine, porcine and ovine embryos. Theriogenology 34, 879-901.

Piironen, J., and Holopainen, I.J. (1986). A note on seasonality in anoxia tolerance of crucian carp (Carassius carassius (L.)) in the laboratory. Ann Zool Fennici, 335-338.

Podrabsky, J.E., Carpenter, J.F., and Hand, S.C. (2001). Survival of water stress in annual fish embryos: dehydration avoidance and egg envelope amyloid fibers. Am J Physiol Regul Integr Comp Physiol 280, R123-131.

Podrabsky, J.E., Garrett, I.D., and Kohl, Z.F. (2010). Alternative developmental pathways associated with diapause regulated by temperature and maternal influences in embryos of the annual killifish Austrofundulus limnaeus. J Exp Biol 213, 3280-3288.

Podrabsky, J.E., and Hand, S.C. (1999). The bioenergetics of embryonic diapause in an annual killifish, austrofundulus limnaeus. J Exp Biol 202 (Pt 19), 2567-2580.

Podrabsky, J.E., Hrbek, T., and Hand, S.C. (1998). Physical and chemical characteristics of ephemeral pond habitats in the Maricaibo basin and Llanos region of Venezuela. Hydrobiologia, 67-78.

Podrabsky, J.E., Lopez, J.P., Fan, T.W., Higashi, R., and Somero, G.N. (2007). Extreme anoxia tolerance in embryos of the annual killifish Austrofundulus limnaeus: insights from a metabolomics analysis. J Exp Biol 210, 2253-2266.

Podrabsky, J.E., and Somero, G.N. (2007). An inducible 70 kDa-class heat shock protein is constitutively expressed during early development and 
diapause in the annual killifish Austrofundulus limnaeus. Cell Stress Chaperones 12, 199-204.

Rivas, C.I., Wisniewski, D., Strife, A., Perez, A., Lambek, C., Bruno, S., Darzynkiewicz, Z., and Clarkson, B. (1992). Constitutive expression of p53 protein in enriched normal human marrow blast cell populations. Blood 79, 1982-1986.

Rodrigo-Brenni, M.C., and Morgan, D.O. (2007). Sequential E2s drive polyubiquitin chain assembly on APC targets. Cell 130, 127-139.

Rodriguez, I., Matsuura, K., Ody, C., Nagata, S., and Vassalli, P. (1996). Systemic injection of a tripeptide inhibits the intracellular activation of CPP32like proteases in vivo and fully protects mice against Fas-mediated fulminant liver destruction and death. J Exp Med 184, 2067-2072.

Saitoh, H., and Hinchey, J. (2000). Functional heterogeneity of small ubiquitinrelated protein modifiers SUMO-1 versus SUMO-2/3. J Biol Chem 275, 62526258.

Sarasin, A., and Dessen, P. (2010). DNA repair pathways and human metastatic malignant melanoma. Curr Mol Med 10, 413-418.

Sarin, A., Williams, M.S., Alexander-Miller, M.A., Berzofsky, J.A., Zacharchuk, C.M., and Henkart, P.A. (1997). Target cell lysis by CTL granule exocytosis is independent of ICE/Ced-3 family proteases. Immunity 6, 209-215.

Scheschonka, A., Tang, Z., and Betz, H. (2007). Sumoylation in neurons: nuclear and synaptic roles? Trends Neurosci 30, 85-91.

Smith, M.L., Chen, I.T., Zhan, Q., O'Connor, P.M., and Fornace, A.J., Jr. (1995). Involvement of the p53 tumor suppressor in repair of u.v.-type DNA damage. Oncogene 10, 1053-1059.

Song, Z., McCall, K., and Steller, H. (1997). DCP-1, a Drosophila cell death protease essential for development. Science 275, 536-540.

Storey, K.B. (2003). Mammalian hibernation. Transcriptional and translational controls. Adv Exp Med Biol 543, 21-38. 
Sukoyan, M.A., Vatolin, S.Y., Golubitsa, A.N., Zhelezova, A.I., Semenova, L.A., and Serov, O.L. (1993). Embryonic stem cells derived from morulae, inner cell mass, and blastocysts of mink: comparisons of their pluripotencies. Mol Reprod Dev 36, 148-158.

Susin, S.A., Lorenzo, H.K., Zamzami, N., Marzo, I., Snow, B.E., Brothers, G.M., Mangion, J., Jacotot, E., Costantini, P., Loeffler, M., et al. (1999). Molecular characterization of mitochondrial apoptosis-inducing factor. Nature 397, 441-446.

Susin, S.A., Zamzami, N., Castedo, M., Daugas, E., Wang, H.G., Geley, S., Fassy, F., Reed, J.C., and Kroemer, G. (1997). The central executioner of apoptosis: multiple connections between protease activation and mitochondria in Fas/APO-1/CD95- and ceramide-induced apoptosis. J Exp Med 186, 25-37.

Susin, S.A., Zamzami, N., Castedo, M., Hirsch, T., Marchetti, P., Macho, A., Daugas, E., Geuskens, M., and Kroemer, G. (1996). Bcl-2 inhibits the mitochondrial release of an apoptogenic protease. J Exp Med 184, 1331-1341.

Taborn, D., and Thomerson, J. (1978). A revision of the South American cypridont fishes of the genera Rachovia and Austrofundulus, with a description of a new genus. Acta Biologica (Venezuela), 377-452.

Testa, U. (2004). Apoptotic mechanisms in the control of erythropoiesis. Leukemia 18, 1176-1199.

Thomson, J.A., Kalishman, J., Golos, T.G., Durning, M., Harris, C.P., Becker, R.A., and Hearn, J.P. (1995). Isolation of a primate embryonic stem cell line. Proc Natl Acad Sci U S A 92, 7844-7848.

Vermeulen, K., Van Bockstaele, D.R., and Berneman, Z.N. (2003). The cell cycle: a review of regulation, deregulation and therapeutic targets in cancer. Cell Prolif 36, 131-149.

Wang, X.W., Yeh, H., Schaeffer, L., Roy, R., Moncollin, V., Egly, J.M., Wang, Z., Freidberg, E.C., Evans, M.K., Taffe, B.G., et al. (1995). p53 modulation of TFIIH-associated nucleotide excision repair activity. Nat Genet 10, 188-195.

Wertz, I.E., O'Rourke, K.M., Zhou, H., Eby, M., Aravind, L., Seshagiri, S., Wu, P., Wiesmann, C., Baker, R., Boone, D.L., et al. (2004). De-ubiquitination and ubiquitin ligase domains of A20 downregulate NF-kappaB signalling. Nature 430, 694-699. 
Westerfield, M. (1995). The Zebrafish Book: A guide for the laboratory use of zebrafish (Brachydanio rerio), 3 edn.

Wheeler, M.B. (1994). Development and validation of swine embryonic stem cells: a review. Reprod Fertil Dev 6, 563-568.

Williams, A.J., Berti, R., Dave, J.R., Elliot, P.J., Adams, J., and Tortella, F.C. (2004). Delayed treatment of ischemia/reperfusion brain injury: extended therapeutic window with the proteosome inhibitor MLN519. Stroke 35, 11861191.

Williams, A.J., Hale, S.L., Moffett, J.R., Dave, J.R., Elliott, P.J., Adams, J., and Tortella, F.C. (2003). Delayed treatment with MLN519 reduces infarction and associated neurologic deficit caused by focal ischemic brain injury in rats via antiinflammatory mechanisms involving nuclear factor-kappaB activation, gliosis, and leukocyte infiltration. J Cereb Blood Flow Metab 23, 75-87.

Wilson, V.G., and Rosas-Acosta, G. (2005). Wrestling with SUMO in a new arena. Sci STKE 2005, pe32.

Windheim, M., Peggie, M., and Cohen, P. (2008). Two different classes of E2 ubiquitin-conjugating enzymes are required for the mono-ubiquitination of proteins and elongation by polyubiquitin chains with a specific topology. Biochem J 409, 723-729.

Wittbrodt, J., Shima, A., and Schartl, M. (2002). Medaka--a model organism from the far East. Nat Rev Genet 3, 53-64.

Wojcik, C., and Di Napoli, M. (2004). Ubiquitin-proteasome system and proteasome inhibition: new strategies in stroke therapy. Stroke 35, 1506-1518.

Wourms, J. (1963). Naturally occurring developmental arrest in teleost fishes with associated modifications of epiboly and embryogenesis. Proceedings of the 16th International Congress of Zoology, 264.

Wourms, J. (1964). Comparative observations on the early embryology of Nothobranchius taeniopygus (Hilgendorf) and Aplocheilichthys pumilis (Boulenger) with special reference to the problem of naturally occurring embryonic diapause in teleost fishes. East African Freshwater Research Organization, 68-73. 
Wourms, J. (1965). Naturally occurring phases of cellular dispersion and reaggregation during early vertebrate development. American Zoology, 662.

Wourms, J. (1967). Annual Fishes (New York, Thomas Y. Cromwell Co.).

Wourms, J. (1972a). The Developmental Biology of Annual Fishes I. Stages in the normal development of Austrofundulus myersi Dahl. Journal of Experimental Zoology, 143-168.

Wourms, J. (1972b). The Developmental Biology of Annual Fishes II. Naturally occuring dispersion and reaggregation of blastomeres during the development of annual fish eggs. Journal of Experimental Zoology, 169-200.

Wourms, J. (1972c). The Developmental Biology of Annual Fishes III. Preembryonic and embryonic diapause of variable duration in the eggs of annual fishes. Journal of Experimental Zoology, 389-414.

Xiang, J., Chao, D.T., and Korsmeyer, S.J. (1996). BAX-induced cell death may not require interleukin 1 beta-converting enzyme-like proteases. Proc Natl Acad Sci U S A 93, 14559-14563.

Xiong, Y., Connolly, T., Futcher, B., and Beach, D. (1991). Human D-type cyclin. Cell 65, 691-699.

Xu, Y., Zhu, X., Hahm, H.S., Wei, W., Hao, E., Hayek, A., and Ding, S. (2010). Revealing a core signaling regulatory mechanism for pluripotent stem cell survival and self-renewal by small molecules. Proc Natl Acad Sci U S A 107, 8129-8134.

Xue, D., and Horvitz, H.R. (1995). Inhibition of the Caenorhabditis elegans cell-death protease CED-3 by a CED-3 cleavage site in baculovirus p35 protein. Nature $377,248-251$.

Yang, J., Liu, X., Bhalla, K., Kim, C.N., Ibrado, A.M., Cai, J., Peng, T.I., Jones, D.P., and Wang, X. (1997). Prevention of apoptosis by Bcl-2: release of cytochrome c from mitochondria blocked. Science 275, 1129-1132.

Yang, M.Y., Chuang, H., Chen, R.F., and Yang, K.D. (2002). Reversible phosphatidylserine expression on blood granulocytes related to membrane perturbation but not DNA strand breaks. J Leukoc Biol 71, 231-237. 
Yang, W., Sheng, H., Warner, D.S., and Paschen, W. (2008a). Transient focal cerebral ischemia induces a dramatic activation of small ubiquitin-like modifier conjugation. J Cereb Blood Flow Metab 28, 892-896.

Yang, W., Sheng, H., Warner, D.S., and Paschen, W. (2008b). Transient global cerebral ischemia induces a massive increase in protein sumoylation. $\mathrm{J}$ Cereb Blood Flow Metab 28, 269-279.

Zou, H., Henzel, W.J., Liu, X., Lutschg, A., and Wang, X. (1997). Apaf-1, a human protein homologous to $C$. elegans CED-4, participates in cytochrome c-dependent activation of caspase-3. Cell 90, 405-413. 